NBER WORKING PAPER SERIES

\title{
CURRENCY WARS OR EFFICIENT SPILLOVERS? \\ A GENERAL THEORY OF INTERNATIONAL POLICY COOPERATION
}

\author{
Anton Korinek \\ Working Paper 23004 \\ http://www.nber.org/papers/w23004 \\ NATIONAL BUREAU OF ECONOMIC RESEARCH \\ 1050 Massachusetts Avenue \\ Cambridge, MA 02138 \\ December 2016
}

I would like to thank Kyle Bagwell, Julien Bengui, Gianluca Benigno, Olivier Blanchard, Michael Bordo, Jeff Campbell, Eduardo Dávila, Emmanuel Farhi, Jon Faust, Rex Ghosh, Ben Hébert, Olivier Jeanne, Sebnem Kalemli-Ozcan, Narayana Kocherlakota, Jonathan Ostry, Pedro Teles, Jean-Charles Rochet, Joseph Stiglitz and Jaume Ventura for detailed comments and conversations on the topic. Jonathan Kreamer and Chang Ma provided excellent research assistance. Part of this paper was written when I was a Research Fellow at the BIS and at the IMF. I also gratefully acknowledge financial support from CIGI/INET. The views expressed herein are those of the author and do not necessarily reflect the views of the National Bureau of Economic Research.

NBER working papers are circulated for discussion and comment purposes. They have not been peer-reviewed or been subject to the review by the NBER Board of Directors that accompanies official NBER publications.

(C) 2016 by Anton Korinek. All rights reserved. Short sections of text, not to exceed two paragraphs, may be quoted without explicit permission provided that full credit, including () notice, is given to the source. 
Currency Wars or Efficient Spillovers?

A General Theory of International Policy Cooperation

Anton Korinek

NBER Working Paper No. 23004

December 2016

JEL No. D61,F13,F33,F42

\begin{abstract}
$\underline{\text { ABSTRACT }}$
In an interconnected world, national economic policies regularly lead to large international spillover effects, which frequently trigger calls for international policy cooperation. However, the premise of successful cooperation is that there is a Pareto inefficiency, i.e. if there is scope to make some nations better off without hurting others. This paper presents a first welfare theorem for open economies that defines an efficient benchmark and spells out the conditions that need to be violated to generate inefficiency and scope for cooperation. These are: (i) policymakers act competitively in the international market,(ii) policymakers have sufficient external policy instruments and (iii) international markets are free of imperfections. Our theorem holds even if each economy suffers from a wide range of domestic market imperfections and targeting problems. We provide examples of current account intervention, monetary policy, fiscal policy, macroprudential policy/capital controls, and exchange rate management and show that the resulting spillovers are consistent with Pareto efficiency, but only if the three conditions are satisfied. Furthermore, we develop general guidelines for how policy cooperation can improve welfare when the conditions are violated.
\end{abstract}

Anton Korinek

Department of Economics

Johns Hopkins University

Wyman Park Building 531

3400 N. Charles Street

Baltimore, MD 21218

and NBER

akorinek@jhu.edu 


\section{Introduction}

In a globally integrated economy, national economic policies regularly lead to international spillover effects, i.e. general equilibrium effects on other countries. These are frequently large and lead to considerable controversy. For example, the Brazilian finance minister Guido Mantega has used the term "currency wars" to describe the effects of US monetary easing on the country's exchange rate (see Wheatley and Garnham, 2010). Other recent national policies that have led to international controversy include the large reserve accumulation by China and other Asian countries, the capital flow management policies by emerging market economies such as Brazil, as well as spillovers from monetary and exchange rate policy in the US, Japan, Switzerland, the euro area and China. These spillovers have frequently triggered calls for greater international policy cooperation 1

However, the premise of successful cooperation among sovereign nations is that the uncooperative equilibrium is Pareto inefficient, i.e. that there is a way of making some countries better off without hurting others. Even though international spillover effects may trigger controversy, this does not necessarily mean that they are Pareto inefficient and that there is scope for cooperation.

The main contribution of this paper is a first welfare theorem for open economies that defines an efficient benchmark. At the same time, the theorem spells out the conditions that need to be violated to generate inefficiency and scope for cooperation. The conditions are that (i) policymakers act competitively in the international market, (ii) policymakers have sufficient policy instruments to target the external transactions of their country and (iii) international markets are free of imperfections. This narrows down the circumstances that are worth expending diplomatic efforts on and channels the debate on international policy cooperation into those areas where it can bear fruit. If the three conditions are met or have been successfully addressed via policy cooperation, then allocations - and spillovers - are Pareto efficient, and any attempts at further cooperation are futile zero-sum games. This result is counter to the intuition of many commentators and policymakers who suggest that spillovers always call for cooperation.

There are two important deviations of our theorem from the standard first welfare theorem: First, we study the equilibrium in a world economy in which two layers of agents in each country interact with each other - optimizing private agents and policymakers. Secondly, our theorem applies even if each individual country suffers from a wide range of domestic market imperfections and targeting problems.2 In other words, we find that a global planner who has access to the same policy instruments as national policymakers and who is subject to the same domestic market imperfections and targeting problems cannot improve outcomes if the conditions of our welfare theorem are met.

We develop our results in an Arrow-Debreu-style framework that is general enough to nest a wide range of open economy models in both macroeconomics and trade theory. If we impose the three efficiency conditions stated above, we observe that we can solve the domestic optimization problem of private agents and the policymaker in each country and express the welfare of country $i$ as a reduced-form function $V^{i}(\cdot)$ that only depends on the country's international transactions. We

\footnotetext{
${ }^{1}$ For a detailed discussion of the policy perspective, see e.g. IMF (2012), Ostry et al. (2012), Aizenman (2016), Blanchard (2016) and Ostry and Ghosh (2016).

'In fact, our welfare theorem also applies in other settings in which two layers of optimizing agents interact, e.g. firms and their individual workers in organizational economics.
} 
can then view the policymakers of different countries as competitive agents in a well-functioning global market and apply the logic of the traditional first welfare theorem to these reduced-form welfare functions. International spillover effects in such a setting constitute pecuniary externalities that are mediated through world market prices, i.e. they are equivalent to wealth transfers and are thus Pareto efficient 3

Two corollaries are useful in simplifying numerical applications of international policy cooperation problems when our theorem applies: first, the domestic allocation of each country and the international allocation can be solved in two separate steps; and secondly, solving for the uncoordinated equilibrium of a global economy is equivalent to solving the corresponding planning problem.

We provide examples of current account intervention, monetary policy, fiscal policy, macroprudential policy/capital controls, and exchange rate management and show that the resulting spillovers are consistent with Pareto efficiency when the three conditions are satisfied. In other words, whether the international spillovers of national economic policies are efficient or not and whether they call for cooperation or not does not depend on the specific policy but on whether the environment in which it is conducted meets the specified conditions.

As in all applications of the first welfare theorem in the literature, the efficiency conditions stated in the theorem are never met $100 \%$ in practice. A second important contribution of our paper is thus to relax each of the conditions one-by-one and study the lessons for international policy cooperation. We also illustrate these lessons in simple and tangible analytic examples for each case. Furthermore, to relate our framework to the existing literature on policy cooperation, we point out which of the three conditions are violated in some of the key contributions to the literature.

(i) When policymakers act strategically and exert market power over world prices, then the goal of cooperation is to restore competitive behavior. This maximizes worldwide gains from both intra- and intertemporal trade. The basic idea has been well understood since the rebuttal of mercantilism by Adam Smith (1776). This motive for cooperation underlies some of the most successful examples of economic policy cooperation in the real world, for example the WTO ${ }_{4}^{4}$ We study this motive for intervention by considering a policymaker in a large economy who rationally internalizes the slope of the rest-of-the-world excess demand curve. Our Arrow-Debreu-style framework delivers general conditions for the direction of monopolistic intervention that unify the results in the trade and international finance literature and that are useful for detecting monopolistic behavior. We also show that a national policymaker would never use domestic policies for monopolistic reasons when external policy instruments are available - distorting external trade via domestic instruments is always a second-best $\left.\right|^{5}$ Furthermore, we demonstrate that it is generi-

\footnotetext{
${ }^{3}$ Technically, we also need to impose a fourth condition for our welfare theorem to hold - that the preferences of policymakers are locally non-satiated. We do not highlight this condition since it does not seem to play a major role in problems of international policy cooperation.

${ }^{4}$ See e.g. Bagwell and Staiger (1999, 2002, 2010) for an extensive treatment of modern optimal tariff theory in the context of international trade, or Staiger and Sykes (2010) and Costinot et al. (2014) for recent contributions that focus on intertemporal rather than intratemporal trade.

${ }^{5}$ This finding is similar to the optimal targeting principle by Bhagwati and Ramaswami (1963). Some of the literature on international cooperation of specific policy instruments, e.g. monetary or fiscal policy, takes it as a given that other
} 
cally impossible to distinguish monopolistic intervention from intervention that corrects domestic market imperfections - it is always possible to construct welfare functions that mimic a given monopolistic intervention as corrective for some domestic objective.

(ii) When policymakers have imperfect external instruments, they cannot optimally target their countries' external transactions. Examples include tariff or capital control instruments that are missing, costly to impose, too coarse, subject to fiscal considerations, or commitment problems, etc. In all these cases, domestic policymakers do not have sufficient control over the external allocations chosen by private agents. Cooperation then aims to use the existing set of policy instruments more efficiently. We describe two tangible examples. Sharing the regulatory burden is desirable when some countries with better, less costly, or less restricted instruments can assist those with worse instruments. For example, if a country experiences externalities from capital inflows but has no instrument to control them, welfare is improved if other countries control their capital outflows. A practical example are the reciprocity clauses in Basel III. Wasteful competitive intervention occurs when competing policy interventions of multiple countries are costly to implement but have offsetting effects. In that case, it is desirable to reduce the intervention to conserve on the wasteful competition. Additionally, when external instruments are imperfect, a country's policymaker will generically distort domestic policies in pursuit of her external objectives, and global cooperation also needs to include cooperation over domestic policies.

Policy cooperation under imperfect instruments has a rich intellectual tradition, going back to the targets and instruments approach of Tinbergen (1952) and Theil (1968). They observed in a reduced-form setting without optimizing private agents that imperfect or incomplete instruments may give rise to a role for economic policy cooperation. In our paper, we embed the TinbergenTheil approach into a general equilibrium framework in which optimizing individual agents interact in a market setting. This leads to a number of novel findings. First, we show that many of the spillover effects that would suggest a role for cooperation in the Tinbergen-Theil framework actually constitute efficient pecuniary externalities. Once the optimizing behavior of private agents is taken into account, a wide range of spillovers can be considered as efficient. Secondly, monopoly power and international market imperfections create independent roles for cooperation even if policy instruments are complete - a fact that was not considered by Tinbergen and Theil $[6$

(iii) When the international market is subject to imperfections, global cooperation is generically necessary since the imperfections are outside of the domain of the policymakers of individual countries 7 We focus on market imperfections that can be captured by constraints on prices or quantities of goods traded in the international market. This encompasses classic global externalities such as pollution, price stickiness, pecuniary externalities and exogenous market incomplete-

policy instruments to target external transactions more directly are not available. See e.g. Persson and Tabellini (1995) for a survey. Corsetti et al. (2011) provide a detailed summary of the implications for monetary policy in open economies. Farhi and Werning (2012) emphasize this motive for cooperation in a multi-country New Keynesian framework.

${ }^{6}$ For a modern exposition of the targets-and-instruments motive of international policy cooperation see Chapter 3 of Ghosh and Masson (1994). In the more recent literature, Jeanne (2014) provides an interesting example where the cooperation of macroprudential policies is warranted because of missing external policy instruments.

${ }^{7}$ Recent applications in which international market imperfections create a case for cooperation include Bengui (2013) who analyzes the need for cooperation on liquidity policies when global markets for liquidity are incomplete, and Jeanne (2014) who analyzes a world economy in which agents are restricted to trading bonds denominated in the currency of a single country. 
ness ${ }^{8}$ The general insight is that global cooperation is useful when it improves the functioning of the price mechanism, e.g. if there are unpriced technological externalities, sticky prices, or pecuniary externalities due to financial constraints. A classic example are global environmental externalities. By contrast, the uncoordinated equilibrium is constrained efficient and there is no scope for global cooperation when there are exogenous restrictions on trade that do not depend on prices, for instance if markets for real goods are simply missing.

The remainder of the paper is structured as follows: Section 2 describes examples of shocks and policy responses that have led to spillovers in recent years, including several cases that have given rise to controversy. A reader who is mainly interested in the technical contribution of the paper can go directly to Sections 3 and 4 , which introduce our general model setup and examine its welfare properties, stating the general conditions under which spillovers are efficient. Sections 5 to 7 examine the case for international policy cooperation to (i) rule out monopolistic behavior and to address imperfections in (ii) external policy instruments and (iii) international markets. Online Appendix Cillustrates the main efficiency result of the paper and the three cases for cooperation in a simple and teachable two-period example.

\section{Examples of Spillovers}

This section formalizes several tangible examples of international spillovers, starting with the spillovers of a real shock and then focusing on policy spillovers. Given the optimizing behavior of policymakers, any change in policy must be driven by a change in fundamentals. We characterize spillovers by describing how a change in fundamentals shifts a country's net demand curve for international transactions. In each example, we assume that policymakers are optimizing domestic welfare while acting with benign neglect towards international prices. This can be either because the country in question is atomistic and has no effects on international prices or because the country acts with "benign neglect" towards international prices because of an implicit or explicit international agreement, as we will discuss in further detail below. If the country in question is non-atomistic, the shifts in its demand curve will also leads to general equilibrium adjustments. We will describe these under the standard assumption that the excess demand function of the rest of the world is downward-sloping for each good.

\subsection{Real Spillovers}

For our first example, assume a simple two-period world economy in which there is a single consumption good and intertemporal trade. Consider a country $i$ that is inhabited by a representative

\footnotetext{
${ }^{8}$ Many of the insights of the rich literature on market imperfections in general equilibrium models apply if we reinterpret national economic policymakers as individual agents who interact in the international market. See for example Arrow (1969) for the classic externalities problem, Geanakoplos and Polemarchakis (1986) and Greenwald and Stiglitz (1986) for pecuniary externalities under incomplete markets, and Farhi and Werning (2016) for aggregate demand externalities under price stickiness.
} 
agent who chooses how to allocate consumption across the two periods

$$
\begin{array}{ll}
\max _{c_{0}^{i}, c_{1}^{i}, m_{0}^{i}, m_{1}^{i}} U^{i}=u\left(c_{0}^{i}\right)+u\left(c_{1}^{i}\right) \quad \text { s.t. } \quad & c_{0}^{i}=y_{0}^{i}+m_{0}^{i} \\
& c_{1}^{i}=y_{1}^{i}+m_{1}^{i} \\
& m_{0}^{i}+m_{1}^{i} / R \leq 0
\end{array}
$$

where $c_{t}^{i}$ and $y_{t}^{i}$ denote consumption and output, $m_{t}^{i} \gtrless 0$ denotes net imports (or, if negative, exports) of the consumption good or equivalently capital inflows (outflows), and $R$ is the relative intertemporal price of consumption goods in period $0 \mathrm{vs}$. period 1 or, equivalently, the gross world interest rate. The period utility functions are given by $u(c)=c^{1-\theta} /(1-\theta)$. The optimization problem is subject to two domestic budget constraints for a given level of net imports in each period, plus a dynamic budget constraint that reflects the intertemporal external budget constraint.

Reduced-Form Welfare Functions We reformulate this setup in vector notation, which will nest into our general framework below. Let us call the column vectors $m^{i}=\left(m_{0}^{i}, m_{1}^{i}\right)^{T}$ and $x^{i}=\left(c_{0}^{i}, c_{1}^{i}\right)$ the external and domestic allocation of country $i$, and let us define the international price vector $Q=(1,1 / R)$. Then we can denote the reduced-form welfare of the representative agent for a given external allocation $m^{i}$ by the function

$$
V^{i}\left(m^{i}\right)=u\left(y_{0}^{i}+m_{0}^{i}\right)+u\left(y_{1}^{i}+m_{1}^{i}\right)
$$

The representative agent in country $i$ solves the optimization problem

$$
\max _{m^{i}} V^{i}\left(m^{i}\right) \quad \text { s.t. } \quad Q \cdot m^{i} \leq 0
$$

Assigning shadow price $\lambda^{i}$, this yields the optimality condition

$$
V_{m}^{i}=\lambda^{i} Q^{T} \quad \text { or, equivalently, } \quad \frac{u^{\prime}\left(c_{0}^{i}\right)}{u^{\prime}\left(c_{1}^{i}\right)}=R
$$

where $V_{m}^{i}=\partial V^{i} / \partial m^{i}=\left(u^{\prime}\left(c_{0}^{i}\right), u^{\prime}\left(c_{1}^{i}\right)\right)^{T}$ denotes the vector of marginal utilities of net imports. The first equation describes optimality in vector notation: the marginal utility of each type of imports equals its market price times the (scalar) shadow price of wealth. The second equation is obtained by substituting out the shadow price: the representative agent equates his intertemporal marginal rate of substitution (MRS) to the common world interest rate. The optimality condition together with the external budget constraint can be solved for

$$
m_{0}^{i}=\frac{y_{1}^{i} R^{-\frac{1}{\theta}}-y_{0}^{i}}{1+R^{\frac{\theta-1}{\theta}}}=-\frac{m_{1}^{i}}{R}
$$

In short, optimal consumption smoothing implies greater net imports the higher the (properly discounted) gap between output in periods 0 and 1 . 
Spillovers of Endowment Shocks An endowment shock creates international spillover effects by shifting the demand curves of the representative agent (for given international prices) by

$$
\left.\frac{d m^{i}}{d y_{0}^{i}}\right|_{Q}=\left(\begin{array}{c}
-s \\
R s
\end{array}\right) \quad \text { where } \quad s=\frac{1}{1+R^{\frac{\theta-1}{\theta}}}
$$

A positive period 0 endowment shock $d y_{0}^{i}$ will lead to a reduction in demand for net imports/capital inflows at date 0 and vice versa at date 1 . In the general equilibrium of the world economy, this will translate into smaller date 0 net inflows and (unless country $i$ is a small open economy) into a lower world interest rate, as we will describe in further detail in the ensuing section. These quantity and price adjustments represent one of the simplest examples of global spillover effects.

The spillovers affect the welfare of other countries disparately depending on their financial position: borrowing countries benefit from the lower world interest rate, whereas lending countries will be hurt.

\subsection{Spillovers of Current Account Intervention}

We extend the example in Section 2.1 by assuming a very simple motive for policy intervention in the current account: learning-by-exporting externalities. 9 Specifically, assume that period 1 output is a function of aggregate period 0 net exports $y_{1}^{i}=y_{1}^{i}\left(-M_{0}^{i}\right)$ that is continuous and increasing $y_{1}^{i \prime}\left(-M_{0}^{i}\right)>0$, capturing that higher aggregate net exports increase growth. We use upper-case letters $M_{t}^{i}$ to distinguish aggregate imports from individual-level imports $m_{t}^{i}$ since individual agents take aggregate allocations as given. In equilibrium, however, aggregate allocations equal individual allocations $M_{t}^{i}=m_{t}^{i}$. Using this notation, the reduced-form welfare function of country $i$ given a pair of individual and aggregate external allocations $\left(m^{i}, M^{i}\right)$ is

$$
V^{i}\left(m^{i}, M^{i}\right)=u\left(y_{0}^{i}+m_{0}^{i}\right)+u\left(y_{1}^{i}\left(-M_{0}^{i}\right)+m_{1}^{i}\right)
$$

A policymaker who can regulate the external transactions of individual agents and internalizes that $m^{i}=M^{i}$ will solve the optimization problem

$$
\max _{M^{i}} V^{i}\left(M^{i}, M^{i}\right) \quad \text { s.t. } \quad Q \cdot M^{i} \leq 0
$$

Assigning shadow price $\Lambda^{i}$, the optimality condition is

$$
V_{m}^{i}+V_{M}^{i}=\Lambda^{i} Q^{T} \quad \text { or, equivalently, } \quad \frac{u^{\prime}\left(c_{0}^{i}\right)}{u^{\prime}\left(c_{1}^{i}\right)}=R+y_{1}^{i \prime}\left(-M_{0}^{i}\right)
$$

The first equation in (4) states that the policymaker equates the sum of the private and uninternalized social marginal utility of imports to the world market price. In the second equation, this is re-written in terms of the MRS of private agents - recall that $y_{1}^{i \prime}>0$ so the policymaker increases the MRS of private agents, encouraging them to export in period 0 in order to benefit from the learning externalities.

\footnotetext{
${ }^{9}$ For a strand of literature that postulates that learning effects have been an important driver for countries that engaged in current account intervention, esp. in East Asia, see for example Rodrik (2008), Benigno and Fornaro (2014) and Korinek and Serven (2016).
} 
Let us express the policymaker's intervention in terms of tax instruments $\tau^{i}=\left(\tau_{0}^{i}, \tau_{1}^{i}\right)$ on the external transactions of private agents $m^{i}$. Tax revenue is rebated as a lump-sum transfer $T^{i}$ so the external budget constraint of private agents takes the form $\frac{Q}{1-\tau^{i}} \cdot m^{i} \leq T^{i}$ and the optimality condition of private agents is $\left(1-\tau^{i}\right) V_{m}^{i}=\lambda_{e}^{i} Q$ (where all vector multiplications and divisions are element-by-element unless indicated by the inner product operator, e.g. in $Q \cdot m^{i}$ ). The optimal tax vector equates this private optimality condition to the policymaker's optimality condition (4)

$$
\tau^{i}=-\left(\frac{V_{M}^{i}}{V_{m}^{i}}\right)^{T}=\left(y_{1}^{i \prime} \cdot \frac{u^{\prime}\left(c_{1}^{i}\right)}{u^{\prime}\left(c_{0}^{i}\right)}, 0\right)
$$

The policymaker subsidizes period 0 exports $\tau_{0}^{i}>0$ (or, equivalently, taxes imports) and sets $\tau_{1}^{i} \equiv 0$ in period 1 since there are no further externalities. She could also use quantity interventions and set period 0 net exports to the optimal level $M_{0}^{i}$ to internalize the externalities. Under closed capital accounts, this is equivalent to accumulating $-M_{0}^{i}$ in foreign reserves.

Policy Spillovers of Current Account Intervention Greater intervention $d \tau_{0}^{i}$ leads to a negative shift in the import demand curve in period 0 and vice versa in period 1 . Under log-utility $u(c)=$ $\log c$, the spillovers are particularly simple,

$$
\left.\frac{d m^{i}}{d \tau_{0}^{i}}\right|_{Q}=\left(\begin{array}{c}
-s \\
R s
\end{array}\right) \quad \text { where } \quad s=\frac{y_{0}^{i}+y_{1}^{i} / R}{\left(2-\tau_{0}^{i}\right)^{2}}
$$

In global equilibrium, other countries will import more in period 0 and less in period 1 . Unless country $i$ is small, the world interest rates declines, and the welfare of other countries increases or decreases depending on whether they are borrowers or lenders.

\subsection{Spillovers of Monetary Policy}

We extend the example in Section 2.1 to study monetary policy. We follow Woodford (2003) in considering a cash-less economy in which a monetary policymaker sets a domestic interest rate. To create a role for a domestic interest rate that differs from the world interest rate, we add non-traded goods to the setup of the previous section and assume that agents consume a Cobb-Douglas consumption basket $c_{t}^{i}=\left(c_{T, t}^{i}\right)^{\gamma}\left(c_{N, t}^{i}\right)^{1-\gamma}$ of traded and non-traded goods each period. For simplicity we assume that the period utility function over this basket is $u\left(c_{t}^{i}\right)=\log c_{t}^{i}$.

Private agents in country $i$ receive endowments of both traded and non-traded goods $y_{T, t}^{i}$ and $y_{N, t}^{i}$ at $t=0,1$ that trade at domestic prices $p_{T, t}^{i}$ and $p_{N, t}^{i}$ respectively. The price of a unit of the optimal consumption basket is $P_{t}=\left(p_{T, t} / \gamma\right)^{\gamma}\left(p_{N, t} / 1-\gamma\right)^{\gamma}$. Private agents trade bonds denoted in international markets that are denominated in traded goods at the world interest rate is $R$, and $d^{i}$ units of a domestic bond that are denominated in units of the domestic consumption basket and pay the domestic gross interest rate $S^{i}$. The monetary policymaker in country $i$ sets this interest rate so as to keep the domestic price index constant over time, w.l.o.g. at $P_{t} \equiv 1$. The full optimization is reported in the appendix. As we derive in detail there, the optimal domestic gross interest rate that achieves the policymaker's price stabilization objective is

$$
S^{i}=\left(\frac{c_{T, 1}^{i}}{c_{T, 0}^{i}}\right)^{\gamma}\left(\frac{c_{N, 1}^{i}}{c_{N, 0}^{i}}\right)^{1-\gamma}=R^{\gamma} \cdot\left(\frac{y_{N, 1}^{i}}{y_{N, 0}^{i}}\right)^{1-\gamma}
$$


where the second step follows from market clearing for non-traded goods plus the Euler equation for traded goods, $R=c_{T, 1}^{i} / c_{T, 0}^{i}$. Furthermore, the country's exchange rate in a given period, i.e. the price of traded goods in terms of the domestic price index, is

$$
\mathcal{E}_{t}^{i}=p_{T, t}^{i}=\gamma\left(c_{N, t}^{i} / c_{T, t}^{i}\right)^{1-\gamma}
$$

Monetary Policy Response to Shocks and Spillovers Now consider a shock to the period 0 endowments of the domestic agent $d y_{0}=d y_{T, 0}^{i}=d y_{N, 0}^{i}>0$. In response to this shock, the monetary policymaker will adjust the domestic interest rate by

$$
\frac{d S^{i}}{d y_{0}}=-(1-\gamma) R^{\gamma}\left(y_{N, 1}^{i}\right)^{1-\gamma}\left(y_{N, 0}^{i}\right)^{-\gamma}<0
$$

In other words, it accommodates the positive supply shock by a lower domestic interest rate to avoid domestic deflation. At the same time, private agents respond to the shock by saving some of the additional income abroad, as in our previous example of real spillovers,

$$
\left.\frac{d m^{i}}{d y_{0}}\right|_{Q}=\left(\begin{array}{c}
-s \\
R s
\end{array}\right) \quad \text { where } \quad s=\frac{1}{1+R}
$$

Furthermore, the country's exchange rate in the two periods will adjust by

$$
\left.\frac{d \mathcal{E}^{i}}{d y_{0}}\right|_{Q}=(1-\gamma)\left(\begin{array}{c}
\mathcal{E}_{0}^{i}\left[1 / y_{N, 0}^{i}-\frac{R}{1+R} / c_{T, 0}^{i}\right] \\
-\frac{R}{1+R} \mathcal{E}_{1}^{i} / c_{T, 1}^{i}
\end{array}\right)
$$

For typical parameterizations, the square brackets are positive and the exchange rate depreciates in period 0 . It always appreciates in period 1 .

The given example of monetary policy is particularly simple - money is neutral, and optimal monetary policy simply replicates the first-best real allocation. However, the basic principle of optimal monetary policy is always the same: it responds to shocks, and there are general equilibrium adjustments - no matter if the shocks under consideration are supply shocks, demand shocks, cost-push shocks or shocks to preferences, and no matter if we explicitly introduce money or sticky prices or limitations on the information set of policymakers. As we will see in Section 3 . all of these cases nest into our general model setup.

\subsection{Spillovers from Current Account Intervention at the ZLB}

This section extends our monetary policy example by imposing a zero lower bound (ZLB) constraint on the domestic nominal interest rate and studying optimal current account policy as well as the resulting spillovers ${ }^{10}$ The ZLB constraint on the domestic net interest rate corresponds to a constraint on the gross interest rate of

$$
S^{i} \geq 1
$$

\footnotetext{
${ }^{10} \mathrm{~A}$ complementary analysis of prudential (as opposed to stimulative) capital account interventions in a small open economy due to aggregate demand externalities at the ZLB is provided in Section 5.2 of Farhi and Werning (2016).
} 
This constraint is commonly motivated by the existence of cash that delivers zero net returns as an alternative savings vehicle. If the optimal interest rate (7) violates this constraint, then the first-best allocation is no longer feasible 11

To model the implications, we follow the New-Keynesian literature and model period 0 output of non-traded goods as demand-determined. We assume that individual agents have the utility function

$$
U^{i}=u\left(c_{0}^{i}\right)-d\left(\ell_{0}^{i}\right)+u\left(c_{1}^{i}\right)
$$

where $c_{t}^{i}$ continues to be consumption of the composite final good and $\ell_{0}^{i}$ is labor supplied in period 0 . We assume a continuum $z \in[0,1]$ of monopolistic intermediate goods producers in the first period $t=0$ who each hire labor at the market wage $w_{0}^{i}$ to produce the demanded amount of an intermediate good of variety $z$ according to the linear function $y_{N, 0}^{i z}=\ell_{0}^{i z}$, where labor market clearing requires $\int \ell_{0}^{i z} d z=\ell_{0}^{i}$. The intermediate goods are combined to produce the period 0 non-traded good using a CES production function

$$
y_{N, 0}^{i}=\left(\int_{0}^{1}\left(y_{N, 0}^{i z}\right)^{\frac{\varepsilon-1}{\varepsilon}} d z\right)^{\frac{\varepsilon}{\varepsilon-1}}
$$

where the elasticity of substitution satisfies $\varepsilon>1$. We assume that the monopoly wedge arising from monopolistic competition is corrected by a proportional subsidy $\frac{1}{\varepsilon-1}$ that is financed by a lump-sum tax on producers. Intermediate firms are collectively owned by private agents, so the period 0 wage income and profits of private agents equal non-traded output $w_{0} \ell_{0}^{i}+\pi_{0}^{i}=p_{N, 0}^{i} y_{N, 0}^{i}$. Labor supply is determined by their optimality condition

$$
d^{\prime}\left(\ell_{0}^{i}\right)=w_{0}^{i} u^{\prime}\left(c_{0}^{i}\right)
$$

If the ZLB constraint is slack, then $w_{0}^{i}=p_{N, 0}^{i}$ and $\pi_{0}^{i}=0$; imposing market-clearing $c_{N, 0}^{i}=y_{N, 0}^{i}=$ $\ell_{0}^{i}$, the above equation simplifies to $d^{\prime}\left(y_{N, 0}^{i}\right)=1-\gamma / y_{N, 0}^{i}$, and this defines the first-best level of nontraded output $y_{N, 0}^{i *}$. Substituting this into the optimal interest rate rule (7), the ZLB constraint is indeed slack whenever the world interest rate satisfies $R \geq\left(y_{N, 0}^{i *} / y_{N, 1}^{i}\right)^{\frac{1-\gamma}{\gamma}}$ and binding otherwise. In that case, the constrained level $S^{i}=1$ in equation (7) defines the demand-determined level of output $C_{N, 0}^{i}<y_{N, 0}^{i *}$, which is given by

$$
C_{N, 0}^{i}\left(M^{i}\right)=\left(\frac{C_{T, 1}^{i}}{C_{T, 0}^{i}}\right)^{\frac{\gamma}{1-\gamma}} y_{N, 1}^{i}=\left(\frac{y_{T, 1}^{i}+M_{1}^{i}}{y_{T, 0}^{i}+M_{0}^{i}}\right)^{\frac{\gamma}{1-\gamma}} y_{N, 1}^{i}
$$

Intuitively, this captures that the relative price of today's goods in terms of tomorrow's goods is too high so private agents choose to consume less than the first-best. The effect of aggregate net imports on aggregate non-traded demand is

$$
C_{N, 0}^{i \prime}\left(M^{i}\right)=\frac{\gamma}{1-\gamma} C_{N, 0}^{i}\left(M^{i}\right) \cdot\left(\begin{array}{c}
-1 / C_{T, 0}^{i} \\
1 / C_{T, 1}^{i}
\end{array}\right)
$$

\footnotetext{
${ }^{11}$ It is well known in the New Keynesian literature that the problems associated with the zero lower bound could be avoided if the monetary authority was only able to commit to a higher inflation rate. See e.g. Krugman (1998) and Eggertsson and Woodford (2003). This would restore the allocation described in Section (2.3). Here we focus on the case where this is not possible, for time consistency or institutional reasons.
} 
The first element of this vector is negative, and the second element is positive since greater period 0 imports reduce demand for period 0 non-tradable goods and vice versa for period 1 imports.

Optimal Policy Since non-traded demand equals employment, the reduced-form welfare function of country $i$ can be written as

$$
\begin{aligned}
V^{i}\left(m^{i}, M^{i}\right) & =\log \left(\left(y_{T, 0}^{i}+m_{0}^{i}\right)^{\gamma}\left(C_{N, 0}^{i}\left(M^{i}\right)\right){ }^{1-\gamma}\right)-d\left(C_{N, 0}^{i}\left(M^{i}\right)\right)+\log \left(\left(y_{T, 1}^{i}+m_{1}^{i}\right)^{\gamma}\left(y_{N, 1}^{i}\right)^{1-\gamma}\right) \\
\text { with } V_{M}^{i}(\cdot) & =\left[(1-\gamma)\left(C_{N, 0}^{i}\right)^{-\gamma}-d^{\prime}\left(L^{i}\right)\right] \cdot C_{N, 0}^{i \prime}\left(M^{i}\right)
\end{aligned}
$$

The square brackets in $V_{M}^{i}(\cdot)$ represent the labor wedge and are positive when there is a demand shortage $C_{N, 0}^{i}<y_{N, 0}^{i *}$. As the signs of vector $C_{N, 0}^{i \prime}\left(M^{i}\right)$ indicate, period 0 and 1 imports then generate negative and positive demand externalities, respectively. This makes it optimal to tax period 0 net imports/inflows and subsidize period 1 net imports/inflows at rates $\tau^{i}=-V_{M}^{i} / V_{m}^{i} \mid 12$ |13

Spillovers of Current Account Intervention at the ZLB The spillovers of the described policy consist of greater net exports in period 0 and greater net imports in period 1, which can be characterized analogously to expression (6). Unless the country is a small economy, the intervention will also lead to a lower world interest rate, potentially exporting the liquidity trap to other countries (see also Jeanne, 2009; Caballero et al., 2015).

\subsection{Spillovers of Fiscal Shocks}

We extend our example on real spillovers to consider fiscal policy ${ }^{14}$ Assume that private agents value private consumption and public spending $G_{t}^{i}$ according to the utility function

$$
u^{i}\left(x^{i}\right)=u\left(c_{0}^{i}\right)+u\left(c_{1}^{i}\right)+\alpha u\left(G_{0}^{i}\right)+u\left(G_{1}^{i}\right)
$$

For simplicity, we use the same period utility $u(\cdot)$ for both types of spending. We will vary the parameter $\alpha$ to induce shocks to the preference for fiscal spending. We assume that the country $i$ policymaker raises the revenue necessary for fiscal spending via lump-sum taxes in the amounts of $G_{0}^{i}$ and $G_{1}^{i}$, giving rise to the period budget constraint $c_{t}^{i}+G_{t}^{i} \leq y_{t}^{i}+m_{t}^{i}{ }^{15}$ The country $i$ policymaker sets fiscal spending such that

$$
u^{\prime}\left(C_{0}^{i}\right)=\alpha u^{\prime}\left(G_{0}^{i}\right)
$$

\footnotetext{
${ }^{12}$ Note that the current account interventions in this setting are second-best policies since first-best policies would abolish the ZLB, e.g. by restoring full domestic price flexibility. The policymaker solves the optimal trade-off between foregoing opportunities for intertemporal trade with foreigners and wasting profitable domestic production opportunities because of the demand shortage.

${ }^{13}$ In a time-consistent setting for capital account interventions, a policymaker would not be able to commit to future actions. The intervention during a liquidity trap would still be given by the same expression for $V_{M, 0}^{i}$, but once the liquidity trap has passed, $V_{M, 1}^{i}=0$ and no further intervention would occur.

${ }^{14}$ In the aftermath of the Great Recession, for example, cooperation of fiscal stimulus has been at the center of discussions in the international economic policy arena (see e.g. the G-20 Leaders' Declaration, Nov. 2008; Spilimbergo et al., 2008). An important consideration in this context is for policymakers to refrain from exerting market power, e.g. by holding back stimulus because part of it spills over to other countries, as discussed in Example 5 on page 31.

${ }^{15}$ Since Ricardian equivalence holds in the described example, it is irrelevant whether private agents or the government or both engage in external transactions - for simplicity, our formulation assumes that only private agents do.
} 
or, equivalently, $C_{0}^{i}=\alpha^{-\frac{1}{\theta}} G_{0}^{i}$, and sets $C_{1}^{i}=G_{1}^{i}$. Using the short-hand notation $A=1+\alpha^{\frac{1}{\theta}}$ and a price vector $Q=(1,1 / R)$, the optimality condition of private agents implies

$$
M_{0}^{i}=\frac{A Y_{1}^{i} / R^{\frac{1}{\theta}}-2 Y_{0}}{A R^{1-\frac{1}{\theta}}+2}
$$

and consumption and fiscal spending satisfy $C_{0}^{i}=\alpha^{-\frac{1}{\theta}} G_{0}^{i}=\left(Y_{0}^{i}+M_{0}^{i}\right) / A$ and $C_{1}^{i}=G_{1}^{i}=$ $\left(Y_{1}^{i}-R M_{0}^{i}\right) / 2$.

Spillovers of Fiscal Shocks A shock to the preference for fiscal spending can be captured by $d \alpha$ or, equivalently, by $d A=\frac{1}{\theta} \alpha^{\frac{1-\theta}{\theta}} d \alpha$, and creates international spillover effects by shifting the demand curves of country $i$ agents by

$$
\left.\frac{d M^{i}}{d A}\right|_{Q}=\left(\begin{array}{c}
S \\
-R S
\end{array}\right) \quad \text { where } \quad S=\frac{2 R^{-\frac{1}{\theta}}\left(Y_{1}^{i}+Y_{0}^{i} R\right)}{\left(A R^{1-\frac{1}{\theta}}+2\right)^{2}}>0
$$

A greater preference $\alpha$ for fiscal spending on good 0 induces the country to import more good 0 and export more good 1. Unless economy $i$ is small in the world market, this raises the relative price of good 0 , with the usual global spillover effects. If we interpret the setup as intertemporal, this translates into a higher world interest rate.

\subsection{Spillovers of Macroprudential Policy}

This example illustrates the spillover effects of macroprudential policy or capital controls to mitigate fire-sale externalities in a country $i$ that suffers from financial frictions ${ }^{16}$ We build on the framework of Jeanne and Korinek (2010) to motivate the policy and focus on the resulting spillovers. We add a third time period to the setup of Section 2.1 so that $t=0,1,2$ and assume a quasilinear utility function

$$
U^{i}=u\left(c_{0}^{i}\right)+u\left(c_{1}^{i}\right)+c_{2}^{i}
$$

where $u\left(c_{t}^{i}\right)=\log c_{t}^{i}$. We collect the prices of discount bonds in the world economy in the row vector $Q=\left(1,1 / R_{1}, 1 /\left(R_{1} R_{2}\right)\right)$ and the net imports in each time period in the column vector $m^{i}=\left(m_{0}^{i}, m_{1}^{i}, m_{2}^{i}\right)^{T}$. Private agents face the usual period budget constraints $c_{t}^{i}=y_{t}^{i}+m_{t}^{i}$ for $t=0,1,2$ as well as the usual intertemporal budget $Q \cdot m^{i} \leq 0$.

To create an interesting case for macroprudential policy, we follow Jeanne and Korinek (2010) in assuming that private agents own a tree that can be used as collateral. The tree delivers a dividend $y_{t}^{i}$ in each period as long as it is held by the private agents in the domestic economy - this captures that domestic agents have an advantage in tending to domestic projects and creates the potential for fire-sale prices. Furthermore, private agents are subject to a commitment problem that limits their borrowing in period 1. In particular, an agent could invest in a scam in period 1 that would enable him to default on his lenders in period 2 and hide all his assets. Lenders can stop the scam by taking the borrower to court in period 1 and recover up to an amount $\phi$ of his tree, but they

\footnotetext{
${ }^{16}$ See Buch and Goldberg (2016) for a summary of recent empirical evidence on macroprudential policy spillovers. See also IMF (2013) for multilateral aspects of macroprudential policy.
} 
need to re-sell the tree to other domestic agents at market price $p^{i}$ lest it loses its value. This gives rise to a financial constraint that limits how much private agents can commit to repay to

$$
-m_{2}^{i} \leq \phi p^{i}
$$

Individual private agents in economy $i$ take the asset price as given when they decide on their optimal consumption allocation. However, the individual optimality condition for asset holdings $p^{i}=u^{\prime}\left(c_{2}^{i}\right) / u^{\prime}\left(c_{1}^{i}\right) \cdot y_{2}^{i}$ together with market clearing defines an aggregate asset price function $p^{i}\left(M_{1}^{i}\right)=\left(y_{1}^{i}+M_{1}^{i}\right) y_{2}^{i}$. This allows us to re-write the constraint as

$$
m_{2}^{i}+\phi p^{i}\left(M_{1}^{i}\right) \geq 0
$$

The policymaker in country $i$ internalizes that greater period 1 consumption raises the asset price and relaxes the borrowing constraint in period 1, which provides a rationale for macroprudential intervention. Denoting the shadow price on the constraint by $\mu^{i}$, the policymaker can improve welfare when the constraint is binding by imposing a macroprudential tax on period 0 borrowing

$$
1-\tau_{0}^{i}=1 /\left(1+\frac{\mu^{i} \phi p^{i \prime}\left(M_{1}^{i}\right)}{u^{\prime}\left(C_{1}^{i}\right)}\right)
$$

Since lenders are foreigners, the macroprudential tax can also be interpreted as a capital control.

Spillovers of Macroprudential Regulation or Capital Controls A prudential policy intervention that marginally reduces period 0 borrowing and net inflows $-d m_{0}^{i}<0$ creates international spillovers by shifting the demand curves of private agents in the three time periods by

$$
-\left.\frac{d m^{i}}{d m_{0}^{i}}\right|_{Q}=\left(\begin{array}{c}
-1 \\
\frac{R_{1}}{1-\phi p^{i \prime}\left(M_{1}^{i}\right)} \\
-\frac{R_{1} R_{2} \phi p^{i \prime}\left(M_{1}^{i}\right)}{1-\phi p^{i \prime}\left(M_{1}^{i}\right)}
\end{array}\right)
$$

The second row captures two effects: the numerator reflects that each unit saved in period 0 implies $R_{1}$ units of liquid wealth in period 1 ; the denominator captures that these $R_{1}$ units of wealth lead to a magnified increase in imports since financial amplification eases the borrowing constraint. The third row captures that agents need to repay the additional borrowing in period 2. Unless country $i$ is small, the described shifts in demand will generally lower the world interest rate $R_{1}$ and increase $R_{2}$; other countries will benefit or suffer depending on their interest rate exposure.

\subsection{Spillovers of Exchange Rate Stabilization}

Next we analyze the spillovers from stabilizing the exchange rate in a developing economy in which exchange rate fluctuations result in undesirable redistributions among agents who do not have access to well-functioning insurance markets. Consider an economy $i$ with two time periods $t=0,1$, a traded and a non-traded intermediate good each period and a final good. There are two categories of private agents, which we call the "financial elite" and the "people" who live hand-tomouth. The financial elite $E$ obtain an endowment of $\alpha y_{T}$ traded goods and $\alpha y_{N}$ non-traded goods 
every period. The people are made up of two types $j \in\{N, T\}$ who obtain their income in one of the two intermediate sectors: those in the traded sector $T$ obtain an endowment of $(1-\alpha) y_{T}$ traded goods; the people in the non-traded sector $N$ obtain $(1-\alpha) y_{N}$ non-traded goods every period $t$. We assume for simplicity that the endowments $\left(y_{T}, y_{N}\right)$ are constant across time and equal to each other. Each type of the people as well as the elite consist of a continuum of agents of mass 1.

Each period there is a spot market in which agents exchange traded and non-traded goods at relative prices $p_{N, t}^{i}$. After having traded, each agent consumes traded $c_{T, t}$ and non-traded goods $c_{N, t}$, which enter their period utility as a Cobb-Douglas composite $c=c_{T}^{\sigma} c_{N}^{1-\sigma}$ where we set w.l.o.g. $\sigma=\frac{1}{2}$ to maintain symmetry. Assuming CES intertemporal preferences, the utility of each type of agent $j \in\{N, T, E\}$ is

$$
U_{j}=\sum_{t=0,1} \frac{\left(c_{T, t}^{\sigma} c_{N, t}^{1-\sigma}\right)^{1-\gamma}}{1-\gamma}
$$

where we assume $\gamma>1$ to ensure agents have sufficient desire for intertemporal smoothing. This condition is satisfied for typical parameter values in macroeconomics.

The People do not have access to financial markets so they cannot borrow, save, or insure; their decision problem is purely intratemporal: they collect their endowment and trade in the spot market to maximize utility. We denote the period $t$ wealth of people of type $j \in\{N, T\}$ by $w_{j t}$ so $w_{N t}=p_{N t}(1-\alpha) y_{N}$ and $w_{T t}=(1-\alpha) y_{T}$. The indirect period $t$ utility of type $j$ is given by

$$
v_{j t}=v\left(p_{N t}, w_{j t}\right)=\frac{\left(\kappa w_{j t} / p_{N t}^{1-\sigma}\right)^{1-\gamma}}{1-\gamma}
$$

where $\kappa=\sigma^{\sigma}(1-\sigma)^{1-\sigma}$ is a constant. For each type of the people, utility is increasing in the quantity and relative price of their endowed good. An appreciation (increase) in the real exchange rate $p_{N t}^{i}$ benefits the people in the nontraded sector at the expense of those in the traded sector, and vice versa for a depreciation. Imposing equal welfare weights, the combined period welfare of the people is

$$
w_{P}\left(p_{N t}\right)=v\left(p_{N t}, y_{T}\right)+v\left(p_{N t}, p_{N t} y_{N}\right)=\frac{[\kappa(1-\alpha)]^{1-\gamma}}{1-\gamma}\left[\left(y_{T} / p_{N t}^{1-\sigma}\right)^{1-\gamma}+\left(p_{N}^{\sigma} y_{N t}\right)^{1-\gamma}\right]
$$

and is concave in $p_{N t}$ around the autarky exchange rate $p_{N}^{a u t}=1$, which constitutes the maximum of the function.

The Financial Elite engages in intertemporal trade $m^{i}$ in international financial markets and solves

$$
\max _{\left\{c_{T t}, c_{N t}, m_{t}^{i}\right\}_{t=0}^{\infty}} U_{E} \quad \text { s.t. } \quad c_{T t}-\alpha y_{T t}+p_{N}^{i}\left(c_{N t}-\alpha y_{N t}\right)-m_{t}^{i} \leq 0 \quad \forall t
$$

subject to the standard intertemporal budget constraint. If the world interest rate is at the autarky level $R=1$, then the elite does not engage in intertemporal trade and the exchange rate will be 
at its autarky level $p_{N}^{a u t}$, maximizing the welfare of the people. If $R \lessgtr 1$, the elite will borrow or lend and thus import and export traded goods. Domestic market clearing implies that the period $t$ exchange rate as a function of net inflows $M_{t}^{i}$ is

$$
p_{N}^{i}\left(M_{t}^{i}\right)=\frac{1-\sigma}{\sigma} \cdot \frac{y_{T}+M_{t}^{i}}{y_{N}}
$$

with $p_{N}^{i \prime}>0$ so inflows appreciate the real exchange rate and vice versa. These real exchange rate fluctuations unambiguously reduce the welfare of the people.

Social Welfare If we assign a social welfare weight $\varphi \in[0,1]$ to the people and $1-\varphi$ to the elite, the reduced-form social welfare function of the economy is

$$
V^{i}\left(m^{i}, M^{i}\right)=\sum_{t=0,1}\left[(1-\varphi) v\left(p_{N}\left(M_{t}^{i}\right), \alpha\left(y_{T}+p_{N}\left(M_{t}^{i}\right) y_{N}\right)+m_{t}^{i}\right)+\varphi v_{P}\left(p_{N}\left(M_{t}^{i}\right)\right)\right]
$$

The uninternalized period $t$ welfare effects from external transactions are given by

$$
\begin{aligned}
V_{M t}^{i} & =\left[(1-\varphi) v_{p}\left(p_{N t}, w_{E}\right)+\varphi \alpha y_{N} v_{w}\left(p_{N t}, w_{E}\right)+\varphi w_{P}^{\prime}\left(p_{N t}\right)\right] p_{N}^{i \prime}\left(M_{t}^{i}\right) \\
& =\left[(1-\varphi) \kappa^{1-\gamma} w^{-\gamma} p_{N t}^{-(1-\sigma)(1-\gamma)}\left(\alpha y_{N}-c_{N t}\right)+\varphi w_{P}^{\prime}\left(p_{N t}\right)\right] p_{N}^{i \prime}\left(M_{t}^{i}\right)
\end{aligned}
$$

The first term in the brackets with weight $(1-\varphi)$ corresponds to the welfare effects of exchange rate fluctuations on the elite, which depends on whether they are net buyers or net sellers of nontraded goods in the domestic economy. When the elite receives inflows of traded goods, it converts some of them into non-traded goods so $c_{N t}>\alpha y_{N}$ and is hurt by real exchange rate appreciations. Conversely, when the elite sells traded goods abroad, it is hurt by domestic real exchange rate depreciations. The second term with weight $\varphi$ corresponds to the welfare effects on the people. As we already noted, they are also hurt by both the exchange rate appreciations when $M_{t}^{i}>0$ and the depreciations when $M_{t}^{i}<0$. We conclude that $V_{M t}^{i}<0$ when $M_{t}^{i}>0$, and $V_{M t}^{i}>0$ when $M_{t}^{i}<0$ for any $\varphi \in[0,1]$. The policymaker will lean against both inflows and outflows by imposing the respective taxes $\tau_{t}^{i}=-V_{M t}^{i} / V_{m t}^{i}$. The greater the weight $\varphi$ on the people, the closer the allocation will be to the autarky allocation with perfect exchange rate stabilization, which maximizes the welfare of the people. In this example, capital flow management is a second-best insurance device since the people do not have access to insurance (either in a market setting or from social insurance) and labor markets are rigid, as is frequently the case in developing and emerging economies.

Spillovers of Exchange Rate Stabilization The spillovers of leaning against inflows and outflows of traded goods are given by an analogous expression to (6). They consist of reduced trading opportunities for the rest of the world, which generally increase the volatility of world interest rates.

\section{General Framework}

This section develops a general framework that nests the described examples - as well as a wide range of other open economy macroeconomic models - in order to derive broadly applicable 
lessons for international policy cooperation. We set up a model of a multi-country world economy in which each country encompasses optimizing private agents as well as a policymaker who maximizes domestic welfare. Both sets of actors are subject to a set of constraints on domestic allocations and a standard budget constraint on external transactions. For simplicity of notation, the main text focuses on the case where there is a representative agent in each economy ${ }^{17}$

Countries Consider a set of countries $\mathcal{I}$ of total measure normalized to $\omega(\mathcal{I})=1$. We denote by $\omega^{i}=\omega(\{i\})$ the measure of a given country $i \in \mathcal{I}$ in the world economy. If $\omega^{i}=0$, then country $i$ is a small open economy.

Private Agents In each country $i \in \mathcal{I}$, there is a continuum of identical private agents of mass 1 . A representative private agent obtains utility according to a function

$$
U^{i}\left(x^{i}\right)
$$

where $U^{i}\left(x^{i}\right)$ is increasing in each element of $x^{i}$ and quasiconcave, and $x^{i}$ is a column vector that includes two types of domestic variables. First, it includes all variables that directly provide utility to private agents, for example the consumption of goods and leisure. Utility is strictly increasing in such variables. Secondly, for compactness of notation, the vector $x^{i}$ may also include other domestic variables that we want to keep track of but that do not directly yield utility, for example the capital stock $k^{i}$ in models of capital accumulation. For the latter type of variables, utility is unaffected. We will provide concrete examples below.

External Budget Constraint We denote the international transactions of the representative private agent in country $i$ by a column vector of net imports $m^{i}$ that are traded at international prices given by the row vector $Q$. The agent may be subject to a vector of taxes/subsidies $\tau^{i}$ on international transactions that are imposed by the country's policymaker. The external budget constraint of the agent is

$$
\frac{Q}{1-\tau^{i}} \cdot m^{i} \leq T^{i}
$$

where we denote by $\frac{Q}{1-\tau^{i}}$ the element-by-element (Hadamard) division of the price vector $Q$ by the tax vector $\left(1-\tau^{i}\right)$ and by $\frac{Q}{1-\tau^{i}} \cdot m^{i}$ the inner product of the price and quantity vectors. $T^{i}$ denotes a lump-sum transfer that rebates the tax revenue from $\tau^{i}$ to the agent so $T^{i}=\frac{\tau^{i} Q}{1-\tau^{i}} \cdot m^{i}$.

Below, we will consider both situations in which the policymaker has complete freedom in setting the tax instruments $\tau^{i}$ - we will call this the case of perfect external instruments - and instances in which the policymaker faces costs, restrictions, or other imperfections in the set of external policy instruments. Likewise, we will consider situations in which the international market is an Arrow-Debreu market that is free of any imperfections and the case of international market imperfections.

\footnotetext{
${ }^{17}$ In Appendix A.3. we extend the described framework in two directions: first, we allow for multiple types of agents in each economy to which a policymaker can assign arbitrary Pareto weights; secondly, we allow for a paternalistic policymaker who assigns a welfare function to the private agents in her country that differs from their individual preferences. We show that our results continue to hold under those extensions.
} 
Domestic Constraints The representative agent in country $i$ is also subject to a collection of domestic constraints, which include domestic budget constraints and, potentially, incentive, selection, financial, or price-setting constraints as well as policy-imposed restrictions. These constraints relate the international transactions and domestic variables $\left(m^{i}, x^{i}\right)$ of the representative agent with each other. Furthermore, to capture domestic general equilibrium effects, policy interventions, and externalities, the domestic constraints also depend on the aggregate level of these variables, which we denote by the upper-case variables $\left(M^{i}, X^{i}\right)$. The representative agent takes these aggregate variables as given since he is small in the domestic economy. However, in equilibrium, individual and aggregate allocations coincide.

The following vector constraint captures all domestic constraints in considerable generality,

$$
f^{i}\left(m^{i}, x^{i}, M^{i}, X^{i}\right) \leq 0
$$

The optimization problem of the representative private agent in country $i$ is to choose the optimal external and domestic allocations $\left(m^{i}, x^{i}\right)$ so as to maximize utility 15 subject to the collection of domestic and external constraints while taking the aggregate $\left(M^{i}, X^{i}\right)$ as given,

$$
\max _{m^{i}, x^{i}} U^{i}\left(x^{i}\right) \text { s.t. (16), (17) }
$$

Policymaker The policymaker in country $i$ internalizes the consistency requirement that the allocations of the representative agent must coincide with the aggregate allocations so $m^{i}=M^{i}$ and $x^{i}=X^{i}$. She chooses the external policy instruments $\tau^{i}$ and the aggregate domestic and external allocations $\left(M^{i}, X^{i}\right)$ in order to maximize the utility (15) of domestic private agents subject to the domestic and external constraints $f^{i}(\cdot) \leq 0$ and $M^{i} \cdot Q \leq 0$ as well as the implementability constraints arising from problem (18), which reflect that the allocations $\left(m^{i}, x^{i}\right)$ have to solve the optimization problem of private agents.

To make our setup a bit more tangible, the following examples illustrate how two common benchmark open economy models map into our framework:

Example 1 (Canonical Open Economy Model). In an infinite-horizon endowment economy $i$ with a single consumption good, the only domestic variable is consumption so $x^{i}=\left\{\left(c_{t}^{i}\right)_{t=0}^{\infty}\right\}$, and he utility function can be denoted by $U^{i}\left(x^{i}\right)=\sum_{t} \beta^{t} u\left(c_{t}^{i}\right)$. The vector of external transactions $m^{i}=\left(m_{t}^{i}\right)_{t=0}^{\infty}$ and the external policy instruments $\tau^{i}=\left(\tau_{t}^{i}\right)_{t=0}^{\infty}$ capture the net imports of the consumption good in each period, which is equivalent to the trade balance, and import tariffs or subsidies. Alternatively, we can interpret $m_{t}^{i}$ as net capital inflows in period $t$ and $\tau_{t}^{i}$ as a capital control. The domestic constraints encompass one budget constraint for each time period, $f^{i}(\cdot)=\left\{f_{t}^{i}(\cdot)\right\}_{t=0}^{\infty}$ where $f_{t}^{i}(\cdot)=c_{t}^{i}-y_{t}^{i}-m_{t}^{i} \leq 0$. If we normalize $Q_{0}=1$ then each element of the vector $Q_{t}$ captures the price of a discount bond that pays one unit of consumption good in period $t$, and the external budget constraint of the economy is given by (16). This fully describes the mapping of a canonical open economy model into our general framework 18

It is straightforward to extend the example to multiple consumption goods per period and/or uncertainty by indexing all variables by good $k \in \mathcal{K}$ and/or state of nature $s \in \mathcal{S}$, for example $\left(m_{k, s, t}^{i}, x_{k, s, t}^{i}\right)$.

\footnotetext{
${ }^{18} \mathrm{It}$ is common in the open economy macroeconomics literature to keep track of the external wealth position $w_{t}^{i}$ of a
} 
Example 2 (Production). In a neoclassical production economy, the domestic variables also includes leisure, investment, and capital so $x^{i}=\left\{\left(c_{t}^{i}, \ell_{t}^{i}, i_{t}^{i}, k_{t+1}^{i}\right)_{t=0}^{\infty}\right\}$, and the utility function includes leisure, $U^{i}\left(x^{i}\right)=\sum_{t} \beta^{t} u\left(c_{t}^{i}, \ell_{t}^{i}\right)$. Denoting labor supply by $1-\ell_{t}^{i}$, the collection of domestic constraints consists of a budget constraint $f_{t, c}^{i}(\cdot)$ and a capital accumulation constraint $f_{t, k}^{i}(\cdot)$ each period that are given by

$$
\begin{aligned}
& f_{t, c}^{i}(\cdot)=c_{t}^{i}+i_{t}^{i}-A_{t}^{i}\left(k_{t}^{i}\right)^{\alpha}\left(1-\ell_{t}^{i}\right)^{1-\alpha}-m_{t}^{i} \leq 0 \\
& f_{t, k}^{i}(\cdot)=k_{t+1}^{i}-(1-\delta) k_{t}^{i}-i_{t}^{i} \leq 0
\end{aligned}
$$

For further examples let us refer to Appendix B, in which we show how to nest the models of Section 2 into our general framework. This includes, among others, an example of how to capture a domestic market for non-traded goods (Appendix B.1) and an example in which intervening in external markets is a second-best policy because of a domestic imperfection (Appendix B.2).

Global Allocations In the following, we define a feasible country $i$ allocation for given world prices $Q$ as a pair $\left(M^{i}, X^{i}\right)$ that satisfies the country $i$ domestic and external constraints $f^{i}\left(M^{i}, X^{i}, M^{i}, X^{i}\right) \leq$ 0 and $M^{i} \cdot Q \leq 0$. Furthermore, we define a feasible global allocation as a collection $\left(M^{i}, X^{i}\right)_{i \in \mathcal{I}}$ that satisfies the domestic constraints $f^{i}(\cdot) \leq 0 \forall i \in \mathcal{I}$ and global market clearing $\int_{i \in \mathcal{I}} M^{i} d \omega(i) \leq 0$. Finally, we call a feasible global allocation $\left(M^{i}, X^{i}\right)_{i \in \mathcal{I}}$ Pareto efficient if there does not exist another feasible global allocation $\nexists\left(\tilde{M}^{i}, \tilde{X}^{i}\right)_{i \in \mathcal{I}}$ that makes at every country weakly better off, $U^{i}\left(\tilde{X}^{i}\right) \geq$ $U^{i}\left(X^{i}\right) \forall i$, and at least one country strictly so, $\exists j \in \mathcal{I}$ s.t. $U^{j}\left(\tilde{X}^{j}\right)>U^{j}\left(X^{j}\right) 19$

Definition 1 (Global Competitive Equilibrium). An equilibrium in the described world economy consists of a feasible global allocation $\left(M^{i}, X^{i}\right)_{i \in \mathcal{I}}$ and a set of external policy measures $\left(\tau^{i}\right)_{i \in \mathcal{I}}$ together with world market prices $Q$ such that in each country $i \in \mathcal{I}$,

- the representative agent optimizes, i.e. the individual allocations $\left(m^{i}, x^{i}\right)$ solve the optimization problem of the representative agent for given prices $Q$, aggregate allocations $\left(M^{i}, X^{i}\right)$ and external policy measures $\left(\tau^{i}\right)$ and

- the policymaker optimizes, i.e. the aggregate allocations $\left(M^{i}, X^{i}\right)$ and external policy measures $\left(\tau^{i}\right)$ are consistent are consistent so $m^{i}=M^{i}$ and $x^{i}=X^{i}$ and solve the optimization problem of the policymaker for given prices $Q$.

country over time and denote the external budget constraint 16 by a period-by-period law of motion

$$
\frac{\left(1-\hat{\tau}_{t+1}^{i}\right) w_{t+1}^{i}}{1+r_{t+1}}=w_{t}^{i}-m_{t}^{i}+T_{t}^{i} \quad \forall t
$$

where the interest rate $r_{t+1}$ corresponds to the relative price of discount bonds in two consecutive periods, $1+r_{t+1}=$ $Q_{t} / Q_{t+1}$, and $\hat{\tau}_{t+1}^{i}$ corresponds to the relative tax wedge $1-\hat{\tau}_{t+1}^{i}=\left(1-\tau_{t}^{i}\right) /\left(1-\tau_{t+1}^{i}\right)$ on external transactions in two consecutive periods. This period-by-period formulation (together with a transversality condition $\lim _{t \rightarrow \infty} Q_{t} w_{t}^{i}=$ 0 ) and the Arrow-Debreu-style formulation in our general framework are equivalent, and we will use both in our applications below.

${ }^{19}$ Observe that our definition of Pareto efficiency is subject to the set of domestic constraints $f^{i}(\cdot)$, which may capture domestic market imperfections. It could therefore also be called constrained Pareto efficiency. 


\section{Efficient Benchmark}

\subsection{Conditions for Efficiency}

This section establishes an efficient benchmark by showing that the global competitive equilibrium in our general framework is Pareto efficient under three general conditions. In Sections 5 to 7 we will relax these conditions one by one to study how each of them generates scope for cooperation.

Condition 1 (Competitive Behavior). The policymaker in each country $i \in \mathcal{I}$ acts as a price-taker.

The first natural interpretation for Condition 1 is that country $i$ is a small open economy with $\omega^{i}=0$ and does not produce a unique product variety. This implies that the country does not have market power over the vector of world market prices $Q$ since $d Q / d M^{i}=0$.

A second interpretation of the condition is that the policymaker in country $i \in \mathcal{I}$ acts as a pricetaker because of an explicit or implicit multilateral agreement such as the WTO, or because of an explicitly domestic policy objective that is prescribed by law and induces the policymaker to act with benign neglect towards international markets.20

Condition 2 (Perfect External Instruments). The policymaker in each country $i \in \mathcal{I}$ possesses a perfect set of external policy instruments $\tau^{i}$.

Formally, this condition implies that the policymaker in each country can choose the vector of external policy interventions $\tau^{i}$ without any restrictions or costs. This ensures that she has the effective means of intervening in the external allocations $M^{i}$ of country $i$. Depending on the structure of the model and the interpretation of the international transactions $M^{i}$, the external instruments can be interpreted as tariffs or capital controls. Note that the condition is silent about what powers the policymaker has in the domestic economy. The condition can be satisfied independently of whether or not the policymaker has domestic instruments to address domestic policy objectives.

We will show below in Section 6 that the condition can in fact be replaced by a weaker condition on effectively complete instruments, i.e. the policymaker needs to possess only those instruments that she actually wants to use for domestic objectives.

Condition 3 (Perfect International Markets). There is a complete and unrestricted international market for trading goods $M^{i}$ at world market price $Q$.

The third condition requires that the international market is complete and free of constraints and other imperfections such as price stickiness. Note that the condition is silent about the domestic market structure in each economy $i$, which may exhibit numerous imperfections even if Condition 3 is satisfied.

\footnotetext{
${ }^{20}$ For example, the US Federal Reserve claims to follow a policy of acting with benign neglect towards external considerations such as exchange rates, as articulated by Bernanke(2013). Similarly, the G-7 Ministers and Governors regularly proclaim that "we reaffirm that our fiscal and monetary policies have been and will remain oriented towards meeting our respective domestic objectives using domestic instruments, and that we will not target exchange rates" (G-7, 2013).
} 
Discussion The three conditions that we stated are strong and, of course, they are never strictly satisfied in the real world. This is typical whenever economists appeal to the first welfare theorem - the underlying conditions are never literally met, but they provide a useful benchmark for organizing the debate, for exploring which deviations from the efficient benchmark matter for efficiency and, in our setting, for identifying when cooperation has a chance to bear fruit.

For completeness, there is a fourth condition, local non-satiation of preferences, that is necessary for the first welfare theorem to hold. We will impose this condition on the reduced-form welfare functions of policymakers below, but we will not further elaborate on it as it does not seem to play an important role in discussions of international policy cooperation.

In the following, we provide a step-by-step analysis of the global competitive equilibrium that develops a number of results that are of independent interest. We start with a lemma that greatly simplifies the analysis:

Lemma 1 (Separability). Under Condition 2, the optimal allocation of country $i \in \mathcal{I}$ can be obtained by following a two-step procedure:

1. Solve for the optimal domestic allocation $\left(x^{i}, X^{i}\right)$ given the external allocation $\left(m^{i}, M^{i}\right)$; this defines a reduced-form utility function $V^{i}\left(m^{i}, M^{i}\right)$.

2. Solve for the optimal external allocation $\left(m^{i}, M^{i}\right)$ by maximizing the reduced-form utility function $V^{i}(\cdot)$.

Proof. See Appendix A.1.

Intuitively, if the country $i$ policymaker has perfect external instruments, the domestic allocation can be determined without considering the interactions with the external allocation - there is no need to distort the domestic allocation in order to achieve external goals. Formally, the separability result follows since the external implementability constraint on a policymaker with perfect instruments is slack and, given $M^{i}$, can be ignored when solving for the optimal domestic allocation. By contrast, if external instruments are imperfect, the policymaker has an incentive to distort her domestic allocation to better target the external allocation, as we will demonstrate in detail in Section 6. Then solving step 1. in the lemma while taking the external allocation as given is no longer optimal.

Our separability result reflects a pecking order of instruments to target external allocations: if possible, use only external instruments to achieve external objectives. If external policy instruments are imperfect, then also use domestic policy measures. This has an interesting practical implication:

Corollary 1 (Separating Domestic and External Economic Policy). Under Condition 2, the task of domestic policymaking can be assigned to a separate agency that maximizes domestic welfare taking the external allocation as given, i.e. without internalizing how its policy actions will affect external allocations.

This corollary provides conditions under which it is sufficient for agencies responsible for domestic policy to have an explicitly domestic policy focus. Even though, in general equilibrium, 
domestic policy will affect the external allocations of private agents, this is irrelevant for the domestic policymaker when Condition 2 is satisfied. The reason is that the external policymaker has perfect instruments to steer the external allocation of the economy.

By contrast, the agency responsible for setting external policy cannot just take the domestic allocation as given - it generally needs to internalize how the external allocation $M^{i}$ affects the incentives of private agents in choosing their optimal domestic allocation. In step 2. of the lemma above, this decision problem is part of the reduced-form utility function $V^{i}(\cdot)$.

The following two subsections follow the solution strategy proposed by the lemma.

\subsection{Domestic Optimization Problem}

Private Agents For a given external allocation $\left(m^{i}, M^{i}\right)$ and domestic aggregate allocation $X^{i}$, the optimization problem of a representative agent in country $i$ is given by the value function

$$
v^{i}\left(m^{i}, M^{i}, X^{i}\right)=\max _{x^{i}} U^{i}\left(x^{i}\right) \quad \text { s.t. } \quad f^{i}\left(m^{i}, x^{i}, M^{i}, X^{i}\right) \leq 0
$$

Denoting the shadow prices on the vector of domestic constraints $f^{i}$ by the row vector $\lambda_{d}^{i}$, the collection of domestic optimality conditions is

$$
U_{x}^{i}=f_{x}^{i^{T}} \lambda_{d}^{i^{T}}
$$

where $U_{x}$ denotes a column vector of partial derivatives of the utility function with respect to $x^{i}$, and $f_{x}^{i}$ is the Jacobian of derivatives of $f^{i}$ with respect to $x^{i}$ and is a matrix of the size of $f^{i}(\cdot)$ times the size of $x^{i}$. We denote the solution to problem (19) by the policy function $x^{i}\left(m^{i}, M^{i}, X^{i}\right)$ capturing the optimal domestic choices of private agents.

Domestic Policymaker For a given aggregate external allocation $M^{i}$, the domestic policymaker chooses the optimal domestic allocation $X^{i}$ subject to the consistency conditions $x^{i}=X^{i}$ and $m^{i}=$ $M^{i}$ as well as the implementability constraint 20. The policymaker's problem is

$$
\max _{X^{i}, \lambda_{d}^{i}} U^{i}\left(X^{i}\right) \quad \text { s.t. } \quad f^{i}\left(M^{i}, X^{i}, M^{i}, X^{i}\right) \leq 0,
$$

We assign the row vector of shadow prices $\Lambda_{d}^{i}$ to the vector of domestic constraints $f^{i}$ and $\mu_{d}^{i}$ to the collection of domestic implementability constraints. The solution to this problem defines a function $X^{i}\left(M^{i}\right)$ that describes the optimal domestic allocation $X^{i}$ for a given external allocation.

Definition 2 (Reduced-Form Utility). Using the value function (19), we define the reduced-form utility function of a representative agent in economy $i$ for a given pair $\left(m^{i}, M^{i}\right)$ by

$$
V^{i}\left(m^{i}, M^{i}\right):=v^{i}\left(m^{i}, M^{i}, X^{i}\left(M^{i}\right)\right)=U^{i}\left(x^{i}\left(m^{i}, M^{i}, X^{i}\left(M^{i}\right)\right)\right)
$$

The reduced-form utility function $V^{i}\left(m^{i}, M^{i}\right)$ contains all the information we need to solve for the external allocations of country $i$ and will play a central role in our welfare analysis. The last equality in the definition follows directly from the definition of $x^{i}(\cdot)$. Note that $V^{i}\left(m^{i}, M^{i}\right)$ is also 
defined for off-equilibrium allocations in which $m^{i}$ and $M^{i}$ differ, since individual agents are in principle free to choose any allocation of $m^{i}$. In equilibrium, however, $m^{i}=M^{i}$ will hold.

For the remainder of our analysis, we will focus on the case where the partial derivatives of this reduced-form utility function satisfy $V_{m}^{i}>0$ and $V_{m}^{i}+V_{M}^{i}>0 \forall i$ : ceteris paribus, a marginal increase in individual imports $m_{t}^{i}$ or a simultaneous marginal increase in both individual and aggregate imports $m^{i}=M^{i}$ increases the welfare of private agents. These are fairly mild regularity conditions that guarantee local non-satiation of preferences and hold for the vast majority of open economy macro models. For instance, the reduced-form utility function in Example 1 is $V^{i}\left(m^{i}, M^{i}\right)=\sum_{t} \beta^{t} u\left(y_{t}^{i}+m_{t}^{i}\right)$, satisfying our regularity conditions since $V_{m, t}^{i}=V_{m, t}^{i}+V_{M, t}^{i}=$ $\beta^{t} u^{\prime}\left(c_{t}^{i}\right)>0 \forall t$.

\subsection{External Allocations}

Representative Agent Given the reduced-form utility $V^{i}\left(m^{i}, M^{i}\right)$, an international price vector $Q$, a vector of tax instruments $\tau^{i}$ on external transactions, transfer $T^{i}$ and aggregate external allocation $M^{i}$, the second-step optimization problem of a representative agent in country $i$ is

$$
\left.\max _{m^{i}} V^{i}\left(m^{i}, M^{i}\right) \quad \text { s.t. } 16\right)
$$

Assigning the scalar shadow price $\lambda_{e}^{i}$ to the external budget constraint $(16)$, the associated optimality condition is

$$
\left(1-\tau^{i}\right)^{T} V_{m}^{i}=\lambda_{e}^{i} Q^{T}
$$

where the tax vector $\left(1-\tau^{i}\right)$ pre-multiplies the column vector $V_{m}^{i}$ in an element-by-element fashion.

The solution to problem 23 defines a reduced-form import demand function $m^{i}\left(Q, \tau^{i}, T^{i}, M^{i}\right)$ of the representative agent. Furthermore, substituting the consistency requirement $m^{i}=M^{i}$ and the government budget constraint $T^{i}=\frac{\tau^{i} Q}{1-\tau^{i}} \cdot M^{i}$, the import demand function of the representative agent defines an aggregate import demand function $M^{i}\left(Q, \tau^{i}\right)$, which is given by the fixed point $M^{i}=m^{i}\left(Q, \tau^{i}, \frac{\tau^{i} Q}{1-\tau^{i}} \cdot M^{i}, M^{i}\right)$.

External Policymaker Since the country $i$ policymaker has a complete set of external policy instruments under Condition 2, the implementability constraint (24) is slack, and we can directly solve for the policymaker's optimal allocation. For a given reduced-form utility function $V^{i}\left(m^{i}, M^{i}\right)$, she solves

$$
\max _{M^{i}} V^{i}\left(M^{i}, M^{i}\right) \quad \text { s.t. } Q \cdot M^{i} \leq 0
$$

Assigning shadow price $\Lambda_{e}^{i}$ to the policymaker's external budget constraint, the optimality condition is

$$
V_{m}^{i}+V_{M}^{i}=\Lambda_{e}^{i} Q^{T}
$$


Lemma 2 (Implementation). (i) The country i policymaker implements her optimal external allocation by setting

$$
\tau^{i}=-\left(V_{M}^{i} / V_{m}^{i}\right)^{T}
$$

where the division $V_{M}^{i} / V_{m}^{i}$ is performed element-by-element at the optimal allocation.

(ii) There is also a continuum of alternative implementations, in which the policy instruments (27) are rescaled by a positive constant $k^{i}>0$ s.t. $\left(1-\tilde{\tau}^{i}\right)=k^{i}\left(1-\tau^{i}\right)$.

Proof. For part (i), substituting the optimal $\tau^{i}$ from (27) into the optimality condition of private agents (24) yields the policymaker's optimality condition (26).

For part (ii), the rescaling of $\tau^{i}$ leaves external budget constraint unaffected since tax revenue is rebated lump-sum. It proportionately rescales the shadow price $\Lambda_{e}^{i}$ in the optimality condition (26) by $1 / k^{i}$ without affecting the real allocation of the economy.

The first part of the lemma defines a function $\tau^{i}(Q)$ that implements the optimal external allocation for given world prices $Q$. According to this implementation, the policymaker does not intervene in time periods/states of nature/goods for which $V_{M, t}^{i}=0$, i.e. for which private agents fully internalize the social marginal benefit of imports. By contrast, if there is an uninternalized soical benefit or cost $V_{M, t}^{i} \gtrless 0$, then $\tau_{t}^{i} \lessgtr 0$ so the policymaker subsidizes or taxes inflows of $m_{t}^{i}$. Furthermore, the policymaker's optimal policy $\tau^{i}(Q)$ defines a reduced-form aggregate import demand function $M^{i}(Q)=M^{i}\left(Q, \tau^{i}(Q)\right)$.

Part (ii) of the lemma observes that the incentive of private agents to shift consumption across time/states of nature/goods only depends on the relative price of goods. Multiplying all after-tax prices by a constant is equivalent to changing the numeraire.

Conversely, part (ii) of the lemma also implies that no policy intervention is necessary if the private and social marginal benefit of import goods are proportional for all goods, i.e. if $V_{M}^{i}=h^{i} V_{m}^{i}$ for some scalar $h^{i} \in(-1, \infty)$. In that case, setting $\tilde{\tau}^{i}=0$ will implement the same allocation as $\tau^{i}=-\left(V_{M}^{i} / V_{m}^{i}\right)^{T}$, as can be verified by setting $k^{i}=\frac{1}{1+h^{i}}$ in the lemma.

\subsection{Welfare Properties of Equilibrium}

We now turn to the welfare properties of the described global equilibrium.

Theorem 1 (Efficiency of Global Equilibrium). (i) Under Conditions 1 to 3 , the global competitive equilibrium allocation is Pareto efficient.

(Efficient Spillovers). (ii) By implication, any spillovers that arise from optimal domestic and external policy intervention constitute efficient pecuniary externalities.

Proof. A formal proof is provided in Appendix A.1.

Intuitively, the theorem is a version of the first welfare theorem, with two modifications. First, it is applied to an environment in which there are two layers of actors - private agents and a policymaker in each country. Secondly, it only applies to the external allocations of each country there can be any number of domestic market imperfections or targeting problems, and the external allocations are still Pareto efficient under the conditions of the theorem. 
The role of the three conditions is as follows. Condition 2 implies that the policymaker in each country has sufficient instruments to freely choose the external allocation of the economy - otherwise, the private agents in the economy may choose inefficient allocations that leave room for Pareto improvements because they neglect domestic externalities, as shown in Section 7. Conditions 1 and 3 capture the typical requirement for the first welfare theorem that agents act as pricetakers and trade in a complete market ${ }^{21}$ Given that the policymaker in each country internalizes all domestic externalities, the excess demand $M^{i}$ of each country correctly reflects the country's social marginal valuation of international transactions. The social marginal rates of substitution of all traded goods are equated across countries, and the resulting equilibrium is Pareto efficient.

Part (ii) of the theorem follows naturally: any time policymakers engage in domestic or external policy intervention, global prices $Q$ and quantities $\left(M^{i}\right)_{i \in \mathcal{I}}$ will adjust. These general equilibrium effects - or spillovers, as they are called in the policy debate - are the natural mechanism by which the world economy re-equilibrates. An immediate implication of point (i) is that such spillovers are Pareto efficient. They constitute pecuniary externalities that are mediated by a complete market for $M^{i}$. As such, they do generate redistributions between countries, but do not impinge on Pareto efficiency.

This insight may explain why the political debate about international policy spillovers and global cooperation is at times so vexing - spillovers generate winners and losers but, after they have taken place, there is no scope for Pareto improvements. Attempts at global cooperation are then zero-sum games.

Tatonnement and Arms Race The equilibrium adjustment process (tatonnement) may sometimes involve dynamics that look like an arms race, even though Theorem 1 applies and the spillovers are Pareto efficient:

Example 3 (Tatonnement and Arms Race). Consider a world economy in which a set of countries $\mathcal{I}$ engage in intertemporal trade. Assume a set of emerging economies $\tilde{\mathcal{I}} \subset \mathcal{I}$ with measure $\omega(\tilde{\mathcal{I}})>0$ that follow the setup described in Section 2.2 and experience negative externalities from capital inflows in period 0 that increase in the amount of the flows: their reduced-form welfare functions satisfy $V_{M, 0}^{i}<0$ and $V_{M M, 0}^{i}<0$ for $i \in \tilde{\mathcal{I}}$. The remaining countries $\mathcal{I} \backslash \tilde{\mathcal{I}}$ follow the setup described in Section 2.1

Assume an exogenous shock that increases the period 0 supply of capital flows from the rest of the world $\mathcal{I} \backslash \tilde{\mathcal{I}}$. This leads to greater capital flows to the emerging economies and greater externalities from capital flows. Each of the affected countries will optimally increase capital controls, but this deflects some of the capital flows to the rest of the world economy - including to the other emerging economies. In response to these deflected capital flows, each of the emerging economies finds it optimal to raise capital controls even more, leading to further deflection and so forth, until a new equilibrium with greater intervention in the emerging economies and a lower world interest rate is reached ${ }^{22}$ Such dynamics may give the appearance of

\footnotetext{
${ }^{21}$ As discussed earlier, there is an additional condition for the standard first welfare theorem to hold, local nonsatiation. We ensure that the condition is satisfied by our earlier assumption that $V_{m}^{i}+V_{M}^{i}>0$, but we do not further elaborate on it as it does not seem to play an important role in discussions of international policy cooperation.

${ }^{22}$ Giordani et al. (2014) provide careful evidence for such capital flow deflection dynamics and the resulting potential for an arms race of capital account intervention. Jeanne (2014) provides a theoretical model in which such dynamics may occur.
} 
an arms race, but they represent the natural mechanism through which the world economy re-equilibrates. They are Pareto efficient under the conditions of Theorem 1

\subsection{Policy Cooperation and Pareto Improvements}

Achieving Pareto improvements rather than merely Pareto-efficient allocations generally requires international policy cooperation. Theorem 1 emphasizes that domestic and external policy interventions and the resulting competitive allocations and spillovers are Pareto efficient, even though they may involve considerable redistributions between countries. This subsection describes two mechanisms by which cooperation among policymakers can undo the redistributions inherent in spillovers so as to generate Pareto improvements.

Pareto Improvements with Explicit Transfers Lump-sum transfers can trivially undo the wealth redistributions that arise from international policy spillovers and achieve a Pareto-superior allocation. To describe this mechanism, let us start from any Pareto-inefficient allocation $\left(\hat{M}^{i}\right)_{i \in \mathcal{I}}$ and show that under global cooperation with lump sum transfers, an allocation that is not only Pareto efficient but also a Pareto improvement over the initial allocation can be achieved. For our purposes, an important example of this is when the world economy has been hit by a shock and private agents have already adjusted their behavior, but policymakers have not yet optimally adjusted their external policy instruments $\left(\tau^{i}\right)_{i \in \mathcal{I}}$ in response to the shock ${ }^{23}$

Proposition 1 (Pareto-Improving Intervention with Transfers). Starting from any Pareto-inefficient allocation $\left(\hat{M}^{i}\right)_{i \in \mathcal{I}}$, global cooperation can achieve a Pareto improvement by setting the interventions $\tau^{i}=$ $-V_{M}^{i} / V_{m}^{i} \forall i$ and providing suitable compensatory international transfers $T^{i}$ across countries that satisfy $\int_{i \in \mathcal{I}} T^{i} d \omega(i)=0$.

Proof. Setting the optimal taxes $\left(\tau^{i}\right)_{i \in \mathcal{I}}$ ensures that the world economy is on the Pareto frontier, but generally leads to spillovers, i.e. price changes that cause redistributions between countries. To construct an example of a Pareto improvement, determine the equilibrium allocation and transfers $\left(M^{i}, T^{i}\right)_{i \in \mathcal{I}}$ with world prices $Q$ that simultaneously satisfy $\tau^{i}=-V_{M}^{i}\left(M^{i}, M^{i}\right) / V_{m}^{i}\left(M^{i}, M^{i}\right)$ and $T^{i}=Q \cdot\left(\hat{M}^{i}-M^{i}\right) \quad \forall i \in \mathcal{I}$. It can easily be verified that the transfers satisfy $\int_{i \in \mathcal{I}} T^{i} d \omega(i)=0$ since both allocations $\left(\hat{M}^{i}\right)$ and $\left(M^{i}\right)$ clear markets. Furthermore, since external instruments are at their optimal level, the allocation is Pareto efficient. Finally, we observe that given the transfers, private agents in each country $i$ could still afford the initial allocation $\left(\hat{M}^{i}\right)$. Since the allocation is still feasible but private agents choose the different allocation $\left(M^{i}\right)$, revealed preference implies that every country is better off under the new allocation.

Although compensatory transfers across sovereign nations may be difficult to implement in practice, countries interact with each other along a multitude of dimensions in today's globalized world, so there is widespread scope for implicit transfers via political horse-trading. Nonetheless, we also consider how transfers can be concealed by coordinated changes in external instruments.

\footnotetext{
${ }^{23}$ This is of course not an equilibrium in our setup, but it can be interpreted as one step in the equilibrium adjustment (tatonnement) mechanism.
} 
Pareto Improvements via Implicit Transfers When explicit transfers are not available, coordinated changes in the external policies $\tau^{i}$ can generate a wide range of implicit transfers among sovereign nations, including the ones required for Pareto improvements according to Proposition 3. The general principle relies on the following observation: consider the budget constraint (16) of private agents, $\frac{Q}{1-\tau^{i}} \cdot m^{i} \leq T^{i}$ where the transfer $T^{i}=\frac{\tau^{i} Q}{1-\tau^{i}} \cdot M^{i}$ simply rebates the tax revenues of the policymaker in country $i$ so there are no explicit transfers across countries. Starting from any initial equilibrium, a coordinated change in tariffs $\left(\tau^{i}\right)_{i \in \mathcal{I}}$ and world prices that keeps $\frac{Q}{1-\tau^{i}}$ constant for all countries generates no substitution effects but changes the transfer $T^{i}$, amounting to lump-sum transfers across nations.

Such implicit transfers play an important role for example in development aid or disaster relief - when subsidized goods are provided across nations (with the understanding that they will not be re-exported at market value to other nations). Implicit transfers are at times also used in political horse-trading when international treaties are negotiated.

For the following proposition, let us collect the external transactions of all countries in a matrix $M=\left(M^{1}{ }^{1} \ldots \mid M^{|\mathcal{I}|}\right)$.

Proposition 2 (Replicating Transfers via Changes in Market Prices). If rank $M=\operatorname{dim} \mathcal{I}$, then any set of marginal lump-sum transfers $\left(d T^{i}\right)_{i \in \mathcal{I}}$ that satisfies $\int_{i \in \mathcal{I}} d T^{i} d \omega^{i}=0$ can be replicated by a coordinated adjustment in external policy instruments $\left(d \tau^{i}\right)_{i \in \mathcal{I}}$.

Proof. The aggregate budget constraint for country $i$ is $Q \cdot M^{i} \leq 0$. A change $d Q$ in world prices is thus equivalent to a cross-country transfer $d T^{i}=d Q \cdot M^{i}$. If the rank condition above is satisfied, then there exists a $d Q$ that satisfies this relationship for any set of marginal lump-sum transfers $\left(d T^{i}\right)_{i \in \mathcal{I}}$. This $d Q$ can be achieved via global cooperation while keeping $\frac{Q}{1-\tau^{i}}$ constant in each country by setting $d \frac{Q}{1-\tau^{i}}=\frac{d Q}{1-\tau^{i}}+\frac{Q d \tau}{\left(1-\tau^{i}\right)^{2}}=0$ or, equivalently, $d \tau^{i}=\left(1-\tau^{i}\right) \frac{d Q}{Q} \forall i \in \mathcal{I}$.

The rank condition in the proposition is rather weak since $\operatorname{dim} \mathcal{I} \ll \operatorname{dim} M^{i}$, i.e. in practice there are many more goods than countries, so there will typically be a continuum of solutions for $d Q$. However, the rank condition captures that countries need to differ in their trading patterns for a coordinated change in world prices to accomplish a transfer. For example, in a model in which two countries are identical so $M^{i}=M^{j}$, a change in prices cannot achieve a transfer between the two; similarly, for a country that does not trade $M^{i}=0$, a change in world prices does not achieve a transfer. To provide non-infinitesimal transfers, a series of infinitesimal transfers as described in the proposition can be provided and integrated over, as long as the rank condition is satisfied.

Holding Market Prices Fixed to Avoid Spillovers A similar result can be obtained to avoid spillovers when a country or a set of countries engage in a policy intervention after a shock takes place.

Proposition 3 (Cooperation to Avoid Spillovers). Consider a shock to a set of countries $\tilde{\mathcal{I}} \subset \mathcal{I}$ that calls for optimal unilateral changes in domestic or external policy instruments that would generate an international spillover $d \tilde{Q}$. The spillover can be avoided if all countries worldwide cooperate and change their external instruments by

$$
d \tau^{i}=-\left(1-\tau^{i}\right) \frac{d \tilde{Q}}{Q} \quad \forall i \in \mathcal{I}
$$


Proof. As demonstrated in the proof of the previous proposition, the coordinated change in external instruments (28) shifts the world price by $-d \tilde{Q}$, thereby offsetting the spillover of the initial policy action.

This proposition tells us how to correct the externalities of individual economies while holding world prices constant so that no spillovers arise. Intuitively, the coordinated policy shifts the net demand curves of all countries to keep world prices constant 24

Practical examples of such cooperation include when exporting countries impose voluntary export restraints following an increase in productivity in their export sector - this meets the policy objective of importing countries that do not want to see rapid price declines in a given industry but at the same time avoids the wealth transfer that arises if importers imposed tariffs 25

The following illustrates the proposition in a simple example:

Example 4 (Pareto-Improving Intervention, Symmetric Countries). Consider a world economy that consists of a unit mass $\mathcal{I}$ of identical economies as described in Example 1 . Assume a set of countries $\tilde{\mathcal{I}}$ with mass $\tilde{\omega}=\omega(\tilde{\mathcal{I}})$ experiences a shock that calls for a marginal change in their external policy instruments $d \tilde{\tau}^{i}$. Under cooperation, the optimal tax wedge between countries $\tilde{\mathcal{I}}$ and $\mathcal{I} \backslash \tilde{\mathcal{I}}$ can be imposed while avoiding any spillovers by setting $\forall i \in \mathcal{I}$

$$
d \tau^{i}= \begin{cases}(1-\tilde{\omega}) d \tilde{\tau}^{i} & \text { if } i \in \tilde{\mathcal{I}} \\ \tilde{\omega} d \tilde{\tau}^{i} & \text { if } i \notin \tilde{\mathcal{I}}\end{cases}
$$

Cooperation shares the burden of policy intervention between countries in $\tilde{\mathcal{I}}$ and the rest of the world according to the relative size of the two blocks. The larger the set of countries $\tilde{\mathcal{I}}$, the greater their impact on world prices, and therefore the more of the intervention must be shifted to other countries so as to keep world prices $Q$ constant and avoid redistributions. Conversely, a small open economy with $\omega^{i}=0$ has no impact on world prices and does not create spillovers, so the above formula implies no need for other countries to share the intervention to keep world prices constant.

\section{Monopolistic Behavior}

\subsection{Optimization Problem}

We drop Condition 1,(Competitive Behvior) and analyze a policymaker that exerts market power to demonstrate how the resulting Pareto inefficiency creates scope for global cooperation. In this and the next section, we continue to assume complete external instruments. In Section 5.3, we consider a situation when a country has both monopoly power and imperfect external instruments, i.e. both Conditions 1 and 2 are violated.

\footnotetext{
${ }^{24}$ Unlike Proposition (2), the result does not rely on a rank condition on the matrix of external transactions since countries with linearly dependent net imports have equal exposure to spillovers. Our result is similar to Kemp and Wan (1976) who observe that countries forming a customs union can hold world prices fixed so as to avoid negative effects on other countries.

${ }^{25}$ Voluntary export restraints were employed heavily for example in textile trade, leading to the multilateral MultiFiber Agreement in the early 1970s and the Agreement on Textiles and Clothing in 1994 (see e.g. Suranovic, 2016). They were also imposed on automobile exports by Japan in the early 1980s (see e.g. Feenstra. 1984).
} 
Consider a country $i$ with positive measure $\omega^{i}>0$ in the world economy. Assume that the country's policymaker internalizes her pricing power over the world market price $Q$. Specifically, the policymaker internalizes how both the external policies $\tau^{j}(Q)$ of the other policymakers and the optimal allocations of the private agents $M^{j}\left(Q, \tau^{j}(Q)\right)$ in the remaining set of countries $j \in$ $\mathcal{I}^{-i}=\mathcal{I} \backslash\{i\}$ depend on the world market price $Q{ }^{26}$ This gives rise to a rest-of-the-world excess demand function

$$
M^{-i}(Q)=\int_{j \in \mathcal{I}^{-i}} M^{j}\left(Q, \tau^{j}(Q)\right) d \omega(j)
$$

which can be inverted to obtain an inverse rest-of-the-world excess demand function $Q^{-i}\left(M^{-i}\right)$. Since global market clearing requires $\omega^{i} M^{i}+M^{-i}(Q)=0$, the country $i$ policymaker internalizes that her external allocations $M^{i}$ imply world prices $Q=Q^{-i}\left(-\omega^{i} M^{i}\right)$, and she solves the optimization problem

$$
\max _{M^{i}} V^{i}\left(M^{i}, M^{i}\right) \quad \text { s.t. } \quad Q^{-i}\left(-\omega^{i} M^{i}\right) \cdot M^{i} \leq 0
$$

The optimality conditions are

$$
V_{m}^{i}+V_{M}^{i}=\Lambda_{e}^{i} Q^{T}\left(1-\mathcal{E}_{Q, M}^{i}\right) \text { with } \mathcal{E}_{Q, M}^{i}=\omega^{i} Q_{M}^{-i} M^{i} / Q^{T}
$$

The column vector $\mathcal{E}_{Q, M}^{i}$ represents the inverse demand elasticity of imports of the rest of the world and consists of four elements: the country weight $\omega^{i}$ reflects the country's market power in the world market; the Jacobian matrix $Q_{M}^{-i}=\partial Q^{-i} / \partial M^{-i}$ captures how much world market prices respond to additional exports from country $i$. The column vector $M^{i}$ post-multiplies this matrix to sum up the marginal revenue accruing to country $i$ from the different goods as a result of the monopolistic intervention. Finally, the result is normalized element-by-element by the price vector $Q$ to obtain elasticities.

Intuitively, a monopolistic policymaker equates the social marginal benefit of imports $V_{m}^{i}+V_{M}^{i}$ to the marginal expenditure $Q^{T}\left(1-\mathcal{E}_{Q, M}^{i}\right)$ rather than to the world price $Q^{T}$ times a factor of proportionality $\Lambda_{e}^{i}$. The policymaker introduces a distortion to shift world prices in her favor and extract monopoly rents from the rest of the global economy. The intervention constitutes a classic inefficient beggar-thy-neighbor policy.

Proposition 4 (Optimal Monopolistic Intervention). (i) If Condition 1 is violated for a given country $i$, the country's policymaker optimally exerts market power by setting her external policy instruments to

$$
1-\hat{\tau}^{i}=\frac{1+V_{M}^{i} / V_{m}^{i}}{1-\mathcal{E}_{Q, M}^{i}}
$$

where all divisions are performed element-by-element.

(ii) The policymaker does not distort domestic policies $X^{i}$ to exert monopoly power.

\footnotetext{
${ }^{26}$ It is immaterial for our analysis whether the optimal policy $\tau^{j}(Q)$ in a given country $j$ in the rest of the world arises from price-taking behavior as described in Section 4 or from monopolistic behavior as described in the current section. The only important assumption is that the excess demand functions $M^{j}\left(Q, \tau^{j}(Q)\right)$ are well-defined and continuously differentiable. This rules out that policymakers respond directly to each other's external instruments $\tau^{j}$, for example using discontinuous trigger strategies. Our assumption is common in the analysis of international policy cooperation (see e.g. Bagwell and Staiger 2002).
} 
(iii) An equilibrium in which a policymaker exerts market power is Pareto-inefficient and creates scope for policy cooperation.

Proof. For part (i), the tax vector $\hat{\tau}^{i}$ ensures that the optimality condition of private agents (24) replicates the monopolistic policymaker's Euler equation (30). For part (ii) observe that Condition 2 ensures that external considerations such as market power do not enter the optimality conditions of the policymaker for domestic policies $X^{i}$. Part (iii) follows immediately from Proposition 1 .

To provide some intuition for part (i), consider an economy with positive measure $\omega^{i}>0$ in the world economy that has, for simplicity, no domestic externalities so $V_{M}^{i}=0$. Assume that the off-diagonal elements of the matrix $Q_{M}^{-i}$ are small compared to the diagonal elements, i.e. that income effects are small in comparison to substitution effects, and consider a good indexed by $t$ that is ordinary so $\partial M_{t}^{-i} / \partial Q_{t}<0$, i.e. the rest of the world imports less if the price of good $t$ goes up. If country $i$ is a net importer $M_{t}^{i}>0$ of the good, then the elasticity $\mathcal{E}_{Q, M, t}^{i}$ is negative and the optimal monopolistic tax on imports $\hat{\tau}_{t}^{i}>0$ is positive and reduces imports. Similarly, if country $i$ is a net exporter $M_{t}^{i}<0$, then the optimal monopolistic tax $\hat{\tau}_{t}^{i}<0$ reduces the country's exports. This captures the standard trade-reducing effects of monopolistic interventions.

The intuition for part (ii) is closely related to the optimal targeting principle established by Bhagwati and Ramaswami (1963): if the goal of a policymaker is to distort international prices, then she uses the instruments that affect international prices in the most direct way possible, and those are the external instruments $\tau^{i}$. It is undesirable to introduce distortions in domestic optimality conditions, given that the policymaker can affect external allocations directly. Conversely, when external instruments are not available, for example because they have been restricted by international agreements on trade or financial flows or "single markets," then a second-best way of exerting market power is to distort domestic instruments. This explains why international trade agreements increasingly include provisions on domestic policies, as we discuss in more detail in Section 5.3. Some of the literature on fiscal or monetary policy cooperation implicitly assumes that countries do not have the instruments to target external transactions directly and proceeds to study how countries distort fiscal or monetary instruments to internalize terms-of-trade effects as a second-best device. Although this may be an appropriate assumption in many cases, we believe that is useful to be explicit about the assumption.

Part (iii) is a natural corollary and is a well-known implication of monopolistic behavior. When one or several players in an economic system exert market power, the resulting Pareto inefficiency creates scope for cooperation.

\subsection{Identifying Monopolistic Behavior}

Whether a policy intervention is Pareto efficient or not - and thus whether there is scope for global cooperation - depends crucially on whether policymakers use their instruments to correct for domestic distortions or to exert market power. In other words, it depends on whether the intervention is driven by the numerator or the denominator of expression (31). Unfortunately there is no general recipe for distinguishing between the two motives for intervention. In fact, the following result is a straightforward corollary of Proposition 4 : 
Corollary 2 (Observational Equivalence of Corrective and Monopolistic Intervention). The external spillover effects of a given policy intervention $\tau^{i}$ in a country $i$ are equivalent no matter if the policy is imposed to correct domestic market distortions or to exert market power.

Proof. Consider two economies $i, j$ of identical size $\omega^{i}=\omega^{j}>0$ and with the identical excess demand functions $M^{i}\left(Q, \tau^{i}\right)$. Assume that economy $i$ exhibits $V_{M}^{i} \neq 0$ and sets its external policy instruments $\tau^{i}$ purely to correct domestic market imperfections according to Lemma 2 without exerting market power. Assume that economy $j$ has no externalities $V_{M}^{j}=0$ and sets its external policy instruments $\tau^{j}$ purely to exert market power as described in Proposition 4 . If $1+V_{M}^{i} / V_{m}^{i}=$ $1 /\left(1-\mathcal{E}_{Q, M}^{j}\right)$, then the two economies will employ identical policy interventions which will create identical spillovers.

The corollary captures that the spillover effects of an intervention in external allocations are the same, no matter what the motive for intervention. It is easy for policymakers to invoke market imperfections, domestic objectives or different political preferences to justify an arbitrary set of policy interventions in the name of domestic efficiency, and it is difficult for the international community to disprove them 27

Monopolistic Behavior and Direction of Intervention However, the direction of the optimal monopolistic policy intervention is often instructive to determine whether it is plausible that a given intervention is for monopolistic reasons. If an observed intervention is inconsistent with this optimal direction, it is unlikely that it was conducted for monopolistic reasons. For this purpose, let us discuss each of the components of the elasticity term $\mathcal{E}_{Q, M}^{i}=-\omega^{i} Q_{M}^{-i} M^{i} / Q^{T}$ :

Country Size $\omega^{i}$ The optimal monopolistic intervention is directly proportional to the country's measure $\omega^{i}$ in the world economy, which reflects the country's impact on the world market. If a small open economy with $\omega^{i} \approx 0$ and undifferentiated exports engages in external intervention, it is unlikely to achieve monopolistic goals.

Responsiveness of World Price $Q_{M}^{-i} \quad$ Monopolistic intervention requires that world market prices are responsive to changes in quantities. If there are, for example, close substitutes to the goods traded by a country so $Q_{M}^{-i} \approx 0$, it is unlikely that the country's intervention is monopolistic.

Direction and Magnitude of Flows $M^{i}$ The optimal monopolistic intervention on a good indexed by date $t /$ good $\mathrm{k} /$ state of nature $s$ is directly proportional to the magnitude of the country's net imports. The larger $M_{t, k, s}^{i}$ in absolute value, the greater the revenue benefits from distorting the price $Q_{t, k, s}$. By contrast, if $M_{t, k, s}^{i} \approx 0$, the optimal monopolistic intervention is zero. The economic interpretation depends on the specific setting: In intertemporal trade, $Q_{t}$ reflects the interest rate and $M_{t}^{i}$ captures date $t$ net capital inflows or, equivalently, the date $t$ trade balance. When $M_{t}^{i} \approx 0$, the country does not gain from distorting the intertemporal price $Q_{t}$. By contrast, a large net capital inflow, or trade deficit, $M_{t}^{i}>0$ invites monopolistic inflow taxes $\tau_{t}^{i}>0$ to keep world interest rates

\footnotetext{
${ }^{27}$ More specifically, for any reduced-form utility function $V^{i}\left(m^{i}, M^{i}\right)$ and intervention $\hat{\tau}^{i}$, a policymaker can claim an alternative reduced-form utility function $\hat{V}^{i}\left(m^{i}, M^{i}\right)$ such that $\hat{\tau}^{i}$ implements the optimal competitive allocation under that utility function,

$$
\hat{V}^{i}\left(m^{i}, M^{i}\right)=V^{i}\left(m^{i}, M^{i}\right)-\hat{\tau}^{i} \cdot\left(V_{m}^{i} M^{i}\right)
$$

The reduced-form utility function $\hat{V}^{i}(\cdot)$ can in turn be interpreted as deriving from a fundamental utility function $\hat{U}^{i}\left(x^{i}\right)$ and a set of constraints $\hat{f}^{i}(\cdot)$ that justify it.
} 
lower, or vice versa for a country with a large net outflow / trade surplus $M_{t}^{i}<0{ }^{28}$ In a stochastic setting, $Q_{t, s}$ reflects the state price of payoffs in state $s$ at date $t$. Each country has - by definition monopoly power over its own idiosyncratic risk. Optimal risk-sharing implies inflows (imports) in bad states and exports in good states of nature. Monopolistic intervention restricts risk-sharing so as to obtain a higher price for the country's idiosyncratic risk and to reduce the price of insurance from abroad. If a country encourages insurance (e.g. by encouraging FDI and forbidding foreign currency debt; see Korinek, 2010), then the motive is unlikely to be monopolistic. In trade policy, it is well-known that monopolistic intervention implies tariffs $\tau_{t . k}^{i}>0$ on imported goods $k$ with $M_{t, k}^{i}>0$ and taxes on exports $\tau_{t, k}^{i}<0$ for $M_{t, k}^{i}<0$ (see e.g. Bagwell and Staiger, 2002).

\subsection{Monopolistic Use of Domestic Policy Instruments}

Proposition 4(ii) demonstrated that a policymaker with complete instruments will only use external instruments $\tau^{i}$ not domestic policies to exert monopoly power. This subsection assumes a policymaker who has market power (violating Condition 1) and faces imperfect external instruments (violating Condition 2) and shows that this makes it optimal to distort domestic policies in pursuit of monopolistic objectives. Restrictions on external policy instruments are of increasing practical relevance since many international agreements have swept away countries' ability to intervene in private trade or capital flows.

Intuitively, a policymaker who aims to exert market power but does not have perfect external instruments proceeds in two steps, which reflect that the separation results of Lemma 1 no longer hold. First, she determines in which direction she would like to distort the external transactions of the economy to optimally exert market power. Secondly, she internalizes how each domestic instrument of hers will affect the external transactions of the economy, and she distorts the domestic instruments accordingly. We formally consider an example in which we assume a policymaker who has no external instruments whatsoever in Appendix A.4. We provide a simple example in the following.

Example 5 (Monopoly Power and Fiscal Policy, With and Without External Instruments). We continue the fiscal policy example in Section 2.5 but consider a policymaker who takes into account monopolistic considerations. For simplicity, we set $\alpha=1$.

First, we consider a policymaker who has complete external instruments $\tau^{i}$ and maximizes utility (10) subject to the intertemporal budget constraint (29). In that case, the optimality condition that determines the mix of private and public spending $\sqrt{11}$ ) is unchanged from that of a competitive policymaker, $u^{\prime}\left(C_{t}^{i}\right)=$ $u^{\prime}\left(G_{t}^{i}\right)$ or $C_{t}^{i}=G_{t}^{i}$ for $t=0,1$, consistent with Proposition 4 (ii). However, the monopolistic policymaker will impose taxes (31) on the external transactions of private agents

$$
1-\tau^{i}=\frac{1}{1-\mathcal{E}_{Q, M}^{i}} \quad \text { where } \mathcal{E}_{Q, M}^{i}=\left(\begin{array}{c}
\partial Q_{1} / \partial M_{0}^{i} \\
\partial Q_{1} / \partial M_{1}^{i}
\end{array}\right) \cdot \frac{M_{1}^{i}}{Q_{1}}
$$

\footnotetext{
${ }^{28}$ If private capital accounts are closed, optimal monopolistic intervention consists of reduced/increased foreign reserve accumulation. For example, when policymakers reduce reserve accumulation because they are concerned that they are pushing down the world interest rate too much, this is classic non-competitive behavior and is equivalent to monopolistic capital controls. This corresponds to statements by some Chinese policymakers that were concerned about pushing down US Treasury yields because of their reserve accumulation in 2014.
} 
where $Q_{1}=1 / R$. Consider w.l.o.g. a borrowing country that imports $t=0$ goods and exports $t=1$ goods so $M_{0}^{i}>0>M_{1}^{i}$. In that case, we find $\left(\mathcal{E}_{Q, M}^{i}\right)_{0}>0>\left(\mathcal{E}_{Q, M}^{i}\right)_{1}$ and therefore $\tau_{0}^{i}<0<\tau_{1}^{i}$, i.e. the country both taxes $t=0$ imports and taxes $t=1$ exports in order to push up the relative price $Q_{1}$ of its exports. In the intertemporal interpretation of the model, she pushes down the interest rate at which the country borrows.

In the absence of external instruments (i.e. if we restrict $\tau^{i} \equiv 0$ ), a monopolistic policymaker distorts public spending to pursue her monopolistic objective in a less efficient manner. Specifically, the policymaker maximizes utility (10) subject to the intertemporal budget constraint and the implementability constraint given by the private Euler equation $Q_{1} u^{\prime}\left(C_{0}^{i}\right)=u^{\prime}\left(C_{1}^{i}\right)$ or $C_{0}^{i}=Q_{1} C_{1}^{i}$ under log-utility, to which we assign shadow price $\mu$. The policymaker's optimality conditions can be combined to yield

$$
\begin{aligned}
& u^{\prime}\left(C_{0}^{i}\right)=u^{\prime}\left(G_{0}^{i}\right)-\mu \\
& u^{\prime}\left(C_{1}^{i}\right)=u^{\prime}\left(G_{1}^{i}\right)+\mu Q_{1}
\end{aligned}
$$

The shadow price satisfies $\mu>0$ and implies that the policymaker now distorts the optimal mix between private and public spending to further her monopolistic objectives. In particular, $t=0$ public spending is reduced compared to private spending, $G_{0}^{i}<C_{0}^{i}$, and vice versa, $G_{1}^{i}>C_{1}^{i}$, for $t=1$ spending. Both interventions serve to push up the relative price $Q_{1}$ or, in the intertemporal interpretation, to push down the world interest rate $R=1 / Q_{1}$ at which the country borrows.

Since the policymaker's optimization problems with and without external instruments only differ by the additional (binding) implementability constraint, country $i$ welfare in the latter case is strictly inferior.

\section{Imperfect External Policy Instruments}

This section analyzes how violations of Condition 2 (Perfect External Policy Instruments) lead to Pareto inefficiency and create scope for policy cooperation. In analogy to Tolstoy's quote on happy families, there is only one way in which a country's set of external policy instruments can be classified as perfect - captured in Condition 2- but a myriad of ways in which external policy instruments can be imperfect. These include situations when some of the external instruments $\tau^{i}$ are costly to implement, restricted, missing, or cannot be fine-tuned, as well as instances when setting external instruments involves fiscal considerations or time consistency problems ${ }^{29}$

We develop a model of imperfect policy instruments that captures implementation costs, missing instruments and coarse policy instruments. We discuss circumstances under which the set of external policy instruments is effectively complete, even if there are limitations on some instruments. Then we illustrate how global cooperation can generically achieve Pareto improvements when some countries face imperfect external policy instruments.

\footnotetext{
${ }^{29}$ Let us remind the reader that it is only imperfect external policy instruments (i.e. those targeting the external transactions $M^{i}$ ) that are relevant for Condition 2 and that justify global cooperation; incomplete or imperfect domestic policy instruments (i.e. problems in targeting domestic variables $X^{i}$ ) do not violate Condition 2 and do not create inefficiencies that can be addressed via global cooperation, as stated in our main Theorem 1
} 


\subsection{A Model of Imperfect External Instruments}

We capture imperfections in the set of instruments of a policymaker in country $i$ by assuming that there is a function $\Gamma^{i}\left(\tau^{i}\right)$ that describes the cost of imposing the vector of policy instruments $\tau^{i}$. The function $\Gamma^{i}$ is non-negative, convex, and satisfies $\Gamma^{i}(0)=0$. For simplicity, we assume that the cost represents a utility cost that enters the policymaker's objective as $\max _{X^{i}, M^{i}, \tau^{i}} U^{i}\left(X^{i}\right)-\Gamma^{i}\left(\tau^{i}\right)$ subject to the usual constraints ${ }^{30}$

Perfect External Instruments Formally, a policymaker in country $i$ has a perfect set of external instruments if $\Gamma^{i} \equiv 0$, i.e. if the policymaker can impose any arbitrary policy instruments $\tau^{i}$ and thus implement any feasible external allocation without incurring implementation costs. This is what Condition (2) assumed.

Imperfect External Instruments Conversely, a policymaker in country $i$ has an imperfect set of external instruments if some instruments are costly to impose, i.e. $\exists \tau^{i}$ s.t. $\Gamma^{i}\left(\tau^{i}\right)>0$. This includes the case in which the cost of a particular configuration of instruments is infinite. By implication, there may be some feasible external allocations that the policymaker cannot implement costlessly as a decentralized allocation. Our setup captures several different types of imperfections in instruments:

Costly Instruments The most straightforward interpretation of the specification is that it is costly to impose policy instruments. If we index the elements of vector $\tau^{i}$ by the letter $t$, a cost function of the simple quadratic form $\Gamma^{i}\left(\tau^{i}\right)=\sum_{t} \gamma_{t}^{i}\left(\tau_{t}^{i}\right)^{2} / 2$ may capture implementation costs that arise from policy intervention and that grow in the square of the intervention. The cost may vary across different elements of the vector $\tau^{i}$ by adjusting $\gamma_{t}^{i}$, for example by setting $\gamma_{t}^{i}=\beta^{t} \bar{\gamma}^{i}$. More generally, implementation costs could also be asymmetric for taxes and subsidies.

Missing or Restricted Instruments In the limit case $\gamma_{t}^{i} \rightarrow \infty$ for some $t$, the cost function captures that instrument $\tau_{t}^{i}$ is not available. For $\gamma_{t}^{i} \rightarrow \infty \forall t$, country $i$ has no external policy instruments. Similarly, if $\Gamma^{i}\left(\tau^{i}\right)=\sum_{t} \gamma_{t}^{i}\left(\tau_{t}^{i}-\bar{\tau}_{t}^{i}\right)^{2} / 2$ then $\gamma_{t}^{i} \rightarrow \infty$ captures that instrument $t$ is restricted to $\bar{\tau}_{t}^{i}$.

Coarse Instruments If we index the vector $\tau^{i}$ along several dimensions, for example to capture different goods $k=1$...K or different states of nature $s \in \Omega$ in each time period $t$, a cost function of the form $\Gamma^{i}\left(\tau^{i}\right)=\sum_{t} \sum_{k=2}^{K} \gamma\left(\tau_{t, k}^{i}-\tau_{t, 1}^{i}\right)^{2} / 2$ or $\Gamma^{i}\left(\tau^{i}\right)=\sum_{t} \sum_{s \in \Omega} \gamma\left(\tau_{t, s}^{i}-\tau_{t, s_{0}}^{i}\right)^{2} / 2$ captures that is is costly for the policymaker to differentiate her policy instruments across different goods or different types of state-contingent financial flows, e.g. flows with different risk profile. In the limit case $\gamma \rightarrow \infty$, the function captures that the policymaker is completely unable to differentiate the instruments and has to set $\tau_{t, k}^{i}=\tau_{t, 1}^{i} \forall k$ or similarly $\forall s \in \Omega$

Effectively Perfect External Instruments and Efficiency Sometimes a policymaker with an imperfect set of instruments has nonetheless all the instruments she wants to use. We say that a pol-

\footnotetext{
${ }^{30}$ Our results are largely unchanged if we assume that the cost is a resource cost that is subtracted from the external budget constraint $Q \cdot M^{i}+\Gamma^{i}\left(\tau^{i}\right) \leq 0$, except that the function $\Gamma^{i}(\cdot)$ is pre-multiplied by the shadow price on the external budget constraint $\Lambda_{e}^{i}$. Similar results can be derived if the cost of policy intervention depends on quantities transacted, e.g. $\Gamma^{i}\left(\tau^{i}, M^{i}\right)$, which may capture for example the costs associated with attempts at circumvention.

${ }^{31}$ Our setup could also capture further types of imperfections in instruments such as asymmetries between taxes and subsidies on external transactions, or instruments that are fixed at non-zero levels.
} 
icymaker has effectively perfect external instruments if the cost of implementing the policymaker's optimal policy is zero, $\Gamma^{i}\left(\tau^{i}\right)=0$. If a policymaker has a perfect set of external instruments, they are also effectively perfect, but not vice versa. This allows us to weaken Condition 2 (Perfect External Instruments) to

Condition 2' (Effectively Perfect External Instruments). The policymaker in country $i \in \mathcal{I}$ possesses an effectively perfect set of external policy instruments.

It is easy to see that the efficiency result of Theorem 1 still holds under the weaker Condition 2 '.

The case $V_{M}^{i}=0$ of no externalities is a trivial example in which the policymaker in country $i$ has an effectively perfect set of external instruments, even if she has no instruments whatsoever. In that case, imperfections in actual policy instruments are irrelevant since the efficient allocation requires zero intervention.

Effectively Perfect Instruments at the Global Level Even if some countries have instruments that are not effectively perfect, it is possible that cooperation can restore a situation in which the imperfections do not matter. We call the worldwide set of external policy instruments of all countries $\left(\tau^{i}\right)_{i \in \mathcal{I}}$ effectively perfect at the global level if global cooperation can implement a Pareto efficient equilibrium in which $\Gamma^{i}\left(\tau^{i}\right)=0 \forall i \in \mathcal{I}$. The intuition is that under global cooperation, it may be possible to fix the externalities of a country with imperfect instruments by using the instruments of other countries with perfect instruments - what matters for efficiency is that the social rates of substitution between different goods are equated, not how this is accomplished.

Example 6 (Effectively Perfect Instruments at the Global Level). Consider a world economy with two countries $\mathcal{I}=\{1,2\}$ that have reduced-form utility functions $V^{i}\left(m^{i}, M^{i}\right)$ and behave competitively. Assume that country 1 suffers externalities $V_{M}^{1}<0$ but does not have any external policy instruments to correct for them. Furthermore, assume that country 2 does not suffer from externalities $V_{M}^{2} \equiv 0$ but has a complete set of external instruments.

If the policymaker in country 1 had the external instruments to do so, she would impose optimal taxes $\tau^{1 *}=-\left(V_{M}^{1} / V_{m}^{1}\right)^{T}$, and the resulting equilibrium would satisfy $\left(1-\tau^{1 *}\right) V_{m}^{1} / \lambda_{e}^{1}=Q=V_{m}^{2} / \lambda_{e}^{2}$. However, since the country has no policy instruments, the global competitive equilibrium coincides with the laissez-faire equilibrium - country 2 has no incentive to intervene in its external transactions.

Under cooperation, country 2 would set its external policy instruments to $1-\tau^{2}=\frac{1}{1-\tau^{1 *}}$ to correct for the externalities of country 1 , and the allocation would satisfy $\frac{1}{1-\tau^{1 *}} V_{m}^{2} / \lambda_{e}^{2}=Q=V_{m}^{1} / \lambda_{e}^{1}$ or $\left(1-\tau^{1 *}\right) V_{m}^{1} / \lambda_{e}^{1}=\left(1-\tau^{1 *}\right) Q=V_{m}^{2} / \lambda_{e}^{2}$, also equating the social marginal rates of substitution between the two countries and restoring a Pareto-efficient allocation.

\subsection{Uncoordinated Policy with Imperfect External Instruments}

In the following, we describe a version of our baseline model with imperfect instruments but in which, for simplicity, we assume away domestic policies so that policymakers only need to focus on external allocations. We maintain Conditions 1/(Competitive Behavior) and 3 (Perfect International Markets). A policymaker who has no domestic choice variables maximizes the reduced-form utility function $V^{i}\left(m^{i}, M^{i}\right)$ of her country net of implementation costs and subject to the external 
budget and implementability constraints

$$
\max _{M^{i}, \tau^{i}, \lambda_{e}^{i}} V^{i}\left(M^{i}, M^{i}\right)-\Gamma^{i}\left(\tau^{i}\right) \quad \text { s.t. } \quad Q \cdot M^{i} \leq 0, V_{m}^{i}=\lambda_{e}^{i}\left(\frac{Q}{1-\tau^{i}}\right)^{T}
$$

A detailed description of the optimization problem is given in Appendix (A.5).

We denote the vector of shadow prices on the implementability constraint by $\mu_{e}^{i}$. These shadow prices capture the extent of mis-targeting for each element of $M^{i}$. We rewrite the policymaker's optimality condition FOC $\left(M^{i}\right)$ as

$$
\left(\mu_{e}^{i}\right)^{T}=\left(V_{m m}^{i}+V_{m M}^{i}\right)^{-1}\left[V_{m}^{i}+V_{M}^{i}-\Lambda_{e}^{i} Q^{T}\right]
$$

The expression in square brackets reflects the social benefit $V_{m}^{i}+V_{M}^{i}$ minus the social cost of net imports $\Lambda_{e}^{i} Q$. If the policymaker had perfect instruments, she would equate the two and the expression would be zero for each element of the vector of external transactions. Under imperfect instruments, the marginal net benefits of imports in the square brackets is positive for all goods for which greater net imports are desirable and vice versa. The expression is pre-multiplied by the negative semi-definite matrix $\left(V_{m m}^{i}+V_{m M}^{i}\right)^{-1}$, which captures the curvature of the $V^{i}$, i.e. how much the marginal social benefit changes in the quantity of net imports. As a result, $\mu_{e}^{i}$ reflects how much a marginal unit of net imports improves the mis-targeting problem. $\mu_{e}^{i}$ is negative for those elements of the import vector $M^{i}$ that are less than optimal and positive for those that are more than optimal.

The policymaker's optimality condition FOC $\left(\tau^{i}\right)$ can be written as

$$
\left(1-\tau^{i}\right) \Gamma^{i \prime}\left(\tau^{i}\right)=\mu_{e}^{i}\left(V_{m}^{i}\right)^{T}
$$

where all multiplications are performed element-by-element $\sqrt{32}$ When there are excessive flows of a good $k$ so $\mu_{e, k}^{i}>0$, the policymaker imposes a positive tax $\tau_{k}^{i}>0$ that leads to a positive marginal cost $\Gamma_{k}^{i \prime}>0$; conversely, if flows of a good are insufficient $\mu_{e, k}^{i}<0$, she imposes a subsidy.

The following proposition characterizes how the policymaker in country $i$ sets costly instruments:

Proposition 5 (Costly Instruments). At the optimum, the country i policymaker (i) sets the weighted average marginal cost of her instruments to zero,

$$
\Gamma^{i \prime}\left(\tau^{i}\right) \cdot\left(1-\tau^{i}\right)^{T}=0
$$

(ii) sets her vector of external policy instruments to

$$
1-\tau^{i}=\frac{1+\left(\frac{V_{M}^{i}}{V_{m}^{i}}\right)^{T}}{\frac{\Lambda_{e}^{i}}{\lambda_{e}^{i}}+\frac{\Gamma^{i}}{\left(V_{m}^{i}\right)^{2}}\left[V_{m m}^{i}+V_{m M}^{i}\right]}
$$

\footnotetext{
${ }^{32}$ In the limit case of fully missing, restricted or coarse instruments, which we captured by $\gamma_{t} \rightarrow \infty$ for quadratic cost functions in Section 6.1 the derivatives $\Gamma_{k}^{i \prime}(\cdot)$ need to be replaced by the more general concept of subgradients, which are set-valued, $\Gamma_{k}^{i \prime}(\cdot)=(-\infty, \infty)$. Intuitively, this captures that a function with kinks does not have a unique derivative but admits tangents of many different slopes. Given this concept, the relevant value for $\Gamma_{k}^{i \prime}(\cdot)$ is determined by the restriction on the instruments, and the described optimality condition still holds.
} 
Proof. See Appendix A.5.

Point (i) of the proposition reflects that it is optimal for the policymaker to impose a combination of taxes and subsidies such that the average marginal cost is zero. Given the constraints on her instruments, the policymaker chooses her allocations such that some flows are too low and others too high compared to the complete instruments case. This minimizes the total implementation cost. Suppose, for example, that there is one good $k$ that creates a negative externality. Given a convex cost of intervention, it would be inefficient to tax this good and not intervene in the markets for other goods since private agents only care about relative after-tax prices of goods to guide their allocations. Instead, an optimizing policymaker would reduce the tax on good $k$ and impose a small subsidy on all other goods to minimize total intervention costs.

To interpret the tax formula (34) in point (ii), observe first that the expression reduces to equation (27) if the denominator is one. This would reflect optimal policy under complete instruments. Under costly instruments, the marginal cost term $\Gamma^{i \prime}$ in the denominator, weighted by the curvature of the reduced-form utility function, increases or reduces the level of policy intervention to account for the costs. Furthermore, the ratio of the social to the private shadow value of wealth $\Lambda_{e}^{i} / \lambda_{e}^{i} \gtrless 1$ in the denominator adjusts the average level of controls to ensure that point (i) is satisfied. For example, if externalities $V_{M}^{i}$ are on average positive, then the policymaker's marginal valuation $\Lambda_{e}^{i}$ of will be above $\lambda_{e}^{i}$ and vice versa.

We illustrate the weighted average marginal cost criterion in the following example:

Example 7 (Costly Instruments). Consider a country $i$ with learning-by-exporting externalities as in Section (2.2) given by $y_{1}^{i}\left(M_{0}^{i}\right)=y_{0}^{i}-\eta^{i} M_{0}^{i}$. Assume there is no discounting, that world prices satisfy $Q=$ $(1,1)$ and that external policy instruments impose a quadratic utility cost of implementation $\Gamma^{i}\left(\tau^{i}\right)=\gamma \tau^{i}$. $\left(\tau^{i}\right)^{T} / 2$. The utility of country $i$ is

$$
V^{i}\left(m^{i}, M^{i}\right)-\Gamma^{i}\left(\tau^{i}\right)=u\left(y_{0}^{i}+m_{0}^{i}\right)+u\left(y_{0}^{i}-\eta^{i} M_{0}^{i}+m_{1}^{i}\right)-\Gamma^{i}\left(\tau^{i}\right)
$$

Let us start from an equilibrium in which $\eta^{i}=0$ and assume a small increase $d \eta^{i}>0$ in the externality. Given the costly instruments, the policymaker will set $\tau_{0}^{i}=d \eta^{i} / 2=-\tau_{1}^{i}$ such that condition (33) is satisfied. The policymaker taxes the externality-generating inflows (or, equivalently, subsidizes outflows) in period 0 but subsidizes inflows (and taxes outflows) in period 1. The policymaker internalizes that higher $m_{1}^{i}$ implies lower $m_{0}^{i}$ by the external budget constraint, and that she can correct the externality while saving on implementation costs by spreading her intervention across both periods.

\subsection{Global Cooperation under Imperfect External Instruments}

To solve for the optimal allocation under global cooperation, we solve the problem of a global planner who faces the same restrictions on instruments and maximizes the weighted sum of welfare

$$
\max _{Q,\left(M^{i}, \tau^{i}, \lambda_{e}^{i}\right)_{i \in \mathcal{I}}} \int_{i \in \mathcal{I}}\left\{\theta^{i}\left[V^{i}\left(M^{i}, M^{i}\right)-\Gamma^{i}\left(\tau^{i}\right)\right]-\mu_{e}^{i} \cdot\left[V_{m}^{i}-\lambda_{e}^{i} \frac{Q}{1-\tau^{i}}\right]^{T}-v \cdot M^{i}\right\} d \omega(i)
$$

for a given set of welfare weights $\left(\theta^{i}\right)_{i \in \mathcal{I}}$. The extent of mis-targeting is now captured by

$$
\left(\mu_{e}^{i}\right)^{T}=\left(V_{m m}^{i}+V_{m M}^{i}\right)^{-1}\left[\theta^{i}\left(V_{m}^{i}+V_{M}^{i}\right)-v\right]
$$


As in our discussion of equation (32), a positive element in $\mu_{e}^{i}$ means that the global planner would like more inflows of the respective good to country $i$ and vice versa.

The main difference between the allocation of country-specific policymakers and a global planner is the following:

Proposition 6 (Global Cooperation with Costly Instruments ). It is optimal to set to zero not only the weighted average marginal cost of instruments within each country, described in (33) $\forall i \in \mathcal{I}$, but also the weighted average marginal cost of instruments for each good across all countries,

$$
\int_{i \in \mathcal{I}}\left[\left(1-\tau^{i}\right) \theta^{i} \Gamma^{i \prime}\left(\tau^{i}\right)\right] d \omega(i)=0
$$

Proof. See Appendix (A.5).

The argument for the first part of the proposition is the same as in the individual country case. However, unlike in the competitive allocation, global cooperation also sets the average marginal distortion across all countries for each good equal to zero. If some countries impose taxes on inflows for certain elements of $M^{i}$, others must impose taxes on outflows. In short, global cooperation spreads interventions across inflow and outflow countries in proportion to the marginal cost of intervention in each. Given that the cost function is convex, this minimizes the total cost of intervention.

We illustrate our findings in the following two examples:

Example 8 (Sharing the Regulatory Burden). Consider a world economy consisting of two sets of atomistic economies $\mathcal{I}_{1}$ and $\mathcal{I}_{2}$ of equal measure that have the structure described in Example 7. with utility functions given by (35) and cost functions $\Gamma^{i}\left(\tau^{i}\right)=\gamma^{i} \tau^{i} \cdot\left(\tau^{i}\right)^{T} / 2$ for $i \in\{1,2\}$. Assume an equilibrium with $\eta^{i}=0 \forall i \in\{1,2\}$ and consider the effects of a small increase $d \eta^{1}>0$ in the externalities in set $\mathcal{I}_{1}$. In the uncoordinated equilibrium, policymakers in set $\mathcal{I}_{1}$ behave as described in Example 7 . The resulting allocation violates condition (36) since $\tau_{0}^{1}>0>\tau_{1}^{1}$ but $\tau^{2} \equiv 0$, indicating inefficiency.

Under global cooperation, both sets of countries would share the regulatory burden to minimize the total cost of intervention. Specifically, they would set policy instruments according to the relative cost of intervention,

$$
d \tau_{0}^{1}=\frac{\gamma^{2} d \eta}{2\left(\gamma^{1}+\gamma^{2}\right)}=-d \tau_{1}^{1} \quad \text { and } \quad d \tau_{0}^{2}=-\frac{\gamma^{1} d \eta}{2\left(\gamma^{1}+\gamma^{2}\right)}=-d \tau_{1}^{2}
$$

This guarantees that the sum of interventions equals the increase in the externality $d \eta$ and that both optimality conditions (33) and (36) are satisfied ${ }^{33}$ If the cost of intervention is equal among the two sets of countries, then the respective fractions are $1 / 4$, i.e. under global cooperation, one quarter of the externality is corrected in each time period in each country to implement a constrained efficient equilibrium.

For given $\gamma^{1}>0$, we can analyze two interesting limit cases: first, if it becomes costless to impose external policy instruments in set $\mathcal{I}_{2}\left(\gamma^{2} \rightarrow 0\right)$, then only those countries would intervene and would fully correct the externality there, leaving $\tau^{1}=0$, as in Example 6 Conversely, if it becomes prohibitively costly to employ policy instruments in set $\mathcal{I}_{2}\left(\gamma^{2} \rightarrow \infty\right)$, then $\tau^{2}=0$ and only the set of countries $\mathcal{I}_{1}$ would interene.

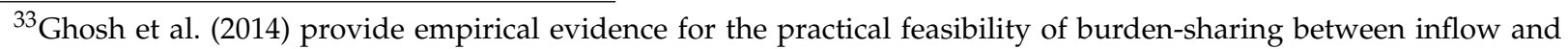
outflow countries.
} 
Example 9 (Wasteful Competitive Intervention). Assume a world economy that consists of a unit mass $\mathcal{I}$ of identical atomistic countries with reduced-form utility functions $V^{i}\left(m^{i}, M^{i}\right)$ that all suffer from externalities $V_{M}^{i} \neq 0$ and from implementation costs $\Gamma^{i}\left(\tau^{i}\right)=\gamma \tau^{i} \cdot\left(\tau^{i}\right)^{T} / 2$ with $\gamma>0$. Following Proposition 5. in the uncoordinated equilibrium, policymakers in all countries impose the same non-zero policy instruments $\tau^{i} \neq 0$ and incur the same costs $\Gamma^{i}\left(\tau^{i}\right)>0$. This clearly violates the optimality condition (36) since the policy instruments have the same sign.

Under global cooperation, countries would recognize that their competitive interventions are wastefulsince they are identical, there is no trade $M^{i}=0 \forall i$ and all countries could save the cost $\Gamma^{i}\left(\tau^{i}\right)$ without changing real allocations by coordinating to reduce their policy instruments to zero. This is the only way to satisfy optimality condition (36). Observe that the set of instruments is effectively perfect at the global level even though all countries have imperfect instruments in this example.

Our examples illustrate that two important rationales for global cooperation are to save on implementation costs by (i) sharing the regulatory burden in the most cost-effective way possible and (ii) avoiding wasteful competition.

Scope for Pareto Improvement The cooperation described in Proposition 6 achieves a constrained Pareto efficient use of external instruments but may generate changes in world prices and thus transfers across nations. There are also two special cases under which the cooperative solution described in Proposition 6 always generates Pareto-improvements: (i) if there is no trade, as in our Example 9 on wasteful competition, so that changes in terms-of-trade have no redistributive effects, and (ii) if the savings from lowering the cost of intervention $\Gamma^{i}\left(\tau^{i}\right)$ are large enough to offset terms-of-trade losses in all countries that experience such losses. Otherwise, Pareto improvements can also be achieved as described in Section 4.5, either by using explicit transfers or via cooperation that involves implicit transfers (Proposition 2), provided that there are sufficient instruments to conduct such transfers.

\subsection{Domestic Policy under Imperfect External Instruments}

We now return to the full setup of our baseline model with domestic policy $\left(X^{i}\right)$ in order to study the effects of imperfect external policy instruments on domestic allocations.

Lemma 3 (Non-Separability). (i) If a domestic policymaker faces a set of external policy instruments that is not effectively perfect, she will generically distort her domestic policy choices $X^{i}$ as a second-best device to target external transactions.

(ii) If the set of policy instruments in the world economy is not effectively perfect at the global level, global cooperation will coordinate the use of both external and domestic policy instruments.

Proof. For (i), we add the utility cost $-\Gamma^{i}\left(\tau^{i}\right)$ to the optimization problem of the country $i$ policymaker in Appendix A.1 and observe that $\mu_{e}^{i} \neq 0$ if the country's set of external policy instruments is not effectively complete; therefore the optimality condition FOC $\left(X^{i}\right)$ of a policymaker is generically affected (except in knife-edge cases when $\partial f_{m}^{i} / \partial X^{i}=0$ happens to hold, i.e. when domestic policy has no effect whatsoever on external transactions).

For (ii) we proceed in the same manner and observe that a global planner faces the same optimality conditions $\operatorname{FOC}\left(X^{i}\right)$. The shadow prices $\mu_{e}^{i}$ on the external implementability constraints 
are generically non-zero if external policy instruments are not effectively perfect at the global level. This makes it optimal to internalize how domestic choices affect external transactions.

Intuitively, it is desirable in both cases to consider not only domestic objectives in setting the domestic policy instruments $X^{i}$ but also how these choices will improve external allocations, which can only be targeted indirectly given the imperfect external instruments. Suppose inflows of good $k$ are excessive $\left(\mu_{e, k}^{i}>0\right)$. If a domestic choice variable $X_{h}^{i}$ is complementary to $m_{k}^{i}$, then a policymaker will reduce $X_{h}^{i}$ to bring down $m_{k^{\prime}}^{i}$ and vice versa for substitutes. This is also illustrated in the second part of Example (5).

\section{International Markets Imperfections}

This section examines how global cooperation can improve outcomes when Condition 3 (Perfect International Markets) is violated. The general lesson is that global cooperation can be a powerful tool to improve the functioning of the international price mechanism, for example when prices are sticky or when there are unpriced pecuniary or technological externalities. By contrast, when international market imperfections constrain only the quantity of real goods traded, the competitive equilibrium is constrained efficient.

\subsection{A Model of International Market Imperfections}

We introduce imperfections in international markets in a general way by imposing a set of constraints on international transactions and market prices of the form 4

$$
\Phi\left(Q,\left(m^{i}\right)_{i \in \mathcal{I}}\right) \leq 0
$$

For simplicity, we limit our attention to specifications in which this defines a non-empty convex set and in which the constraints on the allocations of different countries are independent of each other so that $\Phi(\cdot)$ could be partitioned into the format $\left\{\Phi^{i}\left(Q, m^{i}\right)\right\}_{i \in \mathcal{I}}$.

Let us provide a few of examples for (37): if the market for a good $k$ is missing, this corresponds to a constraint $m_{k}^{i}=0 \forall i$. If risk markets in period $t$ are absent, this is captured by a constraint $m_{t, s}^{i}=m_{t, s^{\prime}}^{i}$ for any two states $s, s^{\prime}$ in period $t$. Financial imperfections that limit the market value of promised resources correspond to $-Q_{k} m_{k}^{i} \leq \phi$. Price stickiness can be captured by constraints of the form $Q_{k}=\bar{Q}_{k}$ or, more generally, Phillips-curve type constraints. Classic technological externalities in the spirit of Arrow (1969), such as pollution, correspond to the restriction $Q_{k}=0$ for the externality-generating activity ${ }^{35}$

When prices cannot play their role of clearing markets, we have to impose an alternative assumption for how markets for a given good will clear. For each good $k$, we define a country

\footnotetext{
${ }^{34}$ This specification is inspired by Farhi and Werning (2016) who use a similar constraint on security market allocations to study aggregate demand externalities. Given their focus, they assume that policymakers have limited instruments to affect spot market transactions, preventing them from restoring the first-best in settings in which the global planner in our setting is able to do so.

${ }^{35}$ We could further generalize constraint 37 by assuming that different countries face different prices in external markets - as is the case e.g. under local currency pricing. This does not alter the main insights of the section.
} 
$\bar{i}(k) \in \mathcal{I}$ that is forced to absorb any excess supply of good $k$ from the other countries and will thus see its net imports rationed $\mathrm{tq}^{36}$

$$
\bar{M}_{k}^{\bar{i}(k)}=-\frac{1}{\omega^{\bar{i}(k)}} \int_{i \in \mathcal{I} \backslash\{\bar{i}(k)\}} M_{k}^{i} d \omega(i)
$$

We assume that both private agents and the policymaker in country $\bar{i}$ take the rationed quantity $\bar{M}_{k}^{i}$ as exogenous. For notational convenience, we partition the net imports of each country $M^{i}=$ $\left(\tilde{M}^{i}, \bar{M}^{i}\right)$ into the part that is optimized $\tilde{M}^{i}$ and the part that is rationed $\bar{M}^{i}$. We add constraints (37) and (38) to our baseline model and observe:

Lemma 4 (Separability under Imperfect International Markets). If Condition 2 (Perfect External Instruments) is satisfied, then, even in the presence of international market imperfections (37):

(i) the separability result of Lemma 1 holds so the policymaker in country i can solve for optimal domestic and external allocations in two separate steps; and

(ii) global cooperation is limited to external policy instruments $\tau^{i}$ and not useful for domestic instruments $X^{i}$.

Proof. For point (i), we add constraints (37) and (38) to the optimization problem of the country $i$ policymaker in Appendix A.1. The choice variables are now limited to the components $\tilde{M}^{i}$ that are not rationed. We observe that the constraint (37) only affects the optimality conditions for $\tilde{M}^{i}$, but not those for domestic policies. For the optimally chosen goods, the implementability constraint on external transactions is slack so $\mu_{e}^{i}=0$ owing to Condition 2. The rationed components $\bar{M}_{k}^{i}$ are exogenous from the perspective of the country $\bar{i}$ policymaker. As a result, the optimality conditions for the domestic allocation $X^{i}$ are unaffected by the international market imperfections.

For point (ii), we observe that constraint (37) is redundant with the international marketclearing constraint; therefore the separability result continues to hold.

The intuition is the same as for all our earlier separability results: external instruments are the only instruments necessary to optimally steer external transactions. Given the redundancy observed in the proof of point (ii) of the lemma, the Lagrangian of a global planner is

$$
\mathcal{L}=\max _{Q,\left(M^{i},\right)_{i \in \mathcal{I}}} \int_{i \in \mathcal{I}}\left\{\theta^{i}\left[V^{i}\left(M^{i}, M^{i}\right)\right]-v M^{i}\right\} d \omega(i)-\phi \Phi\left(Q,\left\{M^{i}\right\}_{i \in \mathcal{I}}\right)
$$

where $\phi$ is a vector of shadow prices on constraint (37). The optimality conditions are

$$
\begin{aligned}
\operatorname{FOC}(Q) & : \phi \Phi_{Q}=0 \\
\operatorname{FOC}\left(M^{i}\right) & : \theta^{i}\left(V_{m}^{i}+V_{M}^{i}\right)=v+\left(\phi \Phi_{M^{i}}\right)^{T}
\end{aligned}
$$

\footnotetext{
${ }^{36}$ Naturally, country $\bar{i}$ needs to be of sufficient size to absorb the excess supply. Our results generalize, at the cost of additional notation, to the case where the excess supply is absorbed by a subgroup $\overline{\mathcal{I}}(k) \subset \mathcal{I}$ with appropriate distribution across the countries within $\overline{\mathcal{I}}(k)$.

${ }^{37}$ In the described setup, we define a general constraint $\Phi(\cdot)$ in 37 that constrains prices and quantities for all countries, and we define a separate rationing scheme if the price mechanism does not clear markets in (38). An alternative notation would be to define country-specific constraints $\Phi^{i}$ that include any price constraints and the rationing rule 38] for the countries that are rationed.
} 
where $\Phi_{Q}=\partial \Phi(\cdot) / \partial Q$ and similar for $\Phi_{M^{i}}$. Observe that the price vector $Q$ does not play an allocative role for a global planner - it only shows up in the constraint. This immediately leads to the following result:

Proposition 7 (Power over Market Prices and Resolving Imperfections). (i) If market imperfections solely restrict real quantities $M^{i}$ not prices so $\Phi_{Q}=0$, then the uncoordinated equilibrium among country i policymakers is constrained efficient.

(ii) Otherwise, if $\Phi_{Q} \neq 0$ and the constraint (37) is binding for some countries with $\phi^{i} \Phi_{Q} \neq 0$, then the uncoordinated equilibrium is constrained inefficient and there is scope for international policy cooperation.

(iii) If rank $\Phi_{Q}=\operatorname{dim} \Phi \forall M^{i}$, then policy cooperation can fully resolve constraint (37) and restore a first-best allocation in the international market. One important example for this is when market imperfections solely restrict prices so $\Phi_{M^{i}}=0 \forall i$.

Proof. In part (i) of the proposition, optimality condition (39) drops out of the problem, and the optimality conditions (39) $\forall i$ replicate the optimality conditions of country $i$ policymakers in the uncoordinated equilibrium for suitable Pareto weights, as in Theorem $1^{38}$

Part (ii) follows because the condition $\phi^{i} \Phi_{Q} \neq 0$ violates the optimality condition (39) of a global planner. A global planner can improve efficiency by using her control over world prices and relaxing the constraint where it is binding.

In part (iii) of the proposition, the rank condition ensures that first-order condition (39) has a unique solution for the vector of shadow prices $\phi$, which is the degenerate solution $\phi=0$. This indicates that the vector constraint (37) is not binding at the optimum. When $\Phi_{M^{i}}=0 \forall i$ then market imperfections depend by definition only on $Q$ so any constraint $\Phi(\cdot)$ can be expressed in a manner that is consistent with the rank condition.

Intuitively, the proposition shows that the ability of global cooperation to increase efficiency depends squarely on the ability to control global market prices, which eludes individual country $i$ policymakers. When the constraints specified in (37) depend on prices, this creates a role for global cooperation to improve upon the uncoordinated equilibrium.

In part (i) of the proposition, the constraints on international markets 37) do not depend on market prices at all, and so a global planner has no additional powers compared to the policymakers in individual countries and cannot improve on the uncoordinated equilibrium allocation, as we illustrate in Example 10 below.

In part (ii), by contrast, the constraints restricting the allocations of policymakers depend on prices. A global planner can coordinate world market prices and relax the constraints, thereby increasing efficiency.

Part (iii) of the proposition is even stronger than part (ii): the rank condition ensures that all the constraints in the vector constraint (37) are responsive to price changes, and that there are sufficiently many price instruments under global cooperation to render all the constraints irrelevant. Since prices play no role in the actual allocation of resources [cf. optimality condition (40)], a global planner then simply picks a price vector that satisfies the constraints and sets the instruments $\left\{\tau^{i}\right\}_{i \in \mathcal{I}}$ so as to implement the optimal real allocation that would prevail in the absence of the international market imperfections.

\footnotetext{
${ }^{38}$ As is well known, prices $Q$ may not be uniquely pinned down when goods markets are incomplete.
} 
We illustrate parts (ii) and (iii) in Examples 11 to 15 below. For reasons of analytical simplicity, most of our examples will focus on cases where the rank condition in part (iii) of the proposition is satisfied and the first-best can be achieved. This highlights the main intuition behind how global cooperation increases efficiency. It is easy to extend our examples, e.g. by assuming certain restrictions on instruments, such that the same motive for international cooperation is still present but only second-best outcomes can be achieved.

The cooperative actions described in Proposition 7.(ii) and (iii) to restore Pareto efficiency generally involve transfers across nations. As described in Section 4.5, Pareto improvements can be achieved either by using explicit transfers or via cooperation that involves implicit transfers, if there is a sufficient number of market prices that are unconstrained, as described in Proposition 2.

\subsection{Missing Markets}

The following example illustrates the constrained efficiency result when the constraint (37) is independent of market prices:

Example 10 (Missing Markets). Consider a world economy in which a set of goods cannot be traded so we can partition $M^{i}=\left(\tilde{M}^{i} ; \hat{M}^{i}\right)$ and specify the constraint (37) as $\hat{M}^{i}=0 \forall i$. Proposition 7 (i) implies that equilibrium is constrained efficient ${ }^{39}$

Additional examples include when there are exogenous quantity restrictions on trade or when certain goods can only be purchased in bundles, e.g. when state-contingent markets are absent. One way of thinking about these cases is to view the restricted net imports $\hat{M}^{i}$ as exogenous parameters in the reduced-form utility functions $V^{i}(\cdot)$, similar to state-contingent utility functions. It is well-known that the first welfare theorem applies in these cases.

\subsection{Price Stickiness in International Markets}

Restrictions on prices are the polar opposite of the restrictions on quantities in international markets in Section 7.2. For example, we capture prices that are perfectly rigid by imposing $Q_{k}=\bar{Q}_{k}$ for some $k$ in constraint (37), together with appropriate rationing assumptions (38). More generally, we could assume constraints capturing Phillips curve-type behavior of prices that link changes in prices to quantities demanded.

Example 11 (Rigid World Prices). We consider a world economy with two countries $i \in\{A, B\}$ of equal mass and a single time period with two goods, a good indexed 0 that is produced using labor $y_{0}^{i}=\ell_{0}^{i}$ and $a$ good indexed 1 with exogenous endowments $y_{1}^{i}$. Private agents in each country derive utility according to an additively separable function $U^{i}=u\left(c_{0}^{i}\right)-d\left(\ell_{0}^{i}\right)+u\left(c_{1}^{i}\right)$. We assume the vector of world market prices is rigid at $Q=\bar{Q}=(1,1)$ and that markets clear by adjusting exports of good 0 of country $A$. For good 1, markets then clear by Walras' Law since $m_{1}^{i}=-m_{0}^{i} \forall i$. W.l.o.g. we consider the case in which there is a demand shortage for good 0 .

\footnotetext{
${ }^{39}$ Since we impose market incompleteness directly on the vector of net imports $M^{i}$ rather than on financial trades, there is no scope for second-best interventions in financial markets to affect spot markets for imports, as in the generically inefficient economies studied by Geanakoplos and Polemarchakis (1986).
} 
In an uncoordinated equilibrium, the policymaker in country $i=B$ sets $V_{m}^{i}+V_{M}^{i}=\Lambda_{e}^{i} \bar{Q}$ so consumption and output is determined by the optimality conditions $u^{\prime}\left(c_{0}^{i}\right)=u^{\prime}\left(c_{1}^{i}\right)=d^{\prime}\left(\ell_{0}^{i}\right)$. There is no role for policy intervention in the country since $V_{M}^{B}=0$ and the private optimality condition $V_{m}^{B}=\lambda_{e}^{B} \bar{Q}$ is satisfied. Country $A$ bears the burden of rationing, so $V_{m, 0}^{A}<\lambda_{e}^{A} \bar{Q}_{0}$. Wages and employment in country A fall to meet the given aggregate demand $\bar{M}_{0}^{A}$. Although the policymaker in country A finds it optimal to subsidize exports of good 0 to counteract the domestic demand shortages, his actions fail to resolve the problem since importers of good 0 in country $B$ face a constant price vector $\bar{Q}$ and do not have incentives to increase their imports.

If world market prices were flexible (and using good 1 as a numeraire $Q_{1}=1$ ), the demand shortage for good 0 would lead to a decline in its relative price to $Q_{0}^{*}<1$. Then country $B$ would import more of it, and country A would have less incentive to export at the lower world price, restoring market clearing through the price mechanism and implementing a first-best allocation.

Global cooperation can replicate this first-best allocation in accordance with Proposition 7 (iii) - simply by imposing an identical tax wedge $1-\tau_{0}^{i}=\bar{Q}_{0} / Q_{0}^{*} \forall i$ across all countries, subsidizing net imports or, equivalently, taxing net exports of good 0 . This ensures that all private agents face the effective world market price $\frac{\bar{Q}}{1-\tau^{i}}=Q^{*}$, corresponding to the price vector that decentralizes the first-best allocation. If we interpret the price rigidity as stemming from fixed exchange rates and sticky domestic prices, the described policy is similar to the "fiscal devaluations" described by Farhi et al. (2016).

Example 12 (Global ZLB). The above example can easily be re-interpreted as reflecting a zero lower bound on the world real interest rate: if we relabel goods 0 and 1 as period 0 and 1 consumption goods and assume that nominal prices of the consumption good are sticky over time, the rigid price vector $\bar{Q}=(1,1)$ corresponds to a nominal interest rate $\iota=\bar{Q}_{0} / \bar{Q}_{1}-1=0$, which is at the zero lower bound and cannot decline any further. In the uncoordinated equilibrium, the world economy then suffers from a global liquidity trap. Under global cooperation, this can be undone by subsidizing net imports in all countries - this policy is a close cousin of the "unconventional fiscal policy" in Correia et al. (2013).

\subsection{Pecuniary Externalities}

Another type of international market imperfection captured by Proposition 7.(ii) and (iii) occurs when quantities transacted are subject to constraints that depend on prices. A prime example of such price-dependent constraints are financial constraints, since expressing such constraints in the Arrow-Debreu-style notation of our general framework generally translates into restrictions (37) that depend on both quantities and prices. More generally, such constraints may arise from incentive, selection or commitment problems in international markets 40 Price-dependent constraints generally gives rise to pecuniary externalities that provide scope for cooperation to influence international market prices so as to mitigate the constraints. We illustrate this in a simple but typical example of financial constraints:

Example 13 (Pecuniary Externalities from Collateral Constraints). Assume a two-period world economy with a set of countries $\mathcal{I}$ that follow the setup of Section 2.1. Consider a first-best allocation and denote

\footnotetext{
4C Greenwald and Stiglitz (1986) and Geanakoplos and Polemarchakis (1986) provide general descriptions of pecuniary externalities. Macroeconomic applications involving exchange rate and asset price fluctuations include Caballero and Krishnamurthy (2003), Lorenzoni (2008) and Davila and Korinek (2016).
} 
the optimal period 1 net imports in each country by $m_{1}^{i *}$ and the market price that would correspond to that allocation by $Q^{*}$. Furthermore, denote by $m_{1}^{*}=\min _{i}\left\{m_{1}^{i *}\right\}$ the net imports of the country with the greatest borrowing need.

Now let us introduce a simple financial constraint that limits the market value of borrowing of a given country $i$ in terms of the numeraire $Q_{0}=1 \mathrm{tc}$

$$
-Q_{1} m_{1}^{i} \leq \phi
$$

Consider the uncoordinated equilibrium of the world economy under this constraint. If $-Q_{1}^{*} m^{*}>\phi$ then the financial constraint (41) is binding on the country with the greatest borrowing need, and the described first-best allocation cannot be implemented in the absence of cooperation.

Following Proposition 7.(iii), global cooperation can replicate the first-best allocation by changing the world market price so the constraint (41) is satisfied for all countries. In particular, a global planner could set $Q_{1}=-\phi / m_{1}^{*}$ so that even the country with the greatest borrowing need is unconstrained. She does so by imposing a uniform tax wedge $1-\tau_{1}^{i}=Q_{1} / Q_{1}^{*}=-\phi /\left(Q_{1}^{*} m_{1}^{*}\right) \forall i \in \mathcal{I}$. This uniform tax leaves the marginal rates of substitution between different countries unaffected but reduces the international price of period 1 goods to the point that constraint (41) is slack for all countries. ${ }^{43}$

A second type of pecuniary externalities occurs when incomplete financial markets inhibit optimal risk-sharing or smoothing across countries but global cooperation can affect the prices at which agents trade to redistribute between countries so as to improve risk-sharing/smoothing. This example highlights that translating financial constraints into Arrow-Debreu notation generally leads to constraints that depend on both prices and quantities.

Example 14 (Market Incompleteness and Pecuniary Externalities ). Consider a world economy with two countries $\mathcal{I}=\{A, B\}$, two time periods $t=0,1$, and two aggregate state of nature $\omega \in\{L, H\}$ that are realized with equal probability $1 / 2$ at the beginning of period 1 . Assume that country $A$ has linear expected utility and ample endowments, whereas country $B$ has utility $U^{B}=u\left(c_{0}^{B}\right)+E\left[u\left(c_{1}^{B, \omega}\right)\right]$ with concave $u(\cdot)$ and endowments $y_{0}^{B}=1-\delta$ and $\left(y_{1}^{B, L}, y_{1}^{B, H}\right)=(1+\delta-\epsilon, 1+\delta+\epsilon)$ where we assume $\delta>\epsilon>0$. The two parameters $\delta$ and $\epsilon$ capture the amount of intertemporal smoothing and risk-sharing that country B would ideally want to engage in. In the first-best, country B can fully smooth and insure by choosing net imports $\left(m_{0}^{B}, m_{1}^{B, L}, m_{1}^{B, H}\right)=(\delta,-\delta+\epsilon,-\delta-\epsilon)$.

However, let us assume that country B cannot access international risk markets to insure against the risky component of its endowment - the financial wealth that agents carry into period 1 is uncontingent,

$$
w_{1}^{i, L}=w_{1}^{i, H}
$$

\footnotetext{
${ }^{41}$ Greater borrowing corresponds to more negative $m_{1}^{i}$. In standard open economy macro notation, this is usually denoted $d_{1}^{i} / R \leq \phi$ where $d_{1}^{i}$ is the face value of debt and $R$ the interest rate. Such constraints are common in the literature. An alternative but closely related interpretation for constraint 41 is that there is a constraint on the financial value of the period 1 repayment, $-w_{1}^{i} \leq \phi$, which is used to buy consumption goods, and that $Q_{1}$ denotes the relative value of period 1 consumption goods in terms of the financial unit of account.

${ }^{42}$ To underline the difference between this example and the example in Section (2.6), observe that the constraint in the latter depends on a domestic price, whereas the constraint here depends on an international price.

43 Benigno et al. (2017) provide a related example in which a domestic policymaker can restore the first-best in an economy subject to a price-dependent collateral constraint.
} 
The financial wealth buys imports $w_{1}^{i, \omega}=Q_{1}^{\omega} m_{1}^{\omega}$, and so the market incompleteness implies the following constraint on real allocations

$$
Q_{1}^{L} m_{1}^{B, L}=Q_{1}^{H} m_{1}^{B, H}
$$

In the uncoordinated equilibrium, the preferences of country A agents pin down the global price vector $Q=(1,1 / 2,1 / 2)$ for any non-degenerate equilibrium. The market incompleteness faced by country $B$ then requires that $m_{1}^{B, L}=m_{1}^{B, H}$ so the country will not obtain any insurance.

By contrast, under global cooperation, a global planner would adjust the external instruments of the two countries so as to restore the first-best: under the price vector $Q_{0}=1$ and $\left(Q_{1}^{L}, Q_{1}^{H}\right)=(1+\epsilon / \delta, 1-\epsilon / \delta) / 2$, the constraint (43) is satisfied for the first-best level of net imports that provides full insurance. The planner can implement these prices by imposing the taxes $\tau_{0}^{i}=0$ and $\tau_{1}^{i}=(-\epsilon / \delta, \epsilon / \delta)$ for both countries, i.e. by subsidizing imports to B in the low state and taxing them in the high state of period 1. It is easily verified that the first-best allocation also satisfies the Euler equation of both countries under the chosen tax instruments.

This example also highlights the limitations on global cooperation to resolve the pecuniary externalities that arise from market incompleteness: there needs to be sufficient trade between countries for a change in prices to redistribute sufficient resources. In the given example, if $\delta<\epsilon$, then there is too little intertemporal trade for a global planner to affect the terms-of-trade and restore the first-best without violating non-negativity constraints on prices - given constraint (43), it is impossible for the sign of net imports $m_{1}^{B, L}$ and $m_{1}^{B, H}$ to differ without one of the prices turning negative \begin{tabular}{r|r|r|}
445 \\
\hline
\end{tabular}

\subsection{Classic Global Externalities}

Our final application is a classic global externalities problem, which may arise for example from emissions of greenhouse gases and ozone-depleting substances, from over-use of antimicrobials that fosters resistance, from the destruction of biodiversity, from nuclear proliferation, or from the development of a general AI that endangers humanity.

We represent externalities as missing markets for goods that capture the external effects of different countries on each other, as proposed by Arrow (1969). Assuming there are $K$ different externalities, we expand our definition of the set of international goods by the vector $\hat{M}=$ $\left(\hat{M}_{i k}\right)_{i \in \mathcal{I}, k=1 \ldots K}$, which has size $\operatorname{dim} \mathcal{I} \times K$, i.e. we add one good for each country and externality ${ }^{46}$ We denote by $\hat{M}_{i k}^{j}$ for $i \neq j$ the externality imposed by country $j$ on country $i$ in category

\footnotetext{
${ }^{44}$ To square this finding with the rank condition in Proposition 7 (iii), observe that - as the global planner subsidizes and taxes the two goods more and more, the matrix $\Phi_{Q}=\left(m_{1}^{B,},-m_{1}^{B, H}\right)$ becomes singular since $m_{1}^{B, \omega} \rightarrow 0$ for both $\omega \in\{L, H\}$.

${ }^{45}$ Another stark example to which Proposition 7 (ii) and (iii) apply is that of Hart (1975) in which two agents trade commodities in spot markets in two consecutive time periods but there are no financial markets for intertemporal trade. In our setting, if we interpret the two agents as countries that do not have access to financial markets, this amounts to a constraint $\sum_{k} Q_{t, k} m_{t, k}^{i}=0 \forall i, t$, i.e. the budget constraint in the spot market needs to be satisfied each period. Global cooperation could emulate the effects of financial markets by first improving and then deteriorating the terms-of-trade of the borrowing country in the two time periods. If there is sufficient trade on spot markets, global cooperation can restore the first-best allocation. For space reasons, we do not describe this example in further detail.

${ }^{46}$ This captures the case in which the externalities experienced by a country depend on the total global amount of an externality-generating activity. We could make externalities specific to both the generating and receiving country by introducing $|\operatorname{dim} \mathcal{I}|^{2} \times K$ goods to capture them.
} 
$k$, and by $\hat{M}_{i k}^{i}$ the total "net imports" of the externality experienced by country $i$. We ensure market clearing by imposing that the total externality experienced ("imported") by country $i$ consists of the sum of what is created by the other countries, i.e. by imposing the rationing assumption $\omega^{i} \hat{M}_{i k}^{i}=-\int_{j \in \mathcal{I} \backslash\{i\}} \hat{M}_{j k}^{i} d \omega(i) \forall i, k$ in accordance with 38 .

As Coase (1960) and Arrow (1969) observed, the problem with externalities is that they are not priced. In our general setup (37), this corresponds to the constraint

$$
\hat{Q}=0
$$

for externality goods. The complete vector of international transactions of each country consists of the usual external transactions in privately traded goods $\tilde{M}^{i}$ plus the trade in externalities $M^{i}=\left(\tilde{M}^{i}, \hat{M}^{i}\right)$, and similar for the global vector of market prices $Q=(\tilde{Q}, \hat{Q})$. The mis-pricing of externalities (44) leads to an inefficient global allocation, as we illustrate in the following example:

Example 15 (Environmental Externalities). Suppose a set of countries $\mathcal{I}$ with a unit mass of private agents each that consume $y^{i}$ units of a good which they value according to a standard utility function $u\left(y^{i}\right)$. Each unit of production of the good creates one unit of private disutility and increases global pollution by one unit, which imposes disutility $\eta$ on all agents worldwide. The utility function of a private agent in country $i$ is thus $U^{i}\left(y^{i}\right)=u\left(y^{i}\right)-y^{i}-\eta^{i} \int_{j \in \mathcal{I}} Y^{j} d \omega(j)$. We assume that the policymaker in each country has a costless tax instrument to control domestic production. Denote by $\hat{M}_{i}^{j}=Y^{i} \forall j \neq i$ the pollution externalities that country $j$ imposes on country $i$. This constraint is part of the domestic constraint set $f^{i}(\cdot) \leq 0$. Furthermore, denote by $\hat{M}_{i}^{i}$ the pollution that country $i$ is forced to import, which is determined by other countries' exports $\hat{M}_{i}^{i}=\int_{j \neq i} \hat{M}_{i}^{j} d \omega^{j}$ as in equation 38 This pollution reduces country $i$ utility by $\eta \hat{M}_{i}^{i}$.

In the uncoordinated equilibrium, the country $i$ policymaker will only internalize the externalities that country $i$ agents impose on each other, resulting in the optimality condition $u^{\prime}\left(Y^{i}\right)=1+\eta \omega^{i}$, i.e. the larger the country, the more of its own pollution it internalizes. There is overproduction since exports of pollution from each country $j$ are unpriced, $V_{\hat{M}, i}^{j}=\hat{Q}_{i}=0$, even though country $i$ suffers marginal disutility $V_{\hat{M}, i}^{i}=-\eta$ from importing pollution.

Global cooperation internalizes these externalities and ensures that private agents equate the marginal benefit of consumption to the global social cost of production,

$$
u^{\prime}\left(y^{i}\right)=1+\eta
$$

This can be achieved either in Coasian fashion, by defining clear property rights on the environment that would trade at the efficient market price $\eta$, or, equivalently, by imposing a tax $\eta$ on production in each country. ${ }^{47}$

\section{Conclusions}

The first welfare theorem for open economies presented in this paper - like other benchmark results in the literature - tells us what to look for when we are concerned about inefficiency and scope for cooperation, both as academics and as policymakers studying international policy cooperation. We

\footnotetext{
${ }^{47}$ Our externalities example requires specific taxes on international transactions rather than ad-valorem taxes as in our baseline framework, since the market price of externalities in the uncoordinated equilibrium is zero.
} 
develop the theorem in a framework that nests a wide range of open economy models. Unlike the traditional first welfare theorem, our theorem applies to settings in which there are two layers of optimizing agents - private agents and national policymakers - and finds that there is constrained efficiency even if there are wide-ranging domestic market imperfections and targeting problems within each economy. When the conditions of our first welfare theorem for open economies are met, any spillovers constitute efficient pecuniary externalities that cancel out at the global level. The three conditions are: (i) national policymakers act competitively, i.e. with "benign neglect," towards international prices (ii) they possess sufficient instruments to control external transactions and (iii) international markets are free of imperfections. As long as these conditions are satisfied, our benchmark efficiency result applies to the spillovers from a wide range of domestic and external policies that we discussed in Section 2, counter to the intuition of many commentators and policymakers.

As with all versions of the first welfare theorem in the literature, the efficiency conditions stated in the theorem are never met $100 \%$ in practice, but the welfare theorem provides us with a way of diagnosing which parts of the international economic system lead to deviations from efficiency. We hope that this will elevate the debate from "we don't like spillovers!" to "what are the specific inefficiencies that we can address via policy cooperation?"

An issue that is beyond the scope of this paper is to quantify the potential gains from cooperation. If policies are designed such that countries cannot distort their intratemporal terms of trade and if markets are close to perfect, then gains from cooperation are small (Obstfeld and Rogoff. 2002) and may not be worth the effort. On the other hand, if countries heavily distort trade to exert market power or if there are severe market imperfections such as financial crises, gains may be significantly larger.

Having said that, even when Pareto inefficiency generates scope for fruitful cooperation, as in Sections 5 to 7 when the efficiency conditions of our first welfare theorem are violated, implementing such cooperation in practice is frequently fraught with difficulties. These difficulties are beyond the scope of the current paper but have given rise to a substantial literature $\sqrt{48}$ One difficulty is to ensure domestic political support for international policy cooperation, especially when both international spillovers and international cooperation lead to domestic redistributions. A second difficulty is to distinguish between policy actions that aim to distort terms of trade and policy actions that correct domestic market imperfections. Yet another difficulty is to agree to a distribution of the gains from cooperation in the international arena that is acceptable to all participants. This is especially difficult when there are also efficient spillovers in response to exogenous shocks that have already generated significant redistributions and have thus shifted the baseline for what gains can be achieved via cooperation. For example, if a country misunderstands the efficient nature of spillovers after a global shock, it may seek to restore a distribution of resources that is no longer feasible in a futile attempt at global cooperation.

\footnotetext{
${ }^{48}$ Willett (1999) discusses a range of political economy problems that make international policy cooperation difficult. Bagwell and Staiger (2002), among others, show that agreements to abstain from monopolistic beggar-thy-neighbor policies require that countries are sufficiently symmetric. Ostry and Ghosh (2016) provide a recent summary of obstacles to international policy cooperation.
} 


\section{References}

Aizenman, J. (2016). International coordination and precautionary policies. International Economic Journal, 30(3):379-391.

Arrow, K. J. (1969). The organization of economic activity: Issues pertinent to the choice of market versus non-market allocation. In The Analysis and Evaluation of Public Expenditures: The PBBSystem. Joint Economic Committee, 91st Congress.

Bagwell, K. and Staiger, R. W. (1999). An economic theory of GATT. American Economic Review, 89(1):215-248.

Bagwell, K. and Staiger, R. W. (2002). The Economics of the World Trading System. MIT Press.

Bagwell, K. and Staiger, R. W. (2010). The WTO: Theory and practice. Annual Review of Economics, 2(1):223-256.

Bengui, J. (2013). Macro-prudential policy coordination. manuscript, University of Montreal.

Benigno, G., Chen, H., Otrok, C., Rebucci, A., and Young, E. R. (2017). Optimal capital controls or exchange rate policies? a pecuniary externality perspective. Journal of Monetary Economics, forthcoming.

Benigno, G. and Fornaro, L. (2014). Reserve accumulation, growth and financial crises. LSE, mimeo.

Bernanke, B. (2013). Monetary policy and the global economy. Speech at Conference in Honor of Meroyn King, London School of Economics, March 25.

Bhagwati, J. and Ramaswami, V. K. (1963). Domestic distortions, tariffs and the theory of optimum subsidy. Journal of Political Economy, 71(1):44-50.

Blanchard, O. (2016). Currency wars, coordination, and capital controls. NBER Working Paper 22388.

Buch, C. M. and Goldberg, L. (2016). Cross-border prudential policy spillovers: How much? how important? evidence from the international banking research network. NBER Working Paper, 22874.

Caballero, R. J., Farhi, E., and Gourinchas, P.-O. (2015). Global imbalances and currency wars at the zlb. NBER Working Paper, 21670.

Caballero, R. J. and Krishnamurthy, A. (2003). Excessive dollar debt: Financial development and underinsurance. Journal of Finance, 58(2):867-894.

Coase, R. H. (1960). The problem of social cost. Journal of Law and Economics, 3:1-44.

Correia, I., Farhi, E., Nicolini, J. P., and Teles, P. (2013). Unconventional fiscal policy at the zero bound. American Economic Review, 103(4):1172-1211.

Corsetti, G., Dedola, L., and Leduc, S. (2011). Optimal monetary policy in open economies. In Friedman, B. M. and Woodford, M., editors, Handbook of Monetary Economics, volume 3B. Elsevier. 
Costinot, A., Lorenzoni, G., and Werning, I. (2014). A theory of capital controls as dynamic termsof-trade manipulation. Journal of Political Economy, 122(1):77-128.

Davila, E. and Korinek, A. (2016). Fire-sale externalities. NBER Working Paper, 22444.

Eggertsson, G. B. and Woodford, M. (2003). The zero bound on interest rates and optimal monetary policy. Brookings Papers on Economic Activity, 2003(1):139-211.

Farhi, E., Gopinath, G., and Itskhoki, O. (2016). Fiscal devaluations. Review of Economic Studies, 81(2):725-760.

Farhi, E. and Werning, I. (2012). Dealing with the trilemma: Optimal capital controls with fixed exchange rates. NBER Working Paper, 18199.

Farhi, E. and Werning, I. (2016). A theory of macroprudential policies in the presence of nominal rigidities. Econometrica, 84(5):1645-1704.

Feenstra, R. C. (1984). Voluntary export restraint in u.s. autos, 1980-81: Quality, employment, and welfare effects. In Baldwin, R. E. and Krueger, A. O., editors, The Structure and Evolution of Recent U.S. Trade Policy, pages 35-60. University of Chicago Press.

G-20 (2008). Leaders' declaration.

G-7 (2013). Official Statement on Exchange Rates. February 12, 2013, http:/ / www.bankofengland.co.uk/publications/Pages/news/2013/027.aspx.

Geanakoplos, J. D. and Polemarchakis, H. M. (1986). Existence, regularity, and constrained suboptimality of competitive allocations when the asset market is incomplete. Cowles Foundation Paper, 652.

Ghosh, A. R. and Masson, P. R. (1994). Economic Cooperation in an Uncertain World. Blackwell Press, Oxford.

Ghosh, A. R., Qureshi, M. S., and Sugawara, N. (2014). Regulating capital flows at both ends: Does it work? IMF Working Paper, 14/188.

Giordani, P., Ruta, M., Weisfeld, H., and Zhu, L. (2014). Capital flow deflection. IMF Working Paper, $14 / 145$.

Greenwald, B. C. and Stiglitz, J. E. (1986). Externalities in economies with imperfect information and incomplete markets. Quarterly Journal of Economics, 90(May):229-264.

Hart, O. (1975). On the optimality of equilibrium when the market structure is incomplete. Journal of Economic Theory, 11:418-443.

IMF (2012). The liberalization and management of capital flows: An institutional view. Board Paper.

IMF (2013). Key aspects of macroprudential policy. Board Paper.

Jeanne, O. (2009). The global liquidity trap. Johns Hopkins University, mimeo.

Jeanne, O. (2014). Macroprudential policies in a global perspective. NBER Working Paper, 19967. 
Jeanne, O. and Korinek, A. (2010). Excessive volatility in capital flows: A Pigouvian taxation approach. American Economic Review, 100(2):403-407.

Kemp, M. C. and Wan, H. Y. (1976). An elementary proposition concerning the formation of customs unions. Journal of International Economics, 6:95-97.

Korinek, A. (2010). Regulating capital flows to emerging markets: An externality view. University of Maryland, mimeo.

Korinek, A. and Serven, L. (2016). Undervaluation through foreign reserve accumulation: Static losses, dynamic gains. Journal of International Money and Finance, 64:104-136.

Korinek, A. and Simsek, A. (2016). Liquidity trap and excessive leverage. American Economic Review, 106(3):699-738.

Krugman, P. R. (1998). It's baaack: Japan's slump and the return of the liquidity trap. Brookings Papers on Economic Activity, 1998(2):137-187.

Lorenzoni, G. (2008). Inefficient credit booms. Review of Economic Studies, 75(3):809 - 833.

Obstfeld, M. and Rogoff, K. (2002). Global implications of self-oriented national monetary rules. Quarterly Journal of Economics, 117(2):503-535.

Ostry, J. D. and Ghosh, A. R. (2016). On the obstacles to international policy coordination. Journal of International Money and Finance, 67:25-40.

Ostry, J. D., Ghosh, A. R., and Korinek, A. (2012). Multilateral aspects of managing the capital account. IMF Staff Discussion Note 12/10.

Persson, T. and Tabellini, G. (1995). Double-edged incentives: Institutions and policy coordination. In Grossman, G. and Rogoff, K., editors, Handbook of Development Economics, volume III. Elsevier.

Rodrik, D. (2008). The real exchange rate and economic growth: Theory and evidence. Brookings Papers on Economic Activity, Fall 2008:365-412.

Smith, A. (1776). The Wealth of Nations. W. Strahan, London.

Spilimbergo, A., Symansky, S., Blanchard, O., and Cottarelli, C. (2008). Fiscal policy for the crisis. IMF Staff Position Note, 08/01.

Staiger, R. W. and Sykes, A. O. (2010). "Currency manipulation" and world trade. World Trade Review, 9(4):583-627.

Suranovic, S. M. (2016). International Trade Theory and Policy. Institute of International Economic Policy, George Washington University. http:/ /internationalecon.com/Trade/tradehome.php.

Theil, H. (1968). Optimal Decision Rules for Government and Industry. North Holland, Amsterdam.

Tinbergen, J. (1952). On the theory of economic policy. North Holland, Amsterdam.

Wheatley, J. and Garnham, P. (2010). Brazil in "currency war" alert, Financial Times, Sept. 27.

Willett, T. D. (1999). Developments in the political economy of policy coordination. Open Economies Review, 10(2):221-253.

Woodford, M. (2003). Interest and Prices: Foundations of a Theory of Monetary Policy. Princeton University Press. 


\section{A Mathematical Derivations of Main Results}

\section{A.1 Combined Optimization Problem}

Proof of Lemma 1 (Separability) We derive the optimality conditions of the full optimization problem of private agents and a policymaker in country $i$ under Conditions (1) to (3) and show that they lead to identical optimality conditions as the two-step procedure described in Sections 4.2 to 4.3 Since they are also subject to the same constraints, the two solution procedures are equivalent, proving the lemma.

The Lagrangian of the combined optimization problem of a private agent is

$$
\begin{aligned}
w^{i}\left(m^{i}, x^{i} ; M^{i}, X^{i}\right)=\max _{m^{i}, x^{i}} U^{i}\left(x^{i}\right) & -\lambda_{d}^{i} \cdot f^{i}\left(m^{i}, x^{i}, M^{i}, X^{i}\right) \\
& -\lambda_{e}^{i}\left[\frac{Q}{1-\tau^{i}} \cdot m^{i}-T^{i}\right]
\end{aligned}
$$

The optimality conditions are given by the vector equations

$$
\begin{aligned}
& \operatorname{FOC}\left(x^{i}\right): U_{x}^{i}=f_{x}^{i T} \lambda_{d}^{i T} \\
& \operatorname{FOC}\left(m^{i}\right): \lambda_{d}^{i} f_{m}^{i}+\lambda_{e}^{i} \frac{Q}{1-\tau^{i}}=0
\end{aligned}
$$

These two conditions represent domestic and external implementability constraints on the problem of the policymaker. By substituting the transfer $T^{i}=\frac{\tau^{i} Q}{1-\tau^{i}}$, the external budget constraint on private agents reduces to $Q \cdot M^{i} \leq 0$, and the optimization problem of the policymaker in country $i$ is given by the Lagrangian

$$
\begin{aligned}
\mathcal{L}^{i}=\max _{M^{i}, X^{i}, \tau^{i}, \lambda_{d}^{i}, \lambda_{e}^{i}} U^{i}\left(X^{i}\right) & -\Lambda_{d}^{i} \cdot f^{i}\left(M^{i}, X^{i}, M^{i}, X^{i}\right) \\
& -\Lambda_{e}^{i}\left[Q \cdot M^{i}\right] \\
& -\mu_{d}^{i} \cdot\left[U_{x}^{i}-f_{x}^{i T} \lambda_{d}^{i T}\right] \\
& -\mu_{e}^{i} \cdot\left[\lambda_{d}^{i} f_{m}^{i}+\lambda_{e}^{i} \frac{Q}{1-\tau^{i}}\right]^{T}
\end{aligned}
$$

This yields the optimality conditions (with all multiplications and divisions in the $\operatorname{FOC}\left(\tau^{i}\right)$ calculated element-by-element)

$$
\begin{aligned}
& \operatorname{FOC}\left(X^{i}\right): U_{x}^{i}=\left(f_{x}^{i}+f_{X}^{i}\right)^{T} \Lambda_{d}^{i T}+U_{x x}^{i}{ }^{T} \mu_{d}^{i T} \\
& -\mu_{d}^{i}\left(f_{x x}^{i}+f_{x X}^{i}\right) \lambda_{d}^{i T}+\mu_{e}^{i}\left(f_{m x}^{i}+f_{m X}^{i}\right) \lambda_{d}^{i T} \\
& \text { FOC }\left(M^{i}\right): 0=\left(f_{m}^{i}+f_{M}^{i}\right)^{T} \Lambda_{d}^{i T}+\Lambda_{e}^{i} Q^{T} \\
& -\mu_{d}^{i}\left(f_{x m}^{i}+f_{x M}^{i}\right) \lambda_{d}^{i T}+\mu_{e}^{i}\left(f_{m m}^{i}+f_{m M}^{i}\right)^{T} \lambda_{d}^{i T} \\
& \operatorname{FOC}\left(\tau^{i}\right) \quad: \quad 0=\mu_{e}^{i}\left[\frac{\lambda_{e}^{i} Q}{\left(1-\tau^{i}\right)^{2}}\right] \\
& \operatorname{FOC}\left(\lambda_{d}^{i}\right): 0=-\mu_{d}^{i} f_{x}^{i T}+\mu_{e}^{i} f_{m}^{i T} \\
& \operatorname{FOC}\left(\lambda_{e}^{i}\right) \quad: \quad 0=\mu_{e}^{i} \cdot\left(\frac{Q}{1-\tau^{i}}\right)^{T}
\end{aligned}
$$


where we denote by $\mu_{d}^{i} f_{x x}^{i} \lambda_{d}^{i T}$ the tensor product 4

$$
\mu_{d}^{i} f_{x x}^{i} \lambda_{d}^{i T}:=\frac{\partial \mu_{d}^{i} f_{x}^{i T} \lambda_{d}^{i T}}{\partial x^{i}}=\sum_{h} \lambda_{d, h}^{i} f_{h, x x}^{i}{ }^{T} \mu_{d}^{i T}=\left(\begin{array}{c}
\sum_{l=1}^{L} \sum_{h=1}^{H} \lambda_{d, h}^{i} \mu_{d, l}^{i} f_{h, x_{l} x_{1}}^{i} \\
\vdots \\
\sum_{l=1}^{L} \sum_{h=1}^{H} \lambda_{d, h}^{i} \mu_{d, l}^{i} f_{h, x_{l} x_{L}}^{i}
\end{array}\right)
$$

which has the same dimension as vector $x^{i}$, and similar for the tensor products $\mu_{d}^{i} f_{x X}^{i} \lambda_{d}^{i T}, \mu_{e}^{i} f_{m x}^{i} \lambda_{d}^{i T}$, etc.

Given the complete set of external instruments $\tau^{i}$, optimality condition FOC $\left(\tau^{i}\right)$ implies that the vector of shadow prices on the external implementability constraint satisfies $\mu_{e}^{i}=0$ - the country $i$ policymaker sets the vector $\tau^{i}$ to whichever levels she wants without facing trade-offs. By implication, the last term in the other four optimality conditions drops out, allowing us to separate the problem into two blocks.

The optimality conditions (A.7) and A.10 with $\mu_{e}^{i}=0$ replicate the optimality conditions of the optimal domestic planning problem (21) in Section 4.2 . Together with the domestic constraint (A.3) and the domestic implementability condition (A.5), these four conditions are identical to the four conditions that pin down the optimal domestic allocation for given $M^{i}$ in Section 4.2 and yield identical solutions for the four domestic variables $\left(X^{i}, \lambda_{d}^{i}, \Lambda_{d}^{i}, \mu_{d}^{i}\right)$.

Given the envelope theorem, the optimality condition (A.8) can equivalently be written as $\partial \mathcal{L}^{i} / \partial M^{i}=$ $d V^{i} / d M^{i}-\Lambda_{e}^{i} Q^{T}=0$, where the latter condition coincides with the optimality condition (26) defining the optimal external allocation in Section 4.3 The optimality conditions A.9 and A.11 for $\mu_{e}^{l}=0$ capture that the country $i$ policymaker can set the product $\lambda_{e}^{i}\left(1-\tau^{i}\right)$ such as to precisely meet the constraints (A.6) where the policymaker has one scalar degree of freedom, as we also emphasized in Section 4.3. The three optimality conditions together with the two constraints yield an identical set of solutions for the five external variables $\left(M^{i}, \tau^{i}, \lambda_{e}^{i}, \Lambda_{e}^{i}, \mu_{e}^{i}\right)$ as we described in Section 4.3. This shows that the two-step procedure yields identical solutions as the combined optimization problem, proving the lemma.

\section{A.2 Proofs of Theorem 1 (Efficiency of Global Equilibrium)}

We offer two separate proofs for our first welfare theorem (Theorem 1) to provide extra intuition. The first proof is the standard proof of the first welfare theorem under local non-satiation. The second proof emphasizes that the first-order optimality conditions of a global planner coincide with those of national policymakers.

First Proof of Theorem 1 (Non-Improvability). Consider a global competitive equilibrium allocation $\left(M^{i}, X^{i}\right)_{i \in \mathcal{I}}$ with price vector $Q$ and suppose, to the contrary, that there is an alternative global allocation $\left(\tilde{M}^{i}, \tilde{X}^{i}\right)_{i \in \mathcal{I}}$ that satisfies all domestic constraints $f^{i}(\cdot) \leq 0 \forall i$ and makes all countries better off, with at least one country strictly better off. If country $i$ prefers $\left(\tilde{M}^{i}, \tilde{X}^{i}\right)$ over $\left(M^{i}, X^{i}\right)$, then $Q \cdot \tilde{M}^{i} \geq Q \cdot \tilde{M}^{i}$, with strict inequality if the preference of country $i$ is strict. But summing up over all countries then implies that $Q \cdot \int_{i \in \mathcal{I}} \tilde{M}^{i} d \omega^{i}>0$, violating global market clearing and implying that the allocation is not feasible.

Second Proof of Theorem 1 (Global Planner's Optimization Problem). An allocation is Pareto efficient if it maximizes the weighted sum of welfare of all countries for some set of country welfare weights $\left\{\theta^{i}\right\}_{i \in \mathcal{I}}$ subject to the global resource constraint as well as the domestic constraints $f^{i}(\cdot)$ and the domestic implementability constraints A.1 for each country $i \in \mathcal{I}$. Given the complete set of external instruments, a global planner can directly choose allocations

$$
\max _{\left\{M^{i}, X^{i}\right\}_{i \in \mathcal{I}}} \int_{i \in \mathcal{I}} \theta^{i} U^{i}\left(X^{i}\right) d \omega(i) \quad \text { s.t. } \quad \text { A.1 }, f^{i}\left(M^{i}, X^{i}, M^{i}, X^{i}\right) \leq 0 \forall i \in \mathcal{I} \text { and } \int_{i \in \mathcal{I}} M^{i} d \omega(i)=0
$$

\footnotetext{
${ }^{49}$ Since the function $f^{i}(\cdot): \mathbb{R}^{2 K+2 L} \rightarrow \mathbb{R}^{H}$ is vector-valued, its second derivative with respect to, say, $x^{i}$ is a threedimensional tensor of dimensions $\operatorname{dim} f^{i} \times \operatorname{dim} x^{i} \times \operatorname{dim} x^{i}$.
} 
By the definition of $V^{i}\left(m^{i}, M^{i}\right)$, and following the same steps as in the proof of Lemma 1 (Separability) above, we can restate this problem in terms of reduced-form utilities of consistent external allocations $m^{i}=$ $M^{i}$,

$$
\max _{\left\{M^{i}\right\}_{i \in \mathcal{I}}} \int_{i \in \mathcal{I}} \theta^{i} V^{i}\left(M^{i}, M^{i}\right) d \omega(i) \quad \text { s.t. } \quad \int_{i \in \mathcal{I}} M^{i} d \omega(i)=0
$$

Assigning the shadow price $v$ to the vector of resource constraints, the optimality conditions of a global planner are

$$
\theta^{i}\left(V_{m}^{i}+V_{M}^{i}\right)=v^{T} \quad \forall i \in \mathcal{I}
$$

Under the conditions of the theorem, any global competitive equilibrium allocation also satisfies these optimality conditions if we use the shadow price on the global resource constraint $v=Q$ and assign the welfare weights $\theta^{i}=1 / \Lambda_{e}^{i}$ where $\Lambda_{e}^{i}$ are the shadow prices on the external budget constraints of the country $i$ policymakers. Therefore the allocation is Pareto efficient.

\section{A.3 Optimization Problem with Heterogeneous Agents and Political Preferences}

This appendix extends the benchmark model of Section 3 to (i) multiple types of agents and (ii) welfare functions that may potentially differ from the utility functions of the private agents so as to capture paternalism. An alternative interpretation of point (i) is that economy $i \in \mathcal{I}$ in fact represents a customs union that consists of several member countries and that is represented by an external policymaker with a welldefined social welfare function over the net imports of the member countries. Our results continue to apply to that case.

Assume that each country $i \in \mathcal{I}$ contains a set $\mathcal{J}^{i}$ of types of atomistic agents with total measure normalized to $w^{i}\left(\mathcal{J}^{i}\right)=1$. We denote the functions and variables referring to each type $j \in \mathcal{J}^{i}$ by the two superscripts $i j$, for example $U^{i j}\left(x^{i j}\right)$, or $m^{i j}$ and $M^{i j}$. Furthermore, assume that the policymaker in country $i$ values the allocations $X^{i j}$ of agent $j$ according to a welfare function $W^{i j}\left(X^{i j}\right)$ that satisfies the same properties as the utility function discussed in Section 3 . This function may simply capture the weight that the policymaker places on type $j$ agents, for example a weight $\alpha^{i j}$ in the specification $W^{i j}\left(X^{i j}\right)=\alpha^{i j} U^{i j}\left(X^{i j}\right)$. More generally, the function $W^{i j}(\cdot)$ may also capture that the policymaker in economy $i$ values the welfare of type $j$ agents differently from their individual preferences, capturing a form of paternalism. Bagwell and Staiger (2002) refer to this situation as "political preferences." Since international policy cooperation is usually conducted at the level of policymakers not private agents, the welfare function of the policymaker in each country $i$ is what matters for the question of whether an allocation is Pareto efficient or whether there is scope for welfare-improving international cooperation between policymakers.

In the following, we repeat the analysis of Appendix A.1 for this extension. The Lagrangian of the combined optimization problem of an agent $j \in \mathcal{J}^{i}$ and the associated optimality conditions are

$$
\begin{aligned}
& w^{i j}\left(m^{i j}, x^{i j} ;\left\{M^{i h}, X^{i h}\right\}_{h \in \mathcal{J}^{i}}\right)=\max _{m^{i j}, x^{i j}} U^{i j}\left(x^{i j}\right) \quad-\lambda_{d}^{i j} \cdot f^{i j}\left(m^{i j}, x^{i j} ;\left\{M^{i h}, X^{i h}\right\}_{h \in \mathcal{J}^{i}}\right) \\
& -\lambda_{e}^{i j}\left[\frac{Q}{1-\tau^{i j}} \cdot m^{i j}-T^{i j}\right] \\
& \text { FOC }\left(x^{i j}\right): U_{x}^{i j}=f_{x}^{i j} \lambda_{d}^{i j T} \\
& \operatorname{FOC}\left(m^{i j}\right): \lambda_{d}^{i j} f_{m}^{i j}+\lambda_{e}^{i j} \frac{Q}{1-\tau^{i j}}=0
\end{aligned}
$$

Using the latter two conditions as domestic and external implementability constraints and employing the welfare functions that the policymaker assigns to private agents, the Lagrangian of the optimization prob- 
lem is

$$
\begin{aligned}
\mathcal{L}^{i}=\max _{\left\{M^{i j}, X^{i j}, \tau^{i j}, \lambda_{d}^{i j}, \lambda_{e}^{i j}\right\}_{j \in \mathcal{J}^{i}}} \int_{j \in \mathcal{J}^{i}}\left\{W^{i j}\left(X^{i j}\right)\right. & -\Lambda_{d}^{i j} \cdot f^{i j}\left(M^{i j}, X^{i j},\left\{M^{i h}, X^{i h}\right\}_{h \in \mathcal{J}^{i}}\right) \\
& -\Lambda_{e}^{i j}\left[Q \cdot M^{i j}\right] \\
& -\mu_{d}^{i j} \cdot\left[U_{x}^{i j}-f_{x}^{i j} \lambda_{d}^{i j T}\right] \\
& \left.-\mu_{e}^{i j} \cdot\left[\lambda_{d}^{i j} f_{m}^{i j}+\lambda_{e}^{i j} \frac{Q}{1-\tau^{i j}}\right]^{T}\right\} d w(j)
\end{aligned}
$$

A set of optimality conditions similar to equations (A.7) to A.11 can be derived. Given a complete set of external instruments $\tau^{i j} \forall j \in \mathcal{J}^{i}$, the shadow prices on the external implementability constraints will again satisfy $\mu_{e}^{i j}=0 \forall j \in \mathcal{J}^{i}$, delivering a separability result analogous to Lemma 1. This makes it straightforward to extend Theorem 1 to heterogeneous agents and political preferences.

\section{A.4 Optimal Monopolistic Use of Domestic Instruments (Section 5.3)}

We formally consider the optimal monopolistic use of domestic instruments for the case in which a country's policymaker has no external instruments at all $\left(\tau^{i} \equiv 0\right)$ but has a full set of domestic instruments so there are no domestic targeting problems. This allows us to ignore the domestic optimization problem of private agents and let the policymaker directly choose the vector $X^{i}$ as part of her optimization problem

$$
\begin{array}{cl}
\max _{M^{i}, X^{i}, \lambda_{e}^{i}} U^{i}\left(X^{i}\right) \quad \text { s.t. } & f^{i}\left(M^{i}, X^{i}, M^{i}, X^{i}\right) \leq 0, \\
& Q^{-i}\left(-\omega^{i} M^{i}\right) \cdot M^{i} \leq 0, \\
& \lambda_{d}^{i} f_{m}^{i}=-\lambda_{e}^{i} Q^{-i}\left(-\omega^{i} M^{i}\right)
\end{array}
$$

The domestic constraint and external budget constraint in the first two lines are the usual ones, but the policymaker internalizes the effects of her external allocations on world market prices $Q^{-i}\left(-\omega^{i} M^{i}\right)$. The implementability constraints in the third line reflect that she lacks external policy instruments. We assign the usual shadow prices $\Lambda_{d}^{i}, \Lambda_{e}^{i}$ and $\mu_{e}^{i}$ to these constraints and obtain the optimality conditions

$$
\begin{aligned}
& \operatorname{FOC}\left(M^{i}\right) \quad: \quad 0=\left(f_{m}^{i}+f_{M}^{i}\right)^{T} \Lambda_{d}^{i T}+\Lambda_{e}^{i} Q^{T}\left(1-\omega^{i} \mathcal{E}_{Q, M}^{i}\right) \\
& +\mu_{e}^{i}\left(f_{m m}^{i}+f_{m M}^{i}\right)^{T} \lambda_{d}^{i T}-\omega^{i} \mu_{e}^{i} Q_{M}^{-i T} \lambda_{e}^{i T} \\
& \operatorname{FOC}\left(X^{i}\right): U_{X}^{i}=\Lambda_{d}^{i} f_{X}^{i}+\mu_{e}^{i}\left(f_{m x}^{i}+f_{m X}^{i}\right) \lambda_{d}^{i T} \\
& \operatorname{FOC}\left(\lambda_{e}^{i}\right): 0=\mu_{e}^{i} \cdot Q^{T}
\end{aligned}
$$

The optimality condition on $\lambda_{e}^{i}$ implies that the price-weighted sum of shadow prices on the external implementability constraint (IC) is zero $\sum_{k} \mu_{e, k}^{i} Q_{k}=0$, i.e. the policymaker chooses the allocation such that the cost of under- and overshooting on some of her individual targets cancels out. Some of the shadow prices on the external IC will therefore in general be positive and some will be negative. In particular, we can re-write the optimality condition on $M^{i}$ as

$$
\mu_{e}^{i}=-A^{-1}\left[\left(f_{m}^{i}+f_{M}^{i}\right)^{T} \Lambda_{d}^{i T}+\Lambda_{e}^{i} Q\left(1-\omega^{i} \mathcal{E}_{Q, M}^{i}\right)\right]
$$

where $A=\left(f_{m m}^{i}+f_{m M}^{i}\right)^{T} \lambda_{d}^{i T}-\omega^{i} Q_{M}^{-i T} \lambda_{e}^{i T}$. To interpret this expression, consider an $A$ that is close to 
diagonal and assume that there are no domestic externalities so $f_{M}^{i}=050$ In the absence of monopolistic behavior, the square brackets in this expression would be zero by the private optimality condition of consumers $\lambda_{d}^{i} f_{m}^{i}+\lambda_{e}^{i} Q=0$. By contrast, for a monopolistic policymaker, the vector of shadow prices $\mu_{e}^{i}$ captures the monopolistic cost (benefit) of increasing imports of each good and is therefore negative for net imports and positive for net exports.

The first-order condition FOC $\left(X^{i}\right)$ for the optimal domestic allocation and policy measures reflects that the monopolistic policymaker equates the marginal benefit of consumption to the marginal cost $\Lambda_{d}^{i} f_{X}^{i}$ augmented by the monopolistic benefits or costs $\mu_{e}^{i}\left(f_{m x}^{i}+f_{m X}^{i}\right) \lambda_{d}^{i T}$. If a domestic consumption action increases net imports of a good that the policymaker wants to increase for monopolistic reasons $\left(\mu_{e, k}^{i}>0\right)$, she will consumer more of it, and vice versa.

\section{A.5 Optimal Use of Costly Instruments (Section 6)}

Simplified National Planning Problem under Costly Instruments The Lagrangian of the simplified optimization problem of a country $i$ policymaker under costly instruments described in Section 6 is

$$
\mathcal{L}^{i}=\max _{M^{i}, \tau^{i}, \lambda_{e}^{i}} V^{i}\left(M^{i}, M^{i}\right)-\Gamma^{i}\left(\tau^{i}\right)-\Lambda_{e}^{i}\left[Q \cdot M^{i}\right]-\mu_{e}^{i} \cdot\left[V_{m}^{i}-\lambda_{e}^{i} \frac{Q}{1-\tau^{i}}\right]^{T}
$$

and delivers the associated optimality conditions (with all multiplications and divisions in the FOC $\left(\tau^{i}\right)$ calculated element-by-element)

$$
\begin{aligned}
& \operatorname{FOC}\left(M^{i}\right): V_{m}^{i}+V_{M}^{i}=\Lambda_{e}^{i} Q^{T}+\left(V_{m m}^{i}+V_{m M}^{i}\right)\left(\mu_{e}^{i}\right)^{T} \\
& \operatorname{FOC}\left(\tau^{i}\right): \quad \Gamma^{i \prime}=\mu_{e}^{i}\left[\frac{\lambda_{e}^{i} Q}{\left(1-\tau^{i}\right)^{2}}\right] \\
& \operatorname{FOC}\left(\lambda_{e}^{i}\right): 0=\mu_{e}^{i} \cdot\left(\frac{Q}{1-\tau^{i}}\right)^{T}
\end{aligned}
$$

From FOC $\left(M^{i}\right)$ we express the shadow prices on the implementability constraint as

$$
\left(\mu_{e}^{i}\right)^{T}=\left(V_{m m}^{i}+V_{m M}^{i}\right)^{-1}\left[\left(V_{m}^{i}+V_{M}^{i}\right)-\Lambda_{e}^{i} Q^{T}\right]
$$

We combine the domestic IC $V_{m}^{i}=\lambda_{e}^{i} Q /\left(1-\tau^{i}\right)$ with FOC $\left(\tau^{i}\right)$ to obtain

$$
\left(1-\tau^{i}\right) \Gamma^{i \prime}=\mu_{e}^{i}\left(V_{m}^{i}\right)^{T}
$$

with element-wise multiplication.

Proof of Proposition $\left[5\right.$ For point (i), we use FOC $\left(\tau^{i}\right)$ to obtain $\mu_{e}^{i}=\left[\frac{\left(1-\tau^{i}\right)^{2}}{\lambda_{e}^{i} Q}\right] \Gamma^{i \prime}$, where all multiplications and divisions are element-wise, and substitute this into FOC $\left(\lambda_{e}^{i}\right)$. Dropping the constant $\lambda_{e}^{i}$, we obtain the result $\left(1-\tau^{i}\right) \cdot \Gamma^{i \prime}=0$.

For point (ii), we use the implementability constraint $\left(1-\tau^{i}\right) V_{m}^{i} / \lambda_{e}^{i}=Q^{T}$ to substitute out $Q^{T}$ from the policymaker's FOC $\left(M^{i}\right)$. Furthermore, we use the FOC $\left(\tau^{i}\right)$ and the implementability constraint to substitute $\mu_{e}^{i}=\left[\frac{\left(1-\tau^{i}\right)^{2}}{\lambda_{e}^{i} Q}\right] \Gamma^{i \prime}=\left[\frac{1-\tau^{i}}{V_{m}^{i}}\right] \Gamma^{i \prime}$. We obtain

$$
V_{m}^{i}+V_{M}^{i}=\Lambda_{e}^{i} / \lambda_{e}^{i}\left(1-\tau^{i}\right) V_{m}^{i}+\left(V_{m m}^{i}+V_{m M}^{i}\right)\left[\left(\frac{1-\tau^{i}}{V_{m}^{i}}\right) \Gamma^{i \prime}\right]^{T}
$$

\footnotetext{
${ }^{50}$ The diagonal elements of the matrix are likely to be an order of magnitude larger than the off-diagonal elements as long as goods aren't strong complements or substitutes.
} 
This is a vector equation of the size of $M^{i}$. We divide element-by-element by $V_{m}^{i}$ and rearrange terms to find

$$
1+V_{M}^{i} / V_{m}^{i}=\left(1-\tau^{i}\right)\left[\frac{\Lambda_{e}^{i}}{\lambda_{e}^{i}}+\left(V_{m m}^{i}+V_{m M}^{i}\right) \frac{\left(\Gamma^{i \prime}\right)^{T}}{\left(V_{m}^{i}\right)^{2}}\right]
$$

The tax formula in the proposition follows immediately.

Global Planning Problem Under international cooperation, the Lagrangian of a global planner in our setup with costly instruments is

$$
\mathcal{L}=\max _{Q,\left(M^{i}, \tau^{i}, \lambda_{e}^{i}\right)_{i \in \mathcal{I}}} \int_{i \in \mathcal{I}}\left\{\theta^{i}\left[V^{i}\left(M^{i}, M^{i}\right)-\Gamma^{i}\left(\tau^{i}\right)\right]-\mu_{e}^{i} \cdot\left[V_{m}^{i}-\lambda_{e}^{i} \frac{Q}{1-\tau^{i}}\right]^{T}-v M^{i}\right\} d \omega(i)
$$

The global planner's optimality conditions are

$$
\begin{aligned}
\operatorname{FOC}(Q) & : \quad 0=\int_{i \in \mathcal{I}}\left\{\mu_{e}^{i}\left[\frac{\lambda_{e}^{i}}{1-\tau^{i}}\right]\right\} d \omega(i) \\
\operatorname{FOC}\left(M^{i}\right) & : \quad \theta^{i}\left(V_{m}^{i}+V_{M}^{i}\right)=\left(V_{m m}^{i}+V_{m M}^{i}\right)\left(\mu_{e}^{i}\right)^{T}+v \\
\operatorname{FOC}\left(\tau^{i}\right) & : \quad \theta^{i} \Gamma^{i \prime}=\mu_{e}^{i}\left[\frac{\lambda_{e}^{i} Q}{\left(1-\tau^{i}\right)^{2}}\right] \\
\operatorname{FOC}\left(\lambda_{e}^{i}\right) & : \quad 0=\mu_{e}^{i} \cdot\left(\frac{Q}{1-\tau^{i}}\right)^{T}
\end{aligned}
$$

The analogous expression to A.15 is

$$
\left(\mu_{e}^{i}\right)^{T}=\left(V_{m m}^{i}+V_{m M}^{i}\right)^{-1}\left[\theta^{i}\left(V_{m}^{i}+V_{M}^{i}\right)-v\right]
$$

Furthermore, expression A.16 can be derived along the same lines as above.

Proof of Proposition 6 The proof follows along the same lines as the proof of Proposition 5 (i). For the second condition, we substitute $\mu_{e}^{i} \frac{\lambda_{e}^{i}}{\left(1-\tau^{i}\right)}=\left(1-\tau^{i}\right) \theta^{i} \Gamma^{i \prime} / Q$, with multiplications and divisions performed element-wise, into FOC $(Q)$ and multiply by the constant $Q$ to obtain the result that $\int_{i \in \mathcal{I}}\left(1-\tau^{i}\right) \theta^{i} \Gamma^{i \prime} d \omega(i)$.

\section{A.6 Optimal Behavior in Model of Imperfect International Markets (Section 7)}

National Planning Problem We set up the Lagrangian of a country $i$ policymaker facing imperfect international markets as described in Section 7. Under Condition 2 (Complete External Instruments), we can formulate the problem in terms of choosing quantities to maximize reduced-form utilities. The country $i$ policymaker thus solves the Lagrangian

$$
\mathcal{L}^{i}=\max _{M^{i}} V^{i}\left(M^{i}, M^{i}\right)-\Lambda_{e}^{i}\left[Q \cdot M^{i}\right]-\phi^{i} \Phi\left(\left\{M^{j}\right\}_{j \in \mathcal{I}}, Q\right)
$$

and obtains the straightforward optimality condition

$$
\operatorname{FOC}\left(M^{i}\right): V_{m}^{i}+V_{M}^{i}=\Lambda_{e}^{i} Q^{T}+\phi^{i} \Phi_{M^{i}}
$$

For any market in which the constraint binds, $M_{k}^{i}$ is restricted and the relevant entry in the vector of shadow prices $\phi_{k}^{i}$ picks up the social cost of the market imperfection. 
Global Planning Problem Under international cooperation, the Lagrangian of a global planner in our model of international market imperfections is

$$
\mathcal{L}=\max _{Q,\left(M^{i},\right)_{i \in \mathcal{I}}} \int_{i \in \mathcal{I}}\left\{\theta^{i}\left[V\left(M^{i}, M^{i}\right)\right]-v M^{i}\right\} d \omega(i)-\phi \Phi\left(\left\{M^{i}\right\}_{i \in \mathcal{I}^{\prime}}, Q\right)
$$

The global planner's optimality conditions are

$$
\begin{aligned}
& F O C(Q): \phi \Phi_{Q} d \omega(i)=0 \\
& \operatorname{FOC}\left(M^{i}\right): \theta^{i}\left(V_{m}^{i}+V_{M}^{i}\right)=v+\phi \Phi_{M^{i}}
\end{aligned}
$$

The first optimality condition captures that international market prices $Q$ do not play an allocative role for the global planner. Since the set of instruments $\left\{\tau^{i}\right\}_{i \in \mathcal{I}}$ is perfect at the international level, the global planner can choose $Q$ so as to optimally satisfy the constraint $\Phi(\cdot)$, and then set all the $\tau^{i}$ s in a manner that implements the desired allocation $\left\{M^{i}\right\}_{i \in \mathcal{I}}$ subject to the constraint $\Phi(\cdot)$. 


\section{B Further Derivations for Examples in Section (2) (Online)}

This appendix presents more detailed derivations of some of the results described in Section 2 as well as a careful mapping of the examples considered into the general model of Section 3. For Sections 2.1 and 2.2. we have described this mapping in the main text.

\section{B.1 Spillovers of Monetary Policy (Section (2.3))}

We proceed in two steps. First, we illustrate how to capture a domestic market using the vector notation of our general framework for a simple one-period framework with two goods denoted $T$ and $N$. Then we demonstrate how to nest and solve the full model of Section 2.3 .

Simple Model of Non-Traded Goods For the first step, we consider a simplified model in which there is only a single time period and no international trade so $m^{i}=\varnothing$. Domestic agents value consumption of $T$ and $N$ according to the utility function $U^{i}=\left(c_{T}^{i}\right)^{\gamma}\left(c_{N}^{i}\right)^{1-\gamma}$ and receive endowments $y_{T}$ and $y_{N}$ of the two goods. We define the vector of domestic variables $x^{i}=\left(c_{T}^{i}, c_{N}^{i}, P_{N}^{i}\right)$ where we assume good $T$ is the numeraire good and $P_{N}^{i}$ is the relative price of good $N$. Furthermore, we define the vector of domestic constraints as

$$
f^{i}\left(x^{i}, X^{i}\right)=\left\{\begin{array}{l}
c_{T}^{i}-y_{T}^{i}+P_{N}^{i}\left(c_{N}^{i}-y_{N}^{i}\right) \leq 0 \\
C_{T}^{i}-y_{T}^{i}=0 \\
C_{N}^{i}-y_{N}^{i}=0
\end{array}\right.
$$

The first line is the budget constraint, which individual agents in country $i$ have to respect. The next two lines are domestic market clearing constraints, which the policymaker in country $i$ has to respect. Observe that these constraints are not relevant for private agents since they only apply to (upper-case) aggregate variables, which they take as exogenous.

The optimality condition of private agents $U_{x}^{i}=f_{X}^{i}{ }^{T} \lambda_{d}^{i T}$ consists of three lines - one for each element of $x^{i}$ - but the last one is degenerate and drops out since only the aggregate price $P_{N}^{i}$ matters for the problem, which individual agents have to take as given. Combining the first two conditions for $c_{T}^{i}$ and $c_{N}^{i}$ we obtain the optimality condition

$$
P_{N}^{i}=\frac{1-\gamma}{\gamma} \cdot \frac{c_{T}^{i}}{c_{N}^{i}}
$$

This condition serves as an implementability constraint for the country $i$ policymaker. It can easily be verified that solving the optimization problem of the policymaker delivers the solutions given by the two market-clearing constraints (A.24 3 ) and (A.24k), and following constraint (A.25), that she picks the domestic price such that markets for $T$ and $N$ clear, i.e. $P_{N}^{i}=(1-\gamma) / \gamma \cdot y_{T}^{i} / y_{N}^{i}$. In a sense, the domestic policymaker acts as the Walrasian auctioneer of the domestic economy, setting a market-clearing price.

Full Setup of Section 2.3 Let us return to the full setup described in Section 2.3. We define the vector of domestic variables as $X^{i}=\left(c_{N, 0}^{i}, c_{T, 0}^{i}, c_{N, 1}^{i}, c_{T, 1}^{i}, d^{i}, P_{N, 0}^{i}, P_{N, 1}^{i}, P_{T, 0}^{i}, P_{T, 1}^{i}, S^{i}\right)$ and use the utility function $U^{i}=\log \left(\left(c_{T, 0}^{i}\right)^{\gamma}\left(c_{N, 0}^{i}\right)^{1-\gamma}\right)+\log \left(\left(c_{T, 1}^{i}\right)^{\gamma}\left(c_{N, 1}^{i}\right)^{1-\gamma}\right)$ indicated in the main text. Furthermore, define the vector of domestic constraints as

$$
f^{i}\left(m^{i}, x^{i}, M^{i}, X^{i}\right)=\left\{\begin{array}{l}
p_{T, 0}^{i}\left(c_{T, 0}^{i}-y_{T, 0}^{i}-m_{0}^{i}\right)+P_{N, 0}^{i}\left(c_{N, 0}^{i}-y_{N, 0}^{i}\right)+d^{i} \leq 0 \\
p_{T, 1}^{i}\left(c_{T, 1}^{i}-y_{T, 1}^{i}-m_{1}^{i}\right)+P_{N, 1}^{i}\left(c_{N, 1}^{i}-y_{N, 1}^{i}\right)-S^{i} d^{i} \leq 0 \\
C_{T, t}^{i}-y_{T, t}^{i}-M_{t}^{i}=0 \text { for } t=0,1 \\
C_{N, t}^{i}-y_{N, t}^{i}=0 \text { for } t=0,1 \\
D^{i}=0 \\
\left(P_{T, t}^{i} \gamma\right)^{\gamma}\left(P_{N, t} / 1-\gamma\right)^{\gamma}=1 \quad \text { for } t=0,1
\end{array}\right.
$$


The first two lines are the budget constraints of private agents, where $S^{i}$ is the gross interest rate on domestic bonds. The next three lines are market clearing conditions for traded, non-traded goods and domestic bonds that only need to hold at the aggregate level, i.e. they are only relevant for the policymaker. The last line describes the monetary policy objective of keeping the domestic price index $P_{t}^{i}$ constant at unity. For simplicity, we take this objective as exogenous.

The relevant optimality conditions of private agents imply a condition similar to (A.25),

$$
\frac{p_{N, t}^{i}}{p_{T, t}^{i}}=\frac{1-\gamma}{\gamma} \cdot \frac{c_{T, t}^{i}}{c_{N, t}^{i}}
$$

We combine this with the central bank's price level target $P_{t}^{i} \equiv 1$ and eliminate $p_{N, t}^{i}$ to obtain (8). The Euler equation for domestic bond holdings is

$$
S^{i}=\frac{\lambda_{d 0}^{i}}{\lambda_{d 1}^{i}}=\left(\frac{c_{T, 1}^{i}}{c_{T, 0}^{i}}\right)^{\gamma}\left(\frac{c_{N, 1}^{i}}{c_{N, 0}^{i}}\right)^{1-\gamma}
$$

where $\lambda_{d 0}^{i}$ and $\lambda_{d 1}^{i}$ are private agents' shadow prices on the period 0 and 1 budget constraints A.26a) and A.26p).

The optimal domestic policy of the country $i$ policymaker is to set the prices $\left(P_{T, 0}^{i}, P_{N, 0}^{i}, P_{T, 1}^{i}, P_{N, 1}^{i}, S^{i}\right)$ to their market-clearing levels while satisfying the objective of monetary policy. The reduced-form welfare function of the country is simply

$$
V^{i}\left(m^{i}, M^{i}\right)=\log \left(\left(y_{T, 0}^{i}+m_{0}^{i}\right)^{\gamma}\left(y_{N, 0}^{i}\right)^{1-\gamma}\right)+\log \left(\left(y_{T, 1}^{i}+m_{1}^{i}\right)^{\gamma}\left(y_{N, 1}^{i}\right)^{1-\gamma}\right)
$$

This function satisfies $V_{M}^{i}=0$ so there is no motive for the policymaker to intervene in external transactions.

Denoting the prices of international goods by the vector $Q=(1,1 / R)$, the optimality condition for the external transactions of private agents imply the Euler equation

$$
R=\frac{c_{T, 1}^{i}}{c_{T, 0}^{i}}
$$

Combining the two Euler equations and imposing domestic market clearing $c_{N, t}^{i}=y_{N, t}^{i} \forall t$, we obtain the interest rate rule (7) in the text. In the given setup, this implements the first-best allocation of the economy.

\section{B.2 Spillovers from Current Account at the ZLB (Section 2.4)}

To capture a ZLB on the domestic interest rate in the previous example, we add a tenth constraint $1-S^{i} \leq 0$ [capturing [9] to the set of constraints $f^{i}(\cdot)$. Furthermore, we capture the supply side of the economy by modifying the market clearing constraint on period 0 nontraded goods to a weak inequality $C_{N, 0}^{i}-y_{N, 0}^{i *} \leq$ 0 and using the utility function $U^{i}=\log \left(\left(c_{T, 0}^{i}\right)^{\gamma}\left(c_{N, 0}^{i}\right)^{1-\gamma}\right)-d\left(c_{N, 0}^{i}\right)+\log \left(\left(c_{T, 1}^{i}\right)^{\gamma}\left(c_{N, 1}^{i}\right)^{1-\gamma}\right)$, which includes the disutility of the labor effort required to produce $y_{N, 0}^{i}$.

\section{B.3 Spillovers of Fiscal Shocks (Section 2.5)}

For the example of fiscal policy, we define $X^{i}=\left(c_{0}^{i}, c_{1}^{i}, G_{0}^{i}, G_{1}^{i}\right)$ and use the utility function (10) in the main text. For a given level of aggregate imports $M^{i}$, the optimality conditions [11] and $C_{1}^{i}=G_{1}^{i}$ each define the optimal distribution of spending on private versus public goods, and the country $i$ policymaker simply taxes the requisite amount of good so $G_{0}^{i}\left(M_{0}^{i}\right)=\alpha^{\frac{1}{\theta}} /\left(1+\alpha^{\frac{1}{\theta}}\right) \cdot\left(y_{0}^{i}+M_{0}^{i}\right)$ and $G_{1}^{i}\left(M_{1}^{i}\right)=\left(y_{1}^{i}+M_{1}^{i}\right) / 2$. The reduced-form welfare function is

$$
V^{i}\left(m^{i}, M^{i}\right)=u\left(y_{0}^{i}+m_{0}^{i}-G_{0}^{i}\left(M_{0}^{i}\right)\right)+\alpha u\left(G_{0}^{i}\left(M_{0}^{i}\right)\right)+u\left(y_{1}^{i}+m_{1}^{i}-G_{1}^{i}\left(M_{1}^{i}\right)\right)+u\left(G_{1}^{i}\left(M_{1}^{i}\right)\right)
$$


The uninternalized welfare effects of net imports are

$$
\frac{\partial V^{i}}{\partial M_{1}^{i}}=\left[-u^{\prime}\left(c_{1}^{i}\right)+u^{\prime}\left(G_{1}^{i}\right)\right] G_{1}^{i \prime}(\cdot)
$$

Optimal public spending implies that the policymaker has equated the two terms in square brackets $u^{\prime}\left(c_{1}^{i}\right)=$ $u^{\prime}\left(G_{1}^{i}\right)$ and similar for good 0 . Therefore the expression vanishes $V_{M}^{i}=0$ and there is no case for intervening in external transactions.

\section{Simple Example of Efficiency and Policy Cooperation (Online)}

This appendix illustrates, in a simple and teachable manner, both our basic efficiency result and how deviations from the three efficiency conditions lead to Pareto inefficient equilibria that call for global cooperation. We do so in a multi-country setting that builds on the simple example of current account intervention in a single country that we developed in Section 2.2

General Equilibrium Let us assume that there are two sets $\mathcal{I}^{A}$ and $\mathcal{I}^{D}$ of countries with measure $\omega\left(\mathcal{I}^{A}\right)=\omega\left(\mathcal{I}^{D}\right)=1 / 2$ that are each made up of identical atomistic countries and that, respectively, represent advanced and developing countries. The setup of each country is as described in Section 2.2 . The only distinction between advanced and developing countries is that advanced countries no longer experience learning externalities so their period 1 endowment is constant. For simplicity we assume that $y_{1}^{A}\left(-M_{0}^{A}\right)=y_{0}^{A} \forall M_{0}^{A}$ and $y_{1}^{D}(0)=y_{0}^{D}$ but $y_{1}^{D}\left(-M_{0}^{D}\right)>0$, capturing the learning externalities. As discussed in Section 2.2, this gives rise to the reduced-form welfare functions

$$
V^{i}\left(m^{i}, M^{i}\right)=u\left(y_{0}^{i}+m_{0}^{i}\right)+u\left(y_{1}^{i}\left(-M_{0}^{i}\right)+m_{1}^{i}\right)
$$

with marginal utility of private net imports is $V_{m}^{i}=\left(u^{\prime}\left(c_{0}^{i}\right), u^{\prime}\left(c_{1}^{i}\right)\right)^{T}$ and uninternalized social marginal utility $V_{M}^{i}=\left(-y_{1}^{i \prime}\left(-M_{0}^{i}\right) \cdot u^{\prime}\left(C_{1}^{i}\right), 0\right)^{T}$, which satisfies $V_{M}^{i} \equiv(0,0)^{T} \forall i \in \mathcal{I}^{A}$ for advanced economies but $V_{M 0}^{i}<0 \forall i \in \mathcal{I}^{D}$ for developing countries.

Laissez-Faire Equilibrium In the global laissez-faire equilibrium, private agents in each country $i$ take the aggregate allocation $M^{i}$ as given and solve the optimization problem

$$
\max _{m^{i}} V^{i}\left(m^{i}, M^{i}\right) \quad \text { s.t. } \quad Q \cdot m^{i} \leq 0
$$

Assigning shadow price $\lambda^{i}$, it is easy to see that the optimality condition is $V_{m}^{i}=\lambda^{i} Q^{T}$ or, equivalently, $u^{\prime}\left(c_{0}^{i}\right) / u^{\prime}\left(c_{1}^{i}\right)=R$. The allocation $m^{i}=M^{i}=(0,0)^{T}$ together with the price vector $Q=(1,1)$ represents an equilibrium of the system since the endowment of both types of countries is constant, implying perfect consumption smoothing for private agents under zero net imports. However, the laissez-faire equilibrium is sub-optimal since private agents in developing countries neglect the potential gains from learning externalities.

Competitive Equilibrium Under Uncoordinated Optimal Policy The policymakers in advanced countries find it optimal not to intervene and set $\tau^{i}=(0,0) \forall i \in \mathcal{I}^{A}$, since their countries do not suffer any domestic market imperfections and are atomistic. However, the policymakers in developing countries $i \in \mathcal{I}^{D}$ internalize the learning externalities. As we emphasized in Section 2.2. their optimality condition is

$$
V_{m}^{i}+V_{M}^{i}=\Lambda^{i} Q
$$

Furthermore, they find it optimal to subsidize period 0 net exports by imposing the tax wedge $\tau_{0}^{i}=$ $-V_{M 0}^{i} / V_{m 0}^{i}=y_{1}^{i \prime} \cdot u^{\prime}\left(c_{1}^{i}\right) / u^{\prime}\left(c_{0}^{i}\right)>0$ and to set $\tau_{1}^{i} \equiv 0$. 
Spillovers In the resulting global equilibrium, developing countries will be net exporters in period 0 and net importers in period 1, and vice versa for advanced countries, so $m_{0}^{C}=-m_{0}^{A}<0$ and $m_{1}^{C}=-m_{1}^{A}>0$. Furthermore, the world interest rate will decline below the laissez-faire level $R<1$. These quantity and price adjustments represent spillovers from the interventions of developing countries 51

Global Optimum The key question of our paper is under what conditions the uncoordinated equilibrium among national policymakers is socially efficient. To answer this question in the current example, we will compare the uncoordinated equilibrium among national policymakers with the allocations that would be chosen by a global planner who maximizes the sum of worldwide welfare for a given set of Pareto weights, which we denote by $\theta^{A}$ and $\theta^{D}$ for advanced and developing countries. Substituting the global market-clearing condition $M^{A}=M=-M^{D}$, the global planner's problem can be described as

$$
\max _{M} \theta^{A} V^{A}(M, M)+\theta^{D} V^{D}(-M,-M)
$$

with associated optimality condition

$$
\theta^{A}\left[V_{m}^{A}+V_{M}^{A}\right]=\theta^{D}\left[V_{m}^{D}+V_{M}^{D}\right]
$$

Consider an uncoordinated equilibrium among national policymakers, which satisfies the optimality conditions A.29) for $i=A, D$. We combine the conditions for both types of countries and observe $V_{M}^{A} \equiv 0$ to obtain

$$
\frac{V_{m}^{A}}{\Lambda^{A}}=Q^{T}=\frac{V_{m}^{D}+V_{M}^{D}}{\Lambda^{D}}
$$

It can be easily seen that these optimality conditions coincide with the optimality conditions of a global planner A.31 with welfare weights $\theta^{i}=1 / \Lambda^{i}$ for $i=A, D$. The uncoordinated equilibrium among national policymakers also satisfies global market clearing and is therefore globally Pareto efficient.

Intuitively, the national policymakers described in the example ensure that each country equates the social marginal benefit of transacting with the rest of the world to the common vector of world market prices. Since (i) the national policymakers act competitively, (ii) they have sufficient external policy instruments and (iii) the international market is complete, the outcome is Pareto efficient. Even though the interventions of developing countries have spillover effects on advanced countries, these effects are Pareto efficient; in fact, they are necessary for the efficient functioning of the market 52

In the following, we illustrate the case for global cooperation by relaxing, in turn, each of the three conditions required for efficiency.

Deviating from Condition (i): Monopoly Power If there is a single large developing country $D$ instead of a unit mass of atomistic countries, then the policymaker in country $D$ has market power and finds it optimal to internalize how the country's international transactions $M^{D}$ affect world prices. Market clearing implies $M^{A}+M^{D}=0$ and so the Euler equation of advanced countries defines a world interest rate schedule as a function of the international transactions of the developing country, $R\left(M^{D}\right)=$ $u^{\prime}\left(y_{0}^{A}-M_{0}^{D}\right) / u^{\prime}\left(y_{1}^{A}-M_{1}^{D}\right)$ or, in vector notation, $Q\left(M^{D}\right)=\left(1,1 / R\left(M^{D}\right)\right)$. A policymaker in country $D$ who optimally exerts market power will solve the optimization problem

$$
\max _{M^{D}} V^{D}\left(M^{D}, M^{D}\right) \quad \text { s.t. } \quad Q\left(M^{D}\right) \cdot M^{D} \leq 0
$$

\footnotetext{
${ }^{51}$ In the described example, advanced countries happen to be better off from the interventions of developing countries. We could easily describe examples in which advanced countries are worse off: if $y_{1}^{A}>y_{2}^{A}$ so that advanced countries are net lenders in the laissez faire equilibrium, then a marginal decline in the interest rate would hurt them, representing a negative spillover effect.

${ }^{52}$ The laissez faire equilibrium is clearly not globally efficient - combining the optimality conditions of private agents, we obtain $V_{m}^{A} / \Lambda^{A}=Q^{T}=V_{m}^{D} / \Lambda^{D}$. This is inconsistent with a global planner's optimality condition A.31 no matter what set of welfare weights $\left(\phi^{A}, \phi^{D}\right)$ the global planner employs since the first element of the vector $V_{M 0}^{D} \neq 0$ but the second element $V_{M 1}^{D}=0$.
} 
The associated optimality condition is

$$
V_{m}^{D}+V_{M}^{D}=\Lambda^{D} Q^{T}\left(1-\mathcal{E}_{Q, M}\right)
$$

where $\mathcal{E}_{Q, M}=-\left[\partial Q / \partial M^{D} \cdot M^{D}\right] / Q^{T}$ is a vector of demand elasticities of world prices which satisfies $\mathcal{E}_{Q, M_{0}}<0<\mathcal{E}_{Q, M_{1}}$, with the division performed element-by-element. The expression captures that the policymaker in the developing country internalizes that manipulating her import and export decisions enables her to improve the country's terms-of-trade vis-à-vis advanced countries. The resulting allocation can be implemented by setting the external policy instruments to

$$
\left(\begin{array}{c}
1-\hat{\tau}_{0}^{D} \\
1-\hat{\tau}_{1}^{D}
\end{array}\right)=\frac{1+V_{M}^{i} / V_{m}^{i}}{1-\mathcal{E}_{Q, M}^{i}}=\left(\begin{array}{c}
\left(1+y_{1}^{i \prime} \cdot \frac{u^{\prime}\left(C_{1}^{D}\right)}{u^{\prime}\left(C_{0}^{D}\right)}\right) /\left(1-\frac{u^{\prime \prime}\left(C_{0}^{A}\right)}{u^{\prime}\left(C_{1}^{A}\right)} \frac{M_{2}^{D}}{R^{2}}\right) \\
1 /\left(1+\frac{u^{\prime \prime}\left(C_{1}^{A}\right)}{u^{\prime}\left(C_{1}^{A}\right)} M_{1}^{D}\right)
\end{array}\right)
$$

where all divisions are performed element-by-element. This implies that $\hat{\tau}_{0}^{D}>0>\hat{\tau}_{1}^{D}-$ in addition to internalizing the growth externalities, the policymaker recognizes that restricting exports in period 1 and restricting imports in period 1 increases the world interest rate, which allows the country to earn a higher return on its savings.

Interestingly, the monopolistic policymaker with market power subsidizes exports in period 0 at a lower rate than a policymaker in an atomistic country (as captured by the denominator in the expression for the period 0 tax rate), i.e. she forgoes part of the benefit of internalizing the learning externalities in order to manipulate the world interest rate. The spillovers created by the monopolistic policymaker are thus smaller than those created by a competitive policymaker. As a result, advanced countries benefit less from valuable intertemporal trading opportunities with the developing country.

Since the monopolistic policymaker imposes monopolistic wedges, the allocation is clearly not Pareto efficient and worldwide welfare is reduced. The deviaton from price-taking behavior creates a clear scope for global cooperation: global policymakers can increase worldwide welfare by forestalling monopolistic behavior.

Deviating from Condition (ii): Imperfect Instruments Let us return to the setup with atomistic countries without market power but assume that developing countries $D$ have imperfect external policy instruments. For simplicity, assume that they are completely unable to affect the external allocations of private agents so $\hat{\tau}^{D}=(0,0)$ at all times, but that advanced countries $A$ have a full set of external policy instruments $\tau^{A}$ that can be set to arbitrary levels.

In the uncoordinated equilibrium, the policymakers in developing countries do not engage in policy intervention because they are not able to; the policymakers in advanced countries do not engage in policy intervention and set $\tau^{A}=(0,0)$ because they do not see any domestic rationale to intervene in markets. The resulting allocation is identical to the global laissez-faire allocation. As we showed earlier, this allocation is not Pareto efficient because it neglects the learning externalities.

There is a clear scope for international policy cooperation: the global optimum described above requires that the social marginal products of the two types of countries are equated, $\left(V_{m}^{D}+V_{M}^{D}\right) / \Lambda^{D}=V_{m}^{A} / \Lambda^{A}$. This allocation can be replicated if the policymakers in advanced countries set their policy instruments to

$$
1-\hat{\tau}^{A}=\frac{1}{1-\tau^{D}} \quad \text { or } \quad \hat{\tau}^{A}=\left(1-\frac{1}{1-y_{1}^{D \prime} \cdot \frac{u^{\prime}\left(c_{1}^{D}\right)}{u^{\prime}\left(c_{0}^{D}\right)}}, 0\right)
$$

to internalize the externalities of developing countries. Intuitively, it does not matter if developing countries subsidize exports or advanced countries subsidize imports in period 0 - the resulting allocation is the same. If the goal is to replicate the distribution of resources described in the first-best uncoordinated equilibrium above, developing countries could provide a transfer to advanced countries to finance the 
policy intervention 53 In short, instead of the policymakers in developing countries subsidizing exports, they pay the policymakers in advanced countries to subsidize imports. The world price vector adjusts to $\hat{Q}=\left(1 /\left(1-\tau_{0}^{D}\right), 1 / R\right)$. At this new price vector and given the transfer payment, the original optimal allocation in the global optimum described above is feasible for both types of countries and the social marginal products of the two types of countries are equated since $V_{m}^{D} / \Lambda^{D}=\hat{Q}=\left(1-\hat{\tau}_{0}^{A}\right) V_{m}^{A} / \Lambda^{A}$.

Deviating from Condition (iii): International Market Imperfections The third area that requires global cooperation are international market imperfections. To illustrate a relevant example, loosely inspired by Jeanne (2014), let us assume that international financial transactions are restricted to take place in the currencies of advanced countries, which are in a liquidity trap and face a zero interest rate so the international price vector is $Q=(1,1)$. Furthermore, as is common in the New Keynesian literature, assume that period 0 output in advanced countries is demand-determined and adjusts so as to clear the market. In other words, when developing countries increase exports, the world interest rate cannot decline, but advanced countries import more and experience a decline in demand for domestic output and thus in $y_{0}^{A}$. Furthermore, assume that period 0 output in each advanced country $A$ is produced at a continuously differentiable convex utility $\operatorname{cost} d\left(y_{0}^{A}\right)$ that satisfies $d(0)=d^{\prime}(0)=0$ and $d^{\prime}(1)=11^{54}$

When the zero-lower-bound in advanced countries is binding, period 0 output is determined by the Euler equation

$$
u^{\prime}\left(C_{0}^{A}\right)=u^{\prime}\left(C_{1}^{A}\right) \quad \text { or } \quad y_{0}^{A}\left(M^{A}\right)=y_{1}^{A}-M_{0}^{A}+M_{1}^{A}
$$

The reduced-form utility function of a representative advanced country $A$ is

$$
V^{A}\left(m^{A}, M^{A}\right)=u\left(y_{0}^{A}\left(M^{A}\right)+m_{0}^{A}\right)-d\left(y_{0}^{A}\left(M^{A}\right)\right)+u\left(y_{1}^{A}+m_{1}^{A}\right)
$$

The policymaker in an advanced country $A$ recognizes that imports lead to aggregate demand externalities and sets her external policy instruments to

$$
\tau^{A}=-\frac{V_{M}^{A}}{V_{m}^{A}}=\left(1-\frac{d^{\prime}\left(y_{0}^{A}\right)}{u^{\prime}\left(C_{0}^{A}\right)}\right)\left(1,-u^{\prime}\left(C_{0}^{A}\right) / u^{\prime}\left(C_{1}^{A}\right)\right)
$$

We can interpret the term $1-d^{\prime}\left(y_{0}^{A}\right) / u^{\prime}\left(C_{0}^{A}\right)>0$ as a labor wedge, which captures the cost of the demand shortage - an additional unit of output would $\operatorname{cost} d^{\prime}\left(y_{0}^{A}\right)$ but bring utility benefit $u^{\prime}\left(C_{0}^{A}\right)$. The policymaker in an advanced country $A$ would thus tax period 0 imports which take away from domestic demand and subsidize period 1 imports, which create a future boom and by implication boost today's output [see equ. A.32)]. The policymakers in developing countries would continue to operate as in the baseline example (5) above. Given the sticky price vector $\bar{Q}=(1,1)$, the resulting global equilibrium is described by the equilibrium condition

$$
\frac{V_{m}^{A}+V_{M}^{A}}{\Lambda^{A}}=\bar{Q}=\frac{V_{m}^{D}+V_{M}^{D}}{\Lambda^{D}}
$$

From this condition, it is apparent that the price mechanism cannot play its usual role of efficiently allocating goods across countries - prices do not reflect the relative social valuation of goods, but are given exogenously.

A global planner would solve the optimization problem A.30) with optimality condition (A.31). It can easily be seen that the equilibrium described by (A.33) can be improved upon: at the described uncoordinated allocation, developing countries internalize learning externalities by equating the marginal benefit of imports/exports in the two periods to the fixed world price vector; however, period 0 exports from developing countries create negative demand externalities for advanced countries. A marginal reduction in period 0 exports from developing countries would come at a second-order cost for developing countries (since they were at their point of optimality, given world prices $\bar{Q}$ ) but would provide a first-order benefit of $u^{\prime}\left(C_{0}^{A}\right)-d^{\prime}\left(y_{0}^{A}\right)>0$ to advanced countries.

\footnotetext{
${ }^{53}$ The transfer is of the exact same magnitude as what developing countries would have used to finance their own export subsidies if that instrument was available, so the same amount of government revenue is required.

${ }^{54}$ See Section 2.4 for a more detailed description of the microfoundations of output rationing in a New-Keynesianstyle setup with a binding zero-lower-bound.
} 